\title{
SEGMENTING VISITORS TO BATTLEFIELD SITES: INTERNATIONAL VISITORS TO THE FORMER DMZ IN VIETNAM
}

by

\section{Diem-Trinh Thi Le}

\author{
A thesis \\ submitted to the Victoria University of Wellington \\ in partial fulfilment of the requirements for the degree of \\ Master of Tourism Management
}

Victoria University of Wellington

2009 


\section{$\underline{\text { Abstract }}$}

Vietnam is an emerging tourist destination with rapid development in the tourism industry over the last decade. Well-known for the Vietnam War, it is expected that battlefield sites are among the country's main attractions for international tourists. However, to date, there has been no research examining visitors to battlefield sites in Vietnam. This study aims to contribute to filling this perceived gap by examining the visitors to the former Vietnamese De-militarised Zone (DMZ). Its objectives are: (1) to identify tourist motivations for visiting the DMZ, (2) to segment the DMZ visitors based on motivations, and (3) to determine the importance of battlefield sites in tourists' decision to travel to Vietnam.

International visitors to the Vinh Moc Tunnels, a site often included in the DMZ tour, were chosen as a study sample. Data in this study was collected in an intercept self-completed questionnaire survey, which resulted in a sample of 481 respondents. Statistical analysis of the data was supplemented by content analysis of qualitative findings where appropriate.

The findings show that respondents visited the DMZ for a variety of motivations. Five motivations were generated from the factor analysis of 22 quantitative motivational items namely: Personal involvement, Interest in war related sites and exhibitions, Education and exploration, Location and convenience, and Novelty seeking. These delineated motivations were supported and extended by respondents' self-expressed motivations. Based on these motivations, three groups of visitors to the DMZ were identified using cluster analysis: the Battlefield Tourism Enthusiast, the Opportunist, and the Passive Tourist. These three visitors segments differed significantly in terms of socio-demographic characteristics, trip related characteristics, and especially travel decision-making. The Enthusiasts had the highest interest in visiting battlefield sites in Vietnam. The Opportunists tended to visit sites based on location and convenience, and the Passive Tourists indicated relatively low rankings for all reasons for visiting battlefield sites. This study also found that battlefield sites only played a small role in tourists' decision to visit Vietnam and that most tourists visited Vietnam for its culture, landscape and history.

Several implications and recommendations arise from this study, including the need for continuing research on motivations for battlefield tourism in other countries. In 
addition, it is suggested that the educative function should be emphasised in developing battlefield sites as tourist attractions.

Key words: battlefield tourism, Vietnam, DMZ, international tourists, motivation, travel decision-making, segmentation, factor analysis, cluster analysis. 


\section{Acknowledgements}

I would like to thank NZAID for giving me the scholarship to study my Master's degree at Victoria University: without it, this thesis could not have been possible.

I am deeply indebted to my supervisors: Prof. Douglas Pearce and Dr. Christian Schott. Doug, thank you very much for your expert guidance, for your understanding of the challenges for international students, and especially for showing me that it is the big picture that I need to see in doing research. Christian, danke schön für your much-appreciated advice, and for always showing me the options and letting me make my own decision.

All the other Tourism staff at Victoria Management School, to whom I would like to express my gratitude: it was an honour getting to know all of you and studying in your classes. Thanks to Linda, Sophia and Helen for their assistance in the administrative work.

During my fieldwork, I was assisted by the most helpful and friendly staff at the Vịnh Mốc Tunnels, and the tour guides and bus drivers of Hương Bình Tourist Co. and Mekong Travel. I also wish to acknowledge my appreciation to the visitors at the Vịnh Mốc Tunnels, especially the survey participants, who despite the incredibly hot weather spent their precious time filling in the long questionnaires.

I would like to thank Dr. Sibanda, Victoria's Statistician Consultant and Dr. Bùi, a colleague of mine at Hue University, for their advice regarding my statistical analysis. Many thanks to Frances for her patience in proof reading this thesis.

The last year would have been very long without the friendship and companionship of my Masters colleagues: Muganda, Rudy, Diana and Ray. Guys, thanks for sharing with me the joy and pain of being a Master's student.

My family back in Vietnam has always encouraged me through the course of my study. I am grateful to my mum, my dad, my sister Ty and my brother Thắng for their life-long love and support. Thanks sis and David for providing me with a home and for taking care of me during my time in Wellington.

Finally, I would like to send my special thanks to Marco, whose endless love and unconditional support have provided me with the inspiration, faith and strength to complete this thesis as well as to achieve the targets in my life. 


\section{Table of contents}

Chapter 1: INTRODUCTION ..................................................................... 12

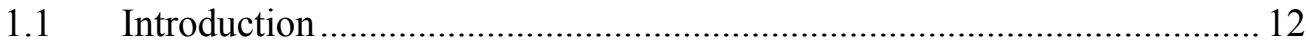

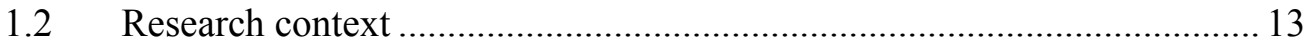

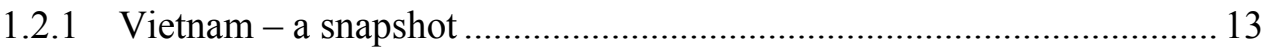

1.2.2 Tourism in Vietnam ........................................................................ 14

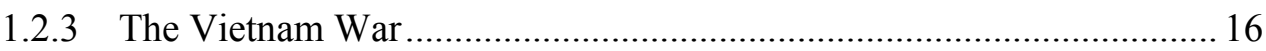

1.2.3.1 Overview of the Vietnam War ................................................... 16

1.2.3.2 The role of the Vietnam War in the country's tourism development

1.2.4 The attraction of the former DMZ in Vietnam..................................... 18

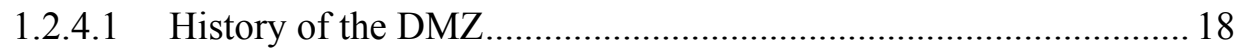

1.2.4.2 The DMZ tour .............................................................................. 20

1.4.4.3 The Vinh Moc Tunnels - a major historical tourist attraction ........... 23

1.3 Research objectives and research questions........................................... 25

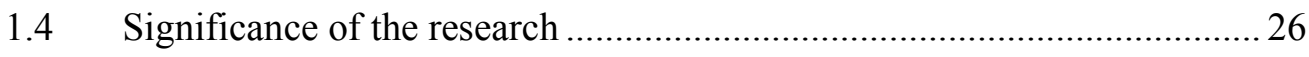

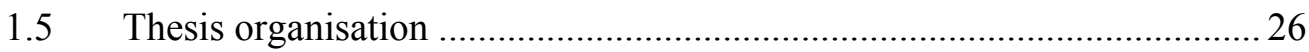

Chapter 2: LITERATURE REVIEW ......................................... 29

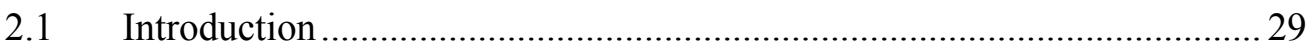

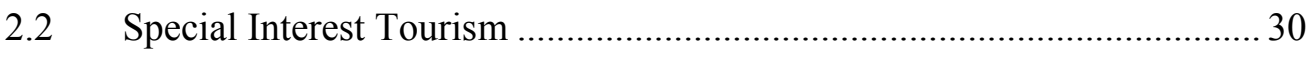

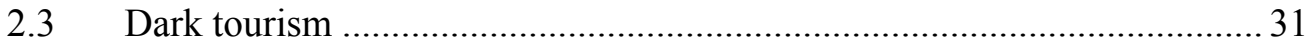

2.3.1 Definition of dark tourism and thanatourism ................................... 31

2.3.2 The influence of media on the increasing phenomenon of dark tourism33

2.3.3 Levels of dark tourism: a supply perspective ....................................... 33

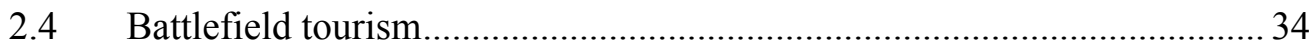

2.4.1 Battlefield tourism and the role of war in tourism industry .................. 34

2.4.2 Battlefield tourism in Vietnam........................................................... 35

2.5 Defining and segmenting the Special Interest Tourist .............................. 37

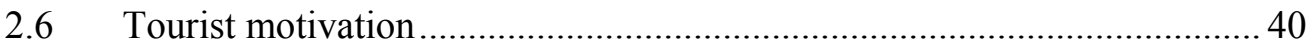

2.6.1 Research models of tourist motivations ............................................. 41

2.6.1.1 The Psychocentric-Allocentric typology...................................... 41

2.6.1.2 The Push and Pull model ............................................................. 41

2.6.1.3 The Extrinsic and Intrinsic Motivation Typology ........................ 42

2.6.1.4 The Travel Career Ladder ........................................................... 42 
2.6.2 Motivations for special interest tourism............................................ 43

2.6.3 Motivations for visiting thanatouristic sites ........................................ 43

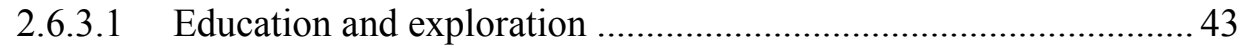

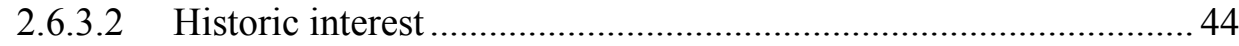

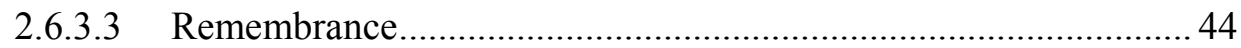

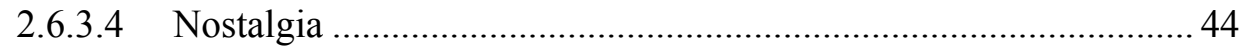

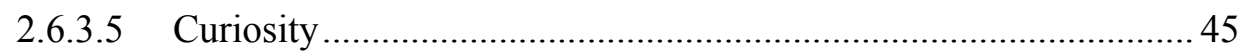

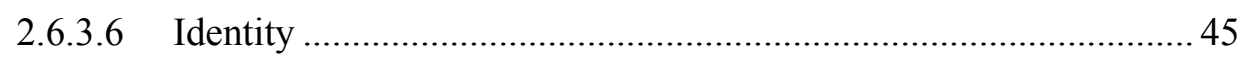

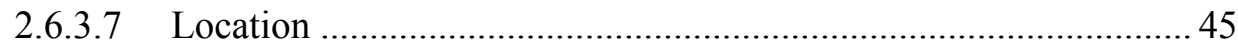

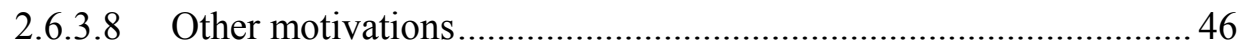

2.6.4 Market segmentation on motivations ................................................. 46

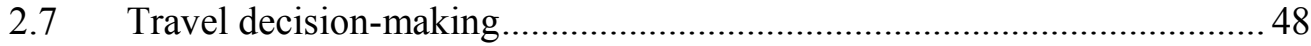

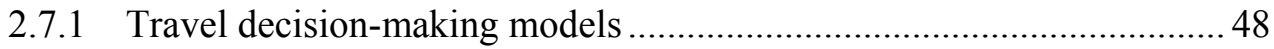

2.7.2 Factors influencing the travel decision-making process ...................... 49

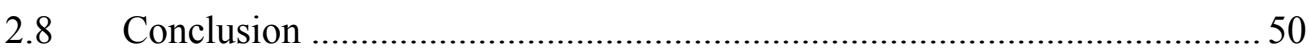

Chapter 3: METHODOLOGY ..............................................................552

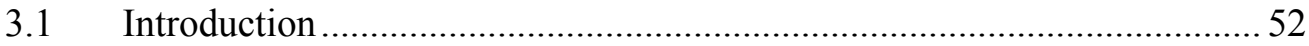

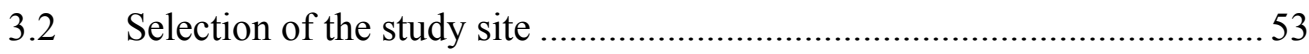

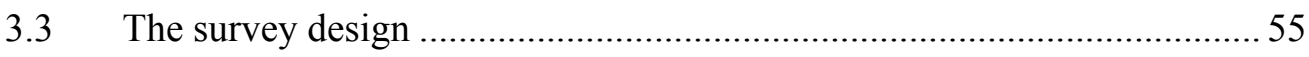

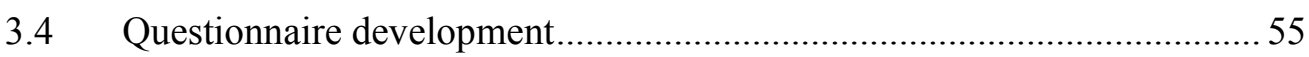

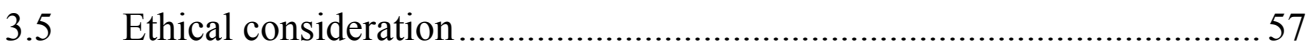

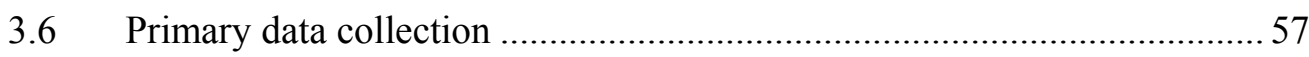

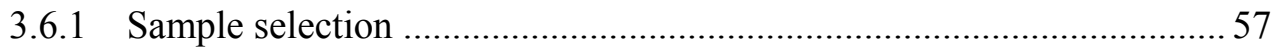

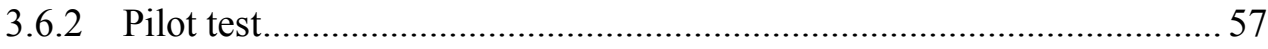

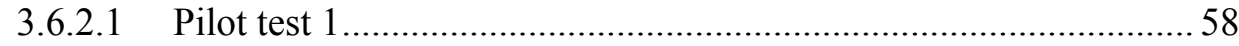

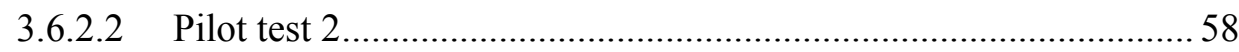

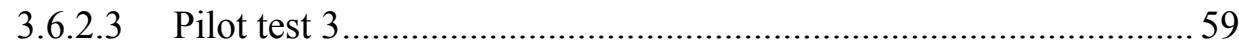

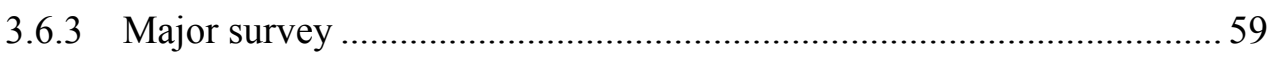

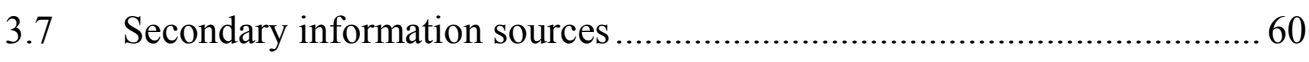

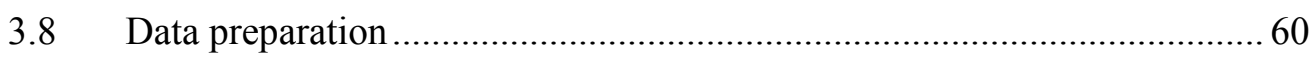

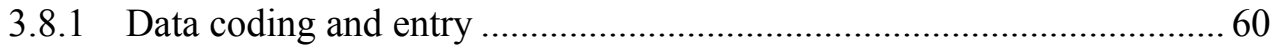

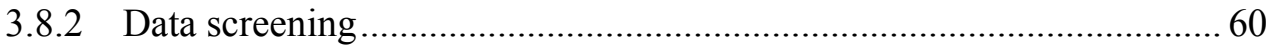

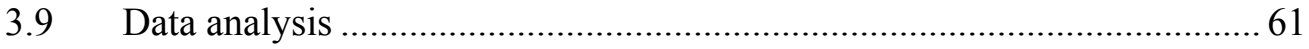

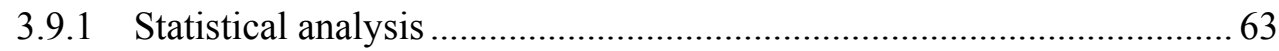

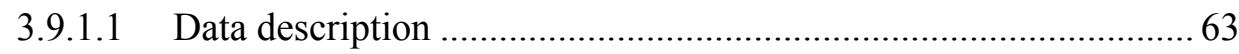


3.9.1.2 Data comparison: Chi-square test and ANOVA ...........................63

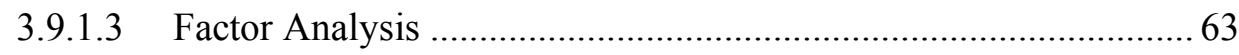

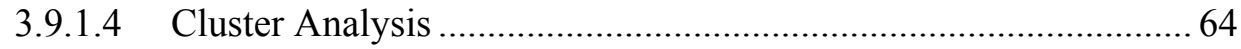

3.9.1.5 Multiple Discriminant Analysis ................................................... 65

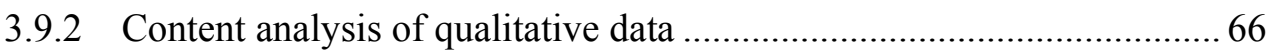

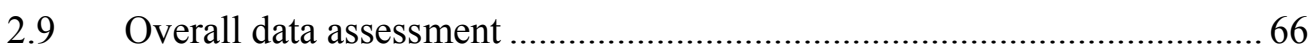

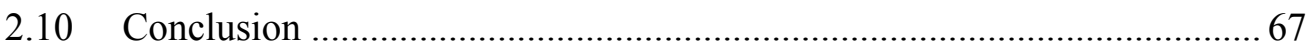

\section{Chapter 4: THE DMZ VISITORS' PROFILE: A DESCRIPTION}

OF THE STUDY SAMPLE ....................................................... 69

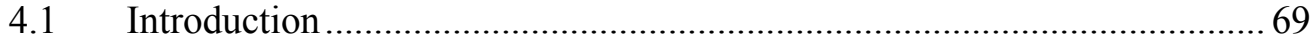

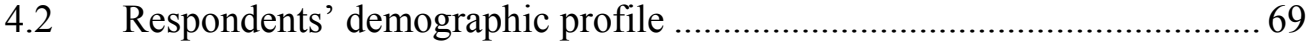

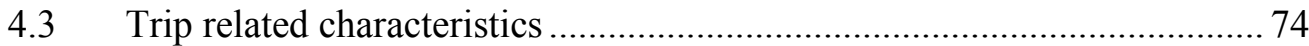

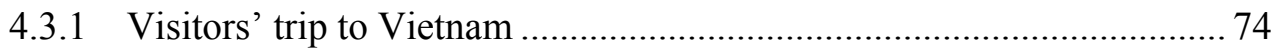

4.3.2 Visitors' trip to the DMZ and the Vịnh Mốc Tunnels ........................... 77

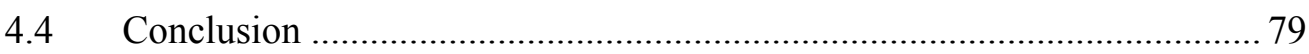

\section{Chapter 5: DMZ VISITOR SEGMENTATION ON}

MOTIVATIONS ................................................................ 81

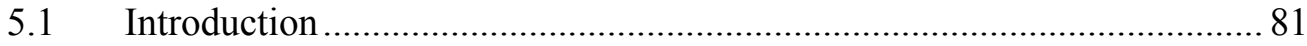

5.1.1 Self-expressed reasons for visiting the DMZ ..................................... 81

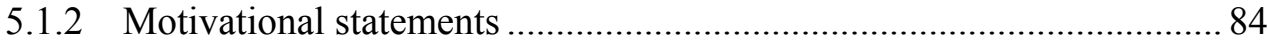

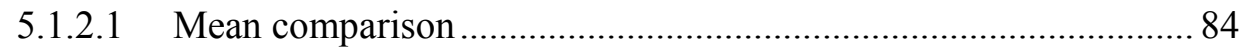

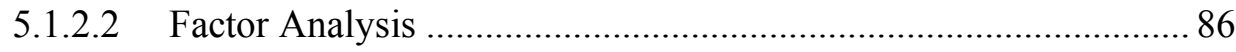

5.2 Cluster identification - Cluster analysis ................................................ 89

5.3 Cluster validation - Discriminant analysis ......................................... 92

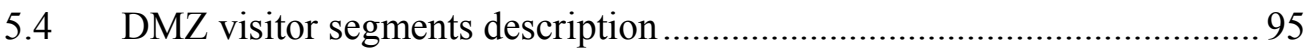

5.4.1 The clusters' demographic profile ...................................................... 95

5.4.2 The Vietnam trip characteristics by clusters ...................................... 99

5.4.3 Description of the DMZ trip characteristics by clusters ..................... 102

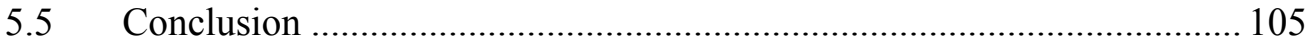

\section{Chapter 6: DMZ VISITORS’ DECISION-MAKING AND}

INTEREST IN BATTLEFIELD TOURISM ......................................106

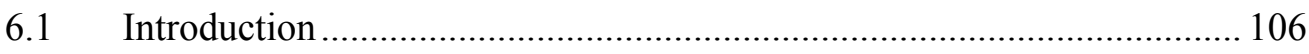

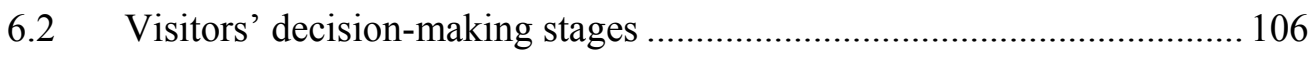

6.3 Level of knowledge of the DMZ by clusters ....................................... 108 
6.4 Information search

6.5 The importance of battlefield sites in tourists' decision to travel to Vietnam 115

6.5.1 The importance of the DMZ ........................................................ 115

6.5.2 The importance of the battlefield sites in Vietnam in general ............ 117

6.6 Level of interest in battlefield tourism .................................................. 119

6.7 Level of participation in battlefield tourism........................................... 120

6.7.1 Battlefield sites in the DMZ ........................................................ 120

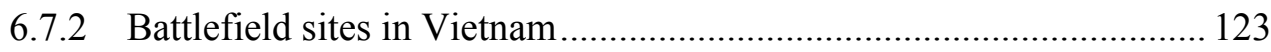

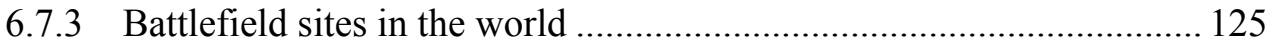

6.8 Satisfaction of the DMZ trip experience .............................................. 127

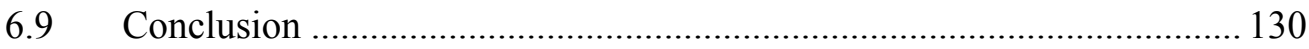

\section{Chapter 7: DISCUSSION, IMPLICATIONS AND CONCLUSION.}

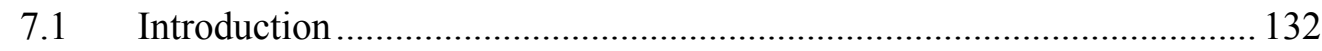

7.2 Motivations for visiting battlefield sites ............................................. 134

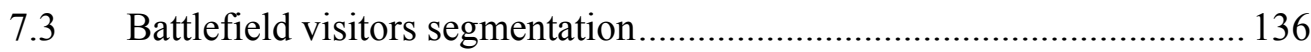

7.4 The attractions of Vietnam: the role of battlefield sites in tourists' decision

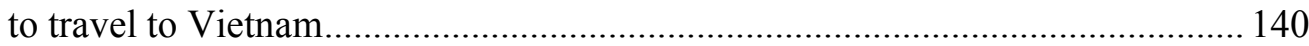

7.5 Implications and recommendations for tourism practitioners................. 142

7.5.1 Implications and recommendations for Vietnam's national tourism

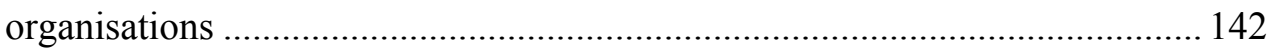

7.5.2 Implications and recommendations for DMZ tour operators.............. 144

7.5.3 Implications and recommendations for the management of the Vịnh Mốc

Tunnels and other Vietnamese historical sites ............................................ 145

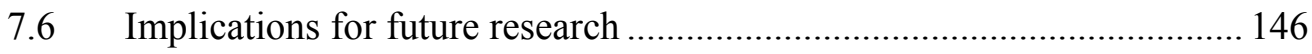

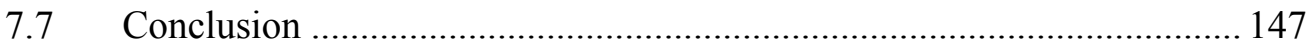

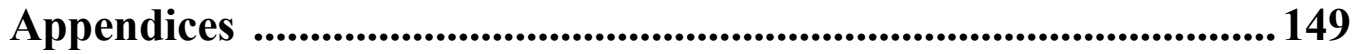

References $\quad$............................................................................................ 160 


\section{List of Tables}

Table 1-1: International visitors to Vietnam from 1990 to 2007 ............................. 15

Table 1-2: Research objectives and research questions .........................................26

Table 2-1: Examples of thanatouristic motivations studied in the literature ............. 46

Table 2-2: SIT market segments on motivations ..................................................... 47

Table 3-1: Visitor Statistics from 2001-2007 ............................................................ 54

Table 3-2: Visitors Statistics from Jan-June 2008 ....................................................... 54

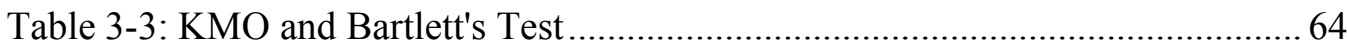

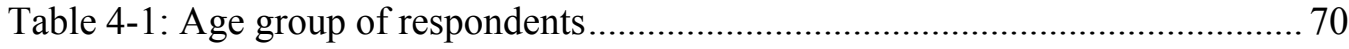

Table 4-2: Highest formal educational level of respondents ................................... 70

Table 4-3: Nationality group of respondents ......................................................... 71

Table 4-4: Comparison of the study sample and total international visitors in

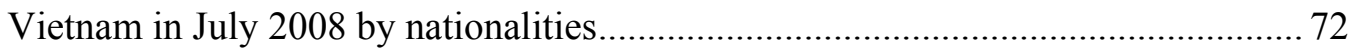

Table 4-5: Respondents' membership of military related association ....................... 73

Table 4-6: Respondents' mode of travel and type of visit to Vietnam ..................... 75

Table 4-7: Attribute of Vietnam attracting tourists................................................. 77

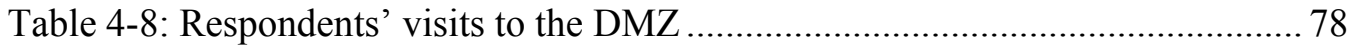

Table 4-9: Respondents' travel companions on the DMZ trip................................... 79

Table 5-1: Self-expressed reasons for visiting the DMZ …................................... 83

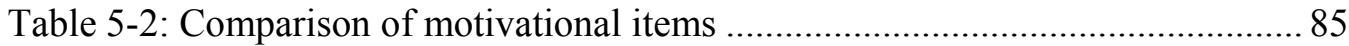

Table 5-3: Factor analysis of tourist motivations for visiting the DMZ .................. 87

Table 5-4: Number of cases in different clustering solutions .................................. 90

Table 5-5: Mean comparison of motivation factor by cluster.................................. 91

Table 5-6: Distances between final cluster centres .................................................. 92

Table 5-7: Summary of discriminant analysis results ............................................. 93

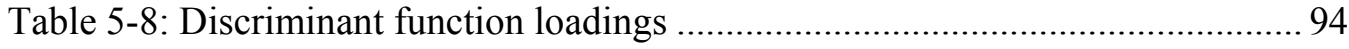

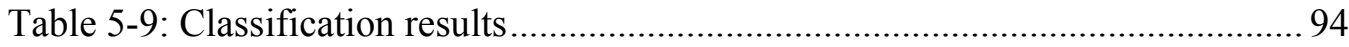

Table 5-10: Summary of the visitor segments' socio-demographic profiles ............. 95

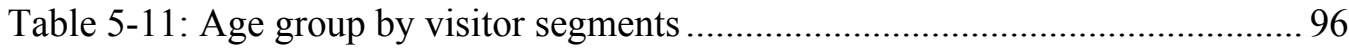

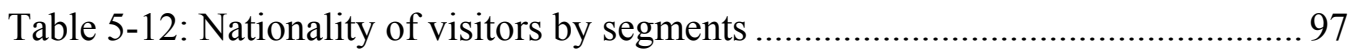

Table 5-13: Connection with the Vietnam War by visitor segments ........................ 98

Table 5-14: Non-significant socio-demographic characteristics by visitor segments 99

Table 5-15: Summary of the visitor segments' Vietnam trip profiles ..................... 100

Table 5-16: The visitors' Vietnam trip characteristics by clusters .......................... 101

Table 5-17: Most important attributes of Vietnam by visitor segments .................. 102 
Table 5-18: Summary of the visitor segments' DMZ trip profiles 103

Table 5-19: The DMZ trip travel arrangement by visitor segments 104

Table 5-20: Time of visit, travel companion, and DMZ trip duration by segments 104

Table 6-1: Stage of decision-making by segments ............................................... 108

Table 6-2: Awareness of the DMZ by visitor segments ........................................ 109

Table 6-3: Respondents' knowledge of the DMZ................................................. 109

Table 6-4: Respondents' knowledge of the DMZ across age groups ...................... 110

Table 6-5: The main aspects of the DMZ known by respondents .......................... 111

Table 6-6: Level of knowledge of the DMZ by visitor segments ........................... 112

Table 6-7: Information sources for the DMZ by visitor segments......................... 113

Table 6-8: The importance of the DMZ in visitors' decision to travel to Vietnam. 115

Table 6-9: The DMZ's level of importance across decision-making stages............ 116

Table 6-10: The importance of the DMZ in the visitor' decision-making............... 117

Table 6-11: The importance of battlefield sites visitors' decisions to travel to

Vietnam

Table 6-12: The importance of battlefield sites in Vietnam in visitors' decisionmaking.

Table 6-13: Respondent's level of interest in visiting the battlefield sites in Vietnam

Table 6-14: Level of interest in visiting battlefield sites in Vietnam by visitor segments

Table 6-15: The number of battlefield sites visited and to be visited in the DMZ by respondents

Table 6-16: List of sites in the DMZ tour and their popularity. 122

Table 6-17: The number of sites visited and to be visited in the DMZ by segments

Table 6-18: The number of battlefield sites visited and to be visited in Vietnam ... 123

Table 6-19: List of some battlefield sites in Vietnam and their popularity among respondents

Table 6-20: The number of battlefield sites visited and to be visited in Vietnam by segments

Table 6-21: Battlefield sites in the world and their popularity among the respondents

Table 6-22: Respondent's satisfaction of the DMZ experience.............................. 128

Table 6-23: Level of satisfaction of the DMZ trip by visitor segments................... 128 
Table 6-24: Most interesting aspect in the DMZ trip............................................ 129

Table 6-25: Things to be improved for the tour................................................. 130

Table 7-1: Summary of the research's objectives, methodology and results........... 133

\section{List of Figures}

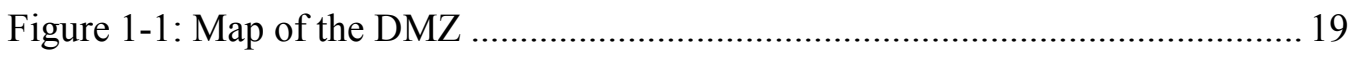

Figure 1-2: The structure of the Vinh Moc Tunnels ................................................. 24

Figure 1-3: One of the entrances and paths inside the Vinh Moc Tunnels ................ 25

Figure 2-1: Summary of the tourism literature related to the study ........................... 30

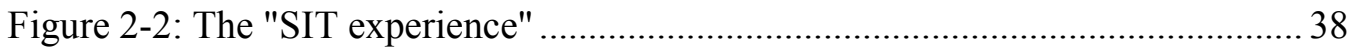

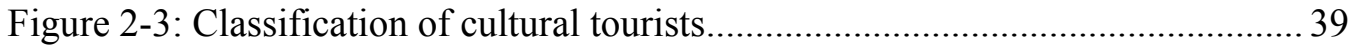

Figure 2-4: The Wine Tourist - a three dimensional analysis ................................. 40

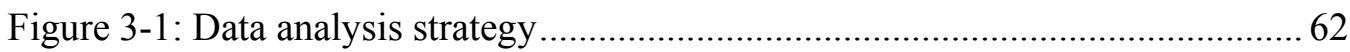

Figure 4-1: Respondents' connection with the Vietnam War .................................. 74

Figure 4-2: Comparison of purpose of visit between survey participants and the total international tourists to Vietnam in July 2008 ....................................................... 76

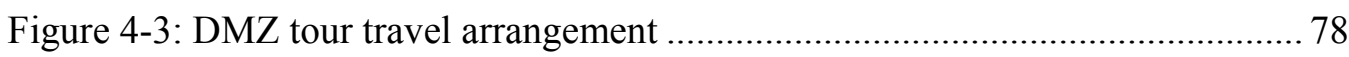

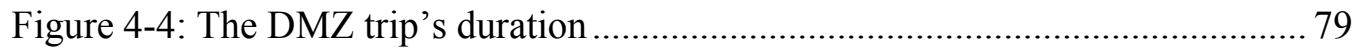

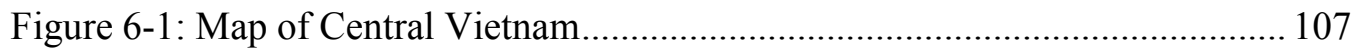




\section{Chapter 1: INTRODUCTION}

\subsection{Introduction}

Mankind has long held a fascination with visiting sites of past wars. In the last decade, significant developments have been made in research of tourism in relation to these battlefield sites, with the field of "battlefield tourism" being identified by a number of researchers as a significant niche tourism market (Lloyd, 1998; Seaton, 1999; Smith, 1998). Battlefield tourism is now considered to play an important role in the tourism industry of many countries (Lloyd, 1998), among which Vietnam is a typical example. Henderson (2000) suggests the battlefields in Vietnam offer untapped potential for tourism development. As part of the country's effort to diversify its tourism products, several battlefield tours were offered in Vietnam from the early 1990s (Schwenkel, 2006). Thirty three years after the Vietnam War ended in 1975, the tourism industry in Vietnam is thriving. The World Tourism and Travel Council expects that the growth rate of the Vietnam tourism industry will stand at $7.7 \%$ in the $2006-2015$ period, the $7^{\text {th }}$ fastest in the world (Vietnam Trade Information Centre, 2005).

However, while battlefield tourism may provide a niche opportunity for developing countries such as Vietnam to exploit, there has been little research examining battlefield tourism in developing countries. To date battlefield tourism has been documented predominantly in Europe (e.g. Gordon, 1998; Lloyd, 1998; Slade, 2003), and North America (e.g. Chandler \& Costello, 2002; Eskew, 2001; Smith, 1998). Only a few studies have been conducted in Asia (e.g. Henderson, 2000, 2007; Lunn, 2007). Moreover, most of the aforesaid studies adopted a supply perspective, mainly looking at management issues in developing wartime heritage as tourist attractions. Understanding why tourists are attracted to a specific site is vital in understanding how such sites should be managed, however, the visitor perspective, especially motivations for visiting battlefield sites, is under examined in current research. Furthermore, groups of visitors to battlefield sites have not been defined. Do all visitors to battlefield sites have a special interest in visiting battlefields or are they just general tourists casually visiting battlefield sites? These questions remain to be explored. 
This study discusses these questions in the context of Vietnam, a country in Indochina which has suffered several wars but is most well-known for the Vietnam War. Thus it is an appropriate case study for battlefield tourism. It seeks to contribute to filling the perceived gap in the literature of battlefield tourism by examining tourists' motivation for visiting battlefield sites and the attraction of battlefields in Vietnam to foreign visitors. It also aims to provide the Vietnam tourism industry with a deeper understanding of visitors to battlefield sites, so that better site management and marketing approaches can be applied.

This chapter sets the scene by introducing the research questions of this study in the research context of Vietnam. After presenting the research objectives, research questions and research significance, this chapter provides a description of the thesis's structure, highlighting the most important points of each part.

The next sections provide background information about Vietnam and its tourism industry. An overview of the Vietnam War and its role in the tourism industry is presented followed by a description of the DMZ and the Vịnh Mốc Tunnels.

\subsection{Research context}

\subsubsection{Vietnam - a snapshot}

Vietnam, officially the Socialist Republic of Vietnam, spreads along the Indochina Peninsula, bordering the South China Sea. It has boundaries with China in the north, and Laos and Cambodia in the west. The country has a total area of $329,560 \mathrm{~km}^{2}$ and an estimated population of around 86 million as of July 2008 (CIA, 2008), of which the majority (90\%) are ethnic Vietnamese (Kinh). Since 1986, Vietnam's economy has expanded rapidly thanks to the "doi moi" policy (economic renovation). The country has enjoyed strong economic development with real GDP growth averaging 7.6\% a year in the period 2000-2007 (Economist Intelligence Unit - EIU, 2008). Besides major industries such as textiles and mining, tourism is a growing industry which plays an increasingly important role in the country's total income (Ibid.). The importance of tourism to national development has been recognised in the country's tourism development master plan (Vietnam National Administration of Tourism VNAT, 1995). 


\subsubsection{Tourism in Vietnam}

Vietnam is a country with a rich history, a variety of landscapes and friendly people, which offer comparative advantages in the development of a tourism industry. In line with strong national economic growth, the tourism industry has developed rapidly since the 1990s. In 2004, revenue generated by the tourism industry reached US\$1.7 billion, equivalent to about 4\% of GDP, making tourism the fourth-largest source of foreign currency (EIU, 2005).

Table 1-1 shows the number of international tourist arrivals to Vietnam from 1990 to 2007. As can be seen, there has been an almost continuous increase in the number of tourist arrivals to Vietnam starting from 250,000 in 1990 and reaching 4.2 million in 2007. The only exceptions were the year 1998 and 2003. The number of tourists visiting Vietnam in 1998 dropped by $11.40 \%$, largely due to the Asian financial crisis. In 2003, the outbreak of Severe Acute Respiratory Syndrome (SARS) caused tourist arrivals to Vietnam to reduce again, this time by $7.60 \%$. However, the national efforts to attract international visitors have paid off as tourist arrivals increased steadily in 2004. In particular, the Vietnam tourism industry set a record when welcoming 2.9 million of international tourist arrivals in 2004, an increase of approximately $20 \%$ over 2003 . The tourism industry was also seriously influenced by the avian flu (bird flu) epidemic of 2006; however, it managed to maintain a growth rate of $3.3 \%$. In 2007, the country welcomed 4.2 million foreign visitors, representing an upsurge of $16 \%$ from 2006. In the first half of the year 2008, the number of international visitors to Vietnam reached $2,289,287$, an increase of $8.1 \%$ over the same period of the previous year (VNAT, 2008). This pattern of recent growth of the visiting tourists indicates huge potential for the Vietnam tourism industry to continue developing in the future. 
Table 1-1: International visitors to Vietnam from 1990 to 2007

\begin{tabular}{|rr|r|}
\hline Year & No. of tourists & $+/-(\%)$ \\
1990 & 250,000 & \\
1991 & 300,000 & 20.00 \\
1992 & 440,000 & 46.67 \\
1993 & 669,862 & 52.24 \\
1994 & $1,018,244$ & 52.01 \\
1995 & $1,351,296$ & 32.71 \\
1996 & $1,607,155$ & 18.93 \\
1997 & $1,715,637$ & 6.75 \\
1998 & $1,520,128$ & -11.40 \\
1999 & $1,781,754$ & 17.21 \\
2000 & $2,140,100$ & 20.10 \\
2001 & $2,330,050$ & 8.90 \\
2002 & $2,627,988$ & 12.80 \\
2003 & $2,428,735$ & -7.60 \\
2004 & $2,927,876$ & 20.50 \\
2005 & $3,467,757$ & 18.40 \\
2006 & $3,583,486$ & 3.30 \\
2007 & $4,171,564$ & 16.40 \\
\hline
\end{tabular}

Source: Vietnam National Administration of Tourism (2008)

Some of the major markets for Vietnam tourism include China, South Korea, the United States and Japan (VNAT, 2008). In the year 2007, China was the largest market with 558,719 visitors, followed by South Korea with 475,535 visitors. The United States and Japan ranked as the third and fourth largest markets with 412,301 and 411,557 visitors respectively (Appendix 4). It is noted that China has been the leading source of foreign visitors since 1996, however, many of these visitors are merely crossing over the northern border between the countries for a few hours shopping (Chan, 2006; Mok \& Lam, 2000).

Along with its growth in tourist arrivals, Vietnam was voted one of the 20 favourite travel destinations in the world through an opinion poll conducted among 30,000 readers of the prestigious travel magazine Condé Nast Traveller (Nguyen, 2007). In addition, the country was predicted to be among the world's top ten tourist destinations by 2016 (Hodgson, 2007). Clearly, Vietnam is growing as an emerging tourist destination. Nevertheless, to date there has been little research on tourism in Vietnam. Most previous tourism research about Vietnam is related to foreign direct investment (e.g. Haley \& Haley, 1997; Hobson, Heung, \& Chon, 1994; Withiam, 1994) or sustainable tourism including environmental management, waste management, and coastal management (Barbara \& Nguyen, 2005; Do \& Kumar, 
2005; Le, 2005; Sekhar, 2005). Despite an increasing number of tourist arrivals, little is known about Vietnam tourism from the tourist perspective. Even less has been revealed about tourist motivation and decision-making. Critical questions such as "Why do tourists visit Vietnam?" and "What are the most important attributes of Vietnam for tourists?" have not been fully examined in the existing literature. According to Alneng (2002), most tourists talked about the Vietnam War when being asked what they knew about Vietnam before their trip. Without doubt, the Vietnam War has attracted much international attention over the years; however, does this mean battlefield sites play a significant role in tourists' decision to travel to Vietnam? Having experienced several wars in its history, battlefield sites are everywhere in Vietnam. Should these sites be positioned as main attractions for tourists in Vietnam? Answering these questions requires an understanding of visitations to battlefields in Vietnam: who are the battlefield visitors and why do they visit battlefield sites?

\subsubsection{The Vietnam War}

\subsubsection{Overview of the Vietnam War}

The Vietnam War, as it is called internationally, refers to the war between the Democratic Republic of Vietnam ${ }^{1}$ (North Vietnam) and the Republic of Vietnam ${ }^{2}$ (South Vietnam) from 1954 to 1975. It is also known as the Second Indochina War or the Vietnam Conflict. Yet the Vietnamese people call it "Kháng Chiến Chống Mỹ" (Resistance War Against America) to distinguish it from other wars throughout the country's history such as wars with the French, the Chinese, and the Mongolians. In this study, the name Vietnam War is used mostly because the research's subjects and target audience are non-Vietnamese.

The main military forces active in the Vietnam War were the People's Liberation Armed Forces PLAF $^{3}$ (North) and the Army of the Republic of Vietnam ARVN (South). However, other foreign military organisations were also deeply involved. While North Vietnam was backed by its communist allies such as the Soviet Union, China and North Korea, the United States, South Korea, Australia, New Zealand, Thailand, and the Philippines were supporters of South Vietnam. The U.S. entered the war to prevent the Communist North Vietnam from taking over South Vietnam,

\footnotetext{
${ }^{1}$ In Vietnamese: Việt Nam Dân Chủ Cộng Hòa

${ }^{2}$ In Vietnamese: Việt Nam Cộng Hòa

${ }^{3}$ In Vietnamese: Quân Giải Phóng and also known as Việt Cộng

${ }^{4}$ In Vietnamese: Quân Đội Quốc Gia Cộng Hòa and also known as Lính Nguỵ
} 
thus stopping the spread of communism in Southeast Asia. During its ten year commitment period in Vietnam, around 58,000 American servicemen were killed and 2,000 soldiers listed as missing-in-action (Rummel, 2008).

Without going into detail about the history, causes and effects of the war, it is worth mentioning that the war had a deep impact on the U.S. economy as well as its political and foreign relation policies (Burstein \& Freudenburg, 1978; Milstein, 1974) and left an important mark in world history. After more than 30 years, the war still affects the lives of many of those who were involved. Needless to say, the aftermath is especially obvious in Vietnam. However, besides the negative consequences, the War is now contributing to the development of tourism in Vietnam.

\subsubsection{The role of the Vietnam War in the country's tourism development}

In Vietnam, undoubtedly, the war left severe scars on the lives of the local people. After the war, the country's economy almost collapsed and millions were plunged into poverty and made homeless. On the other hand, however, it is the war that has made Vietnam famous as a country, which consequently contributes to the development of a modern tourist industry (Alneng, 2002). In fact, most tourists got their first impression of Vietnam from movies about the Vietnam War such as Platoon, Good Morning Vietnam, Heaven and Earth, and so on (Ibid.). The war has helped the formulation of a type of travel that combines memory, history, tragedy, and entertainment in one package tour to former battlegrounds in Vietnam (Schwenkel, 2006). Tourists to these sites often seek to see, experience and understand mass destruction and violence in contemporary times.

In the beginning, the Vietnam War was not promoted by the Vietnam National Administration of Tourism (Biles et al., 1999 as cited in Alneng, 2002). Only from the early 1990s has the war been used as a construct in marketing Vietnam to international visitors (Schwenkel, 2006).

After the war ended in Vietnam in 1975, Americans were not allowed to travel to or to trade with Vietnam. Yet demand for travel to Vietnam still existed (Blaine, Mohammed, Ruppel, \& Var, 1995). Since the U.S. lifted the trade embargo in 1993 and diplomatic relations were established between the two countries in 1995, there has been an increase in the number of American tourists to Vietnam (VNAT, 2008). 
Specifically, from 10,425 visitors in 1990, the number of American visitors in Vietnam increased by five times in 1995, reaching 57,500. In 2007, American tourists reached 412,301, making it one of the most important markets for Vietnam tourism and the target market for war tourism products (Schwenkel, 2006). Obviously, given the intense American involvement in the Vietnam War, it is expected that international tourists, especially Americans, are interested in visiting battlefield sites in Vietnam, especially those related to the former American bases. The fact that several famous commercial battlefield tours in the world, such as the Great War tour on the Western Front, and the DMZ tour in Korea, have attracted a substantial number of people since their inception lends further weight to this supposition (Iles, 2006; C.-K. Lee, Yoon, \& Lee, 2007; Timothy, Prideaux, \& Seongseop-Kim, 2004). In Vietnam specifically, together with the emerging touristification of several former war related sites, the DMZ is now one of the most well-known attractions among tourists due to its historic significance (Lunn, 2007).

\subsubsection{The attraction of the former DMZ in Vietnam}

\subsubsection{History of the DMZ}

One of the battlefield sites in Vietnam that is often visited by international tourists is the former DMZ, the border area between North and South Vietnam during the Vietnam War. It extended five km north and south of the Bến Hải River and ran approximately $100 \mathrm{~km}$ from the South China Sea to the Laos border. The establishment of the DMZ was a result of the Geneva Conference ending the war between the Việt Minh ${ }^{5}$ and the French in July $1954 .^{6}$

The DMZ is now part of the Quảng Trị Province, about $70 \mathrm{~km}$ north of Huế city the ancient capital of Vietnam and another major tourist destination. In Figure 1-1, the $\mathrm{DMZ}$ is the white area running from left to right. It extends from the western border with Laos, across Vietnam, to the South China Sea in the east.

\footnotetext{
${ }^{5}$ Việt Nam Độc Lập Đồng Minh Hội (In English: League for the Independence of Vietnam)

${ }^{6}$ The First Indochina War (1945-1954), also known as the French Indochina War, the Anti-French War, the Franco-Vietnamese War, or the Franco-Vietminh War.
} 


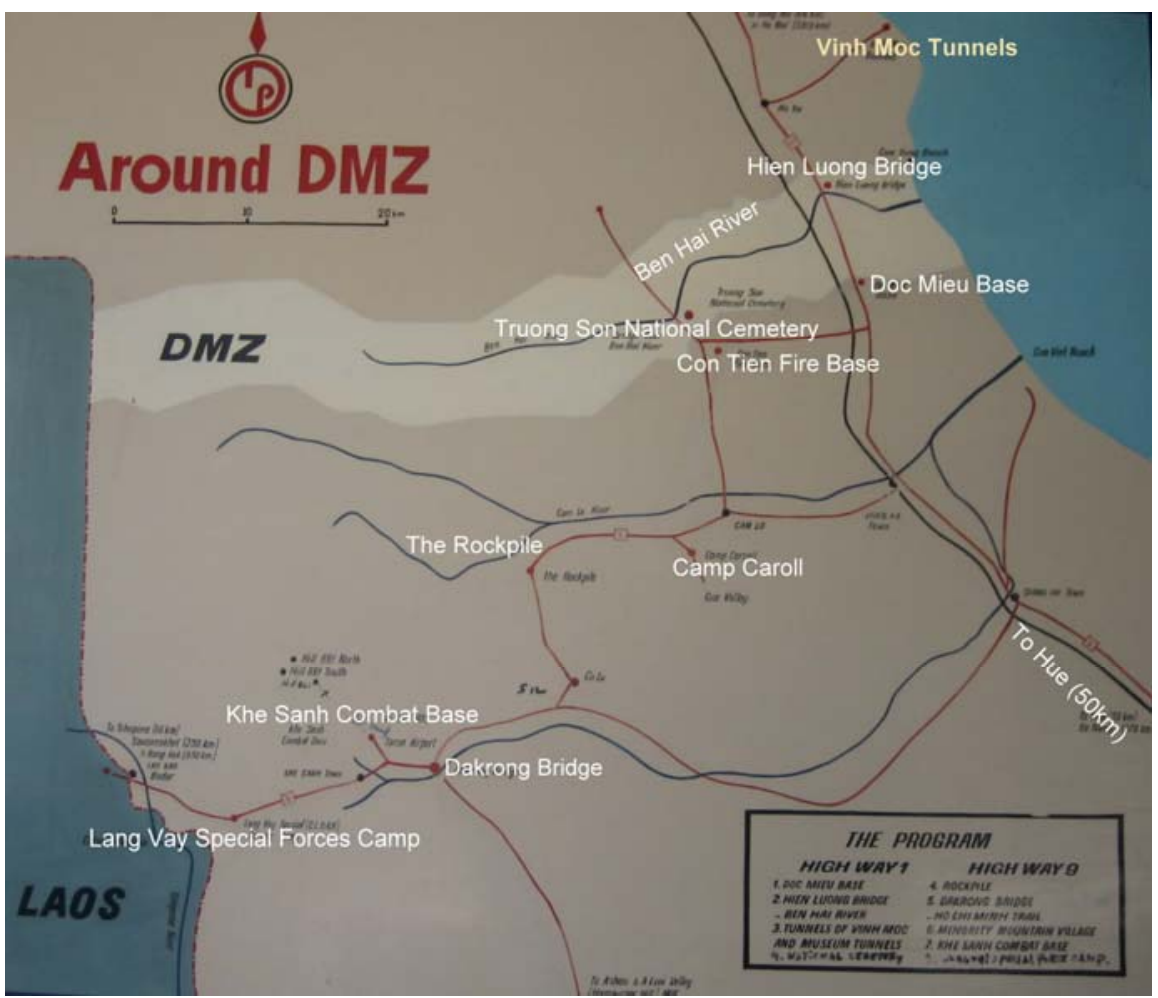

(Photo taken by Diem-Trinh Le at DMZ Travel Agent in Quang Tri)

Figure 1-1: Map of the DMZ

After being defeated in the battle of Điện Biên Phủ on 7 May 1954, France was forced to withdraw from Vietnam. By the Geneva Agreement, Vietnam was temporarily divided into Southern and Northern parts and the $17^{\text {th }}$ parallel was recognised as the demarcation line.

The Geneva Accords promised elections in 1956 to determine a national government for a united Vietnam. Yet the election was never held and the DMZ remained a de facto border between North Vietnam and South Vietnam. In 1972, the North Vietnamese stormed the DMZ and pushed the border $20 \mathrm{~km}$ further south. The Thạch Hãn River was the new border until the country's reunification in 1975.

During the war, several interconnecting roads and trails (approximately $20,000 \mathrm{~km}$ in total) were built by the North Vietnamese Army to transport supplies for their allies in the south. These roads became known as the now infamous Hồ Chí Minh Trail. On the other side, South Vietnam and its allies created a series of bases along Route 9 (which parallels the DMZ approximately $10 \mathrm{~km}$ to the south) in an attempt to stop this flow of munitions. This series of bases, mines and electrified fencing was often known as the McNamara Line. 
Despite its function as a de-militarised zone, the area was one of the major battlefields in the Vietnam War. Some of the fiercest, bloodiest and most important battles took place in and around this area, especially along the McNamara Line, at places such as Khe Sanh Combat Base, The Rockpile, Camp Carroll, Cồn Tiên Firebase, and Dốc Miếu Base. Quảng Trị province in general was one of the most intensively bombed areas in Vietnamese military history (Quang Tri's Historical Relics and Tourism Spots Management Office - HRTSMO, 2006). Some areas, such as Vĩnh Linh were termed "Free Fire Zone", an area where anyone unidentified was considered an enemy and could be shot without reason by U.S. soldiers. It is estimated that the province suffered 328,000 tons of bombs, of which the combined explosive power was equivalent to seven of the atomic bombs dropped on Hiroshima (Japan) in 1945 (HRTSMO, 2007). On average, a local in the Vĩnh Linh district had to endure seven tons of bombing and ammunition, culminating in about ten thousand houses in Quảng Trị being completely destroyed (Ibid.). To shelter from the bombs, the local people had to either leave the area or live beneath the ground. Several tunnels were built in the area among which the Vịnh Mốc Tunnels are the biggest and most complex. These tunnels are also the only ones that remain intact today.

Being located in a harsh region which is prone to calamities such as floods and storms together with the severe damage from the war, nowadays, Quảng Trị remains one of the poorest provinces in Vietnam and is known mostly for its battlefield tourism. Every year, thousands of Vietnamese people visit Quảng Trị on a "Back to the Roots"7 pilgrimage. Outside Vietnam, the "DMZ tour" has become well-known among foreign tourists visiting in Vietnam.

\subsubsection{The DMZ tour}

First introduced by a tourist company in Huế in the early 1990s, the name "DMZ tour" has become widely known among Western tourists in Vietnam. To date the tours called "DMZ tour" have been offered by several local tourist companies. In Quảng Trị, as well as Huế and Quảng Bình (neighbouring provinces), the sign "DMZ tour" can be found everywhere especially in front of travel agency offices, hotels and tourist centres.

\footnotetext{
${ }^{7}$ In Vietnamese: Trở Về Cội Nguồn
} 


\section{Tour description}

Despite being named the "DMZ tour", these tours are not limited to the DMZ but takes tourists to war related sites and battlefields in the whole Quảng Trị province. Most of the sites included in the tour are in fact geographically outside what was the DMZ. As mentioned earlier, the DMZ is a narrow area spreading five $\mathrm{km}$ each side of the Ben Hai River. Although remnants of the war are still to be found within the DMZ area, the most significant relics (i.e. American bases) are along Highway 9, while most war memorials, tunnels, and museums are north of the DMZ, including the most interesting sites for tourists such as Khe Sanh Marine Base, Camp Carroll, and the Vinh Moc Tunnels. Such tours were given the name "DMZ" as a short, effective and attractive description and to present the most important characteristic of the tour: a visit to the place that was in between the two sides of the Vietnam War, which was witness to an important period of the country's history. In this study, the term DMZ refers to the "extended DMZ", i.e. the whole battlefield area in Quảng Trị province, including but not limited to the former DMZ.

Visitors to the DMZ can opt to visit different sites, depending on the tour company or the type of the tour (private or group tour). The most popular tour organised by Huế's Huong Bình and An Phú Tourist Company in cooperation with the MeKong Travel Agent in Quảng Trị has the following itinerary:

- 6.00am: pick up by bus at hotel and head for Dong Ha town

- 8.30am: free breakfast at MeKong hotel in Dong Ha

- 9.15am: visit sites along High Way 9 (Rockpile, Dakrong bridge-Ho Chi Minh Trail, and Khe Sanh Marine Base)

- 12.30pm: lunch

- 1.30pm: visit sites along High Way 1 (Doc Mieu and Vinh Moc Tunnels)

- 4.00pm: ends tour and back to Hue city at 6.00 ish

\section{Accessibility}

Most of the sites in the area can be easily accessed by bus, car or motorbike. Some sites such as A Sầu Valley, Hamburger Hill and Cồn Tiên Fire Base are only 
accessible by motorbike or on foot. Most tourists opt for the option of a one day bus tour from Huế while the choice of a private tour is preferred by those who would like a more flexible itinerary.

\section{Description of the sites in the DMZ tour}

As mentioned earlier, there are several sites of historical importance in the Quảng Trị province, which are often regarded as a part of the DMZ tour. Some of the major sites as seen in Figure 1-1 are described below.

- Bến Hải river and Hiền Luong bridge: at the $17^{\text {th }}$ parallel, the place marked the official partition point between North and South Vietnam from 1954.

- Dốc Miếu base: located $8 \mathrm{~km}$ south of Bến Hải river, was part of an elaborate electronic system (McNamara Line) intended to prevent penetration across the DMZ by the North Vietnamese Army.

- Vịnh Mốc Tunnels: a system of tunnels built by the North Vietnamese people and army as a shield from the heavy bombings by the US, a place that illustrates the bravery and hardship of the Vietnamese people during the war.

- The Rockpile: located on Highway 9, it is an important lookout spot for the U.S. Marine Corps during the war. It was named after what can only be seen as a $230 \mathrm{~m}$ high pile of rock.

- Dakrong Bridge and the Hồ Chí Minh Trail: located at the junction of Highway 9 and Highway 15, which leads to A Sầu Valley and Hamburger Hill. Dakrong Bridge was the main access point to multiple paths of the Hồ Chí Minh's trail during the war.

- Khe Sanh Combat Base/Tà Con Airfield Museum: is the site of one of the most important battles of the Vietnam War. Hundreds of US marine soldiers were killed and the base was taken over by the North Vietnamese Army in July 1968. The site is located south of the DMZ, east of the border with Laos.

- Truong Son National Cemetery: created in 1975, is the biggest national war cemetery in Vietnam, which holds over 10,000 graves. 
- Ái Tu Airfield: built in 1967 on the bank of the Thạch Hãn River and considered the biggest airfield in "the first tactics zone".

- A Sầu Valley and Hamburger Hill: its original name was Hill 937, a heavily fortified place known for the battle between the U.S. and ARVN against the North Vietnamese Army on 10-20 May, 1969, became famous after the release of the movie "Hamburger Hill" (1987).

- Camp Carroll: was the largest fire-support base for the U.S. Marines, named after Captain J.J. Carroll, the commanding officer of Mike Company, $3^{\text {rd }}$ Battalion, $4^{\text {th }}$ Marine.

- Làng Vây Special Forces Camp: established in 1962 to train and arm the Bru (an ethnic minority), is known for the famous attack in February 1968 by nine tanks of North Vietnamese Army.

- Cồn Tiên Fire Base: was the most important outpost along the McNamara Line which saw some of the heaviest combat during the war, received more artillery fire than any other single spot in the DMZ area.

Of these sites, Vinh Moc Tunnels is one of the most famous and most visited attractions in Quảng Trị province (HRTSMO, 2006).

\subsubsection{The Vinh Moc Tunnels - a major historical tourist attraction}

The Vịnh Mốc Tunnels are situated in Vĩnh Mốc Village, Vĩnh Linh District, Quảng Trị Province. It is the most typical construction of village tunnels in the area if not the whole country. For many years, it has been the most visited historical site in Quảng Trị, attracting both international and domestic visitors (HRTSMO, 2006). Specifically, in 2007, there were 62,625 visitors to the Vinh Moc Tunnels, among which 42,642 were foreign visitors (Vinh Moc Tunnels: Visitor Statistics, 2008). While this is the highest number of visitors for a tourist site in the Quảng Trị province, compared to the total international visitors to Vietnam in 2007, visitors to the Vịnh Mốc Tunnels accounted for only a small proportion (1\%). This suggests that Vietnamese battlefield sites are not attracting a great number of tourists, in contrast to the national tourism strategy. Therefore, further research is needed to gain understanding of the attraction of battlefield sites in Vietnam. 
Originally the systems consisted of three separate tunnels: the tunnel of the borderguard force 140, the tunnel of the Vịnh Mốc guerrillas, and the one of the Son Hạ guerrillas. Later for the purpose of fighting and cooperation, these three were connected with each other making one big interlinked system. The system is $1701 \mathrm{~m}$ long with 13 entrances/exits (seven opening to the sea and six to the hills, which also function as ventilators). The Tunnels have three levels with the deepest being $23 \mathrm{~m}$ underground (Figure 1-2).

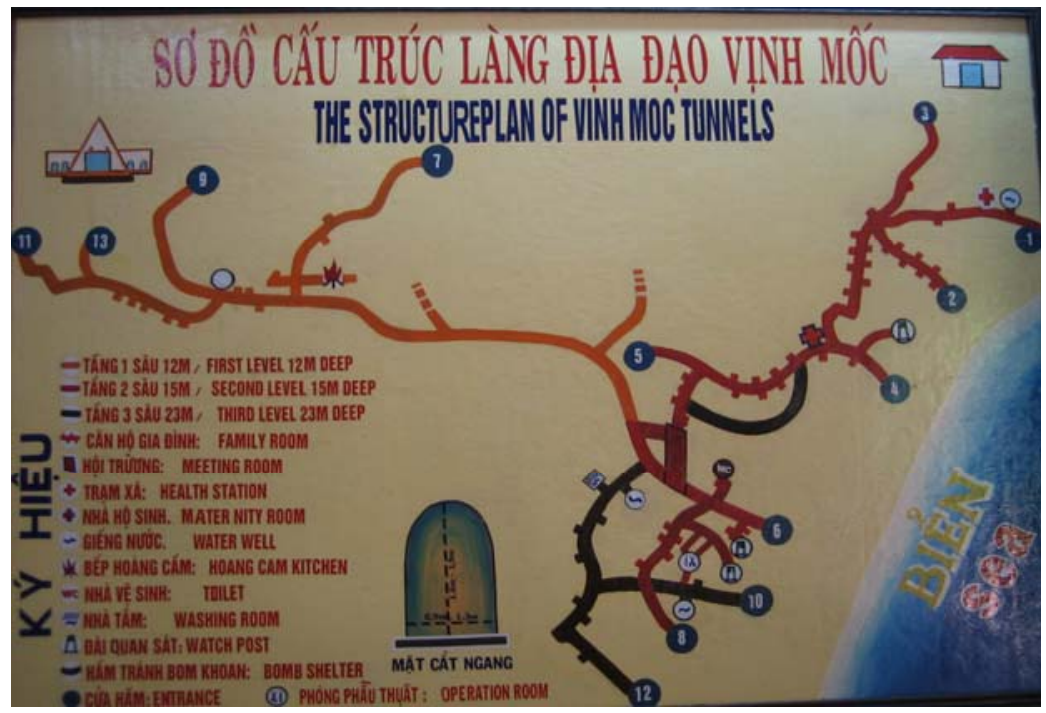

(Photo taken by Diem-Trinh Le at the Vinh Moc Tunnels)

Figure 1-2: The structure of the Vinh Moc Tunnels

Inside the Tunnels (Figure 1-3), shelters for families were built along the two sides of the main axis. There are also a meeting hall with seating capacity for 60 people, an operating room, Hoàng Cầm's kitchen ${ }^{8}$, food storehouse and a maternity ward where 17 babies were born. The Tunnels served not only as a shelter for people but also as a base to transport supplies of food, ammunition, and medicine to the North Vietnam's army on Cồn Cỏ Island. ${ }^{9}$

The Vịnh Mốc Tunnels were recognised as a national heritage site by the Vietnamese Ministry of Culture and Information in 1976. To ensure safety and security of the increasing number of tourists, the Tunnels were restored with reinforced concrete at the entrances/exits and equipped with lights along the axis (Figure 1-3).

\footnotetext{
${ }^{8}$ This is a unique stove that was widely used during the war. It allowed underground cooking without emitting smoke, thus prevent discovery by the enemy. It was named after a Vietnamese soldier who invented it.

${ }^{9}$ Cồn Cỏ Island belongs to the Quảng Trị Province, holding a strategic position for the protection of Vĩnh Linh district. It is located in the South China Sea, at the $17^{\circ} 10^{\prime}$ latitude.
} 

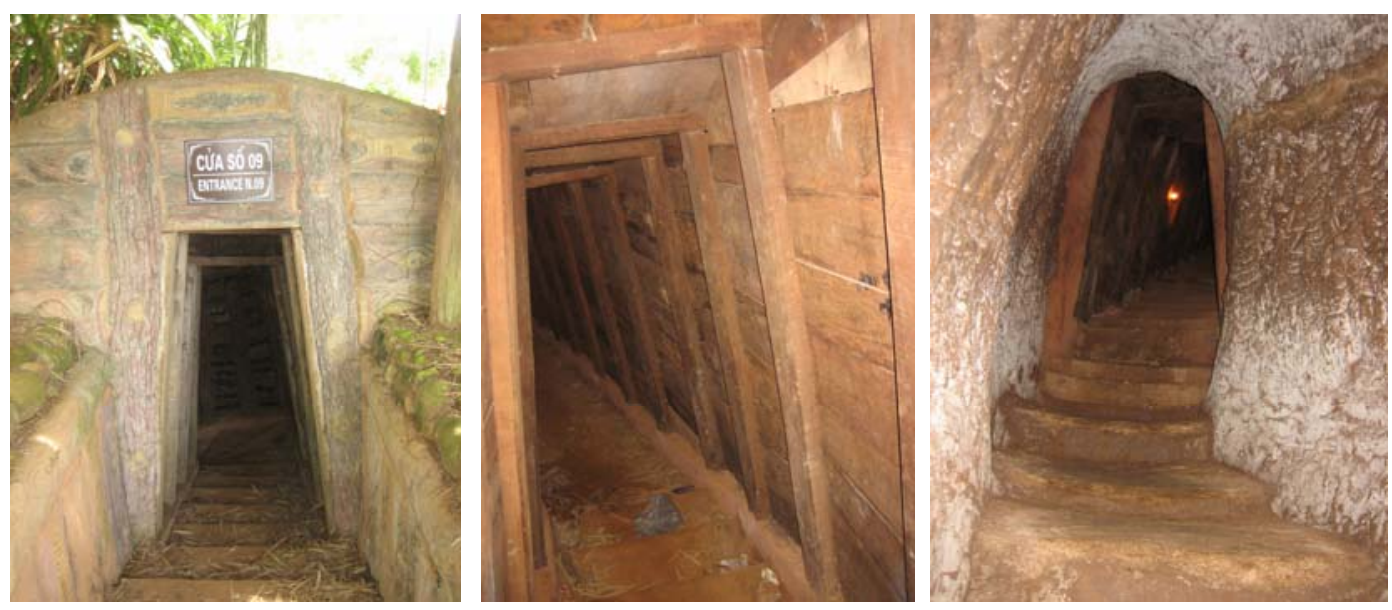

(Photos by Diem-Trinh Le)

Figure 1-3: One of the entrances and paths inside the Vinh Moc Tunnels

\subsection{Research objectives and research questions}

As mentioned earlier, to date there has been a lack of research regarding tourism in Vietnam, especially from a demand perspective. Furthermore, despite a significant number of battlefield sites and battlefield tours in the country, no one has explored the motivations of tourists for visiting these sites. This study, therefore, seeks to fill this gap by examining the visitors to battlefield sites in Vietnam. It aims to contribute to the understanding of battlefield tourism, especially with regards to visitor motivations and tourist segmentation. The primary objectives are:

(1) to identify the international tourists' motivations for visiting the Vietnamese $\mathrm{DMZ}$

(2) to segment the visitors based on their motivations for visiting the $\mathrm{DMZ}$

(3) to define the importance of the battlefield sites in tourists' decision to travel to Vietnam

These objectives are to be achieved by seeking the answers to the following research questions as displayed in Table 1-2: 
Table 1-2: Research objectives and research questions

\begin{tabular}{|c|c|c|}
\hline Objectives & Primary question & Secondary questions \\
\hline $\begin{array}{l}\text { (1) To identify tourists' } \\
\text { motivations for visiting } \\
\text { the Vietnamese DMZ }\end{array}$ & $\begin{array}{l}\text { Why do tourists visit the } \\
\text { DMZ? }\end{array}$ & $\begin{array}{l}\text { How are the motivations } \\
\text { for visiting the DMZ } \\
\text { different between visitors? }\end{array}$ \\
\hline $\begin{array}{l}\text { (2) To segment visitors } \\
\text { based on their } \\
\text { motivations for visiting } \\
\text { the DMZ }\end{array}$ & $\begin{array}{l}\text { What are the groups of } \\
\text { visitors to the DMZ based } \\
\text { on motivations? (What } \\
\text { type of tourists visit the } \\
\text { DMZ?) }\end{array}$ & $\begin{array}{l}\text { What are the socio- } \\
\text { demographic } \\
\text { characteristics of visitors to } \\
\text { the DMZ? } \\
\text { What are their trip related } \\
\text { characteristics? } \\
\text { How do visitors' } \\
\text { characteristics differ } \\
\text { between groups? }\end{array}$ \\
\hline $\begin{array}{l}\text { (3) To determine the } \\
\text { importance of battlefield } \\
\text { sites in tourists' decision } \\
\text { to travel to Vietnam }\end{array}$ & $\begin{array}{l}\text { What is the role of } \\
\text { battlefield sites in tourists' } \\
\text { decision to visit Vietnam? }\end{array}$ & $\begin{array}{l}\text { How do the visitor groups } \\
\text { differ in terms of their } \\
\text { travel decision-making? }\end{array}$ \\
\hline
\end{tabular}

\subsection{Significance of the research}

By achieving these objectives, this study can make a significant contribution to both the tourism literature and directly to Vietnamese tourism. First, it contributes to the literature on battlefield tourism by identifying the motivations for visiting battlefield sites. Second, it furthers the understanding of battlefield visitor segmentation by providing visitor segment profiles of socio-demographic characteristics, motivation and decision-making. What is more, it provides the tourism organisations in Vietnam with useful information regarding tourists to war related attractions so as to build appropriate marketing strategies and improve war tourism products. Accordingly, a study of DMZ visitor segmentation on motivations is essential.

\subsection{Thesis organisation}

This thesis has a seven-chapter structure. This opening chapter has presented the research context with an overview of Vietnam and its tourism industry. The Vietnam War was briefly outlined as an introduction to its role in the country's tourism development. The DMZ was described as one of the most typical Vietnamese battlefield sites, and accordingly presents itself as an appropriate site for a case study of visitors to battlefield sites in Vietnam. This chapter also highlighted the objectives and significance of this thesis. 
Chapter Two aims to set up a theoretical background for this study by means of a literature review. It discusses the literature specifically related to the three research objectives: tourist motivation, market segmentation and travel decision-making. In addition, the next chapter provides a background for a study in battlefield tourism in Vietnam by introducing the general theme of special interest tourism, dark tourism, narrowing down to battlefield tourism. Finally, these literature components are linked together to highlight a research gap that calls for further exploration, which confirms the significance of the present study.

The process of developing the research methodology is described in Chapter Three. The choice of a quantitative approach is justified. Detailed explanation of how data was collected and entered is included together with an outline of how the data was analysed. Overall data assessment is provided while limitations of the methodology are also acknowledged.

The results of the research are presented in three chapters. Chapter Four introduces the findings by providing an overview of the total study sample. In particular, it presents the respondents' socio-demographic and trip related characteristic profiles. Detailed analysis of the visitor segments are then presented in Chapters Five and Six.

Chapter Five addresses the first two objectives of this thesis: identifying the tourist motivations for visiting the $\mathrm{DMZ}$ and classifying the $\mathrm{DMZ}$ visitors based on their motivations. It involves both content analysis of the qualitative data and statistical analysis of quantitative items. Specifically, content analysis and factor analysis is performed to identify the tourist motivations while cluster analysis and discriminant analysis is adopted to define visitor segments. Profiles of the visitor segments are also compared to emphasise the differences between them.

Chapter Six addresses the third research objective, which is to determine the importance of battlefield sites in the survey respondents' decision to visit Vietnam. It discusses the information about visitors' decision-making stage, information search and level of knowledge of the DMZ. In addition, visitors' level of interest and participation in battlefield tourism in Vietnam are considered. Furthermore, this chapter reports on visitor satisfaction of the $\mathrm{DMZ}$ experience, the aspects of the tour that were highly appreciated as well as some suggestions for improvements. 
Chapter Seven summarises and discusses the findings in relation to previous studies. Moreover, the entire research is reviewed and the objectives are revisited. This chapter also discusses the implications emanating from the findings and makes recommendations for tourism practitioners and future research. 


\section{Chapter 2: LITERATURE REVIEW}

\subsection{Introduction}

The previous chapter mentioned the three main objectives of this study. The first two objectives are to understand tourists' motivations for visiting battlefield sites and consequently, identify distinctive groups of visitors based on their motivations. The third objective is to determine the importance of battlefield sites in tourists' decision to travel to Vietnam. In order to achieve these aims, it is critical to build an appropriate methodology to conduct the empirical research. However, this can not be done without a thorough understanding of the theoretical background of the study. Therefore, a review of the previous related studies is needed.

This chapter reviews the related literature with relevance to the research questions. Figure 2-1 demonstrates how the literature's components relate to the research questions. Specifically, this study focuses on visitation to battlefield sites, thus a general understanding of battlefield tourism is critical. As battlefield tourism is generally classified as a type of dark tourism/thanatourism (Ashworth, 2004; Seaton \& Lennon, 2004), which in turn is a form of special interest tourism, these two subjects are necessarily included. Likewise, the literature on tourist motivation in general and thanatouristic motivation in particular provides insight into the understanding of tourist motivations for visiting the DMZ. An overview of market segmentation on motivation is vital to identify the appropriate method of segmenting the visitors to the DMZ. In addition, studies on travel decision-making are useful to determine the importance of the Vietnamese battlefield sites in tourists' decision to travel to Vietnam. 


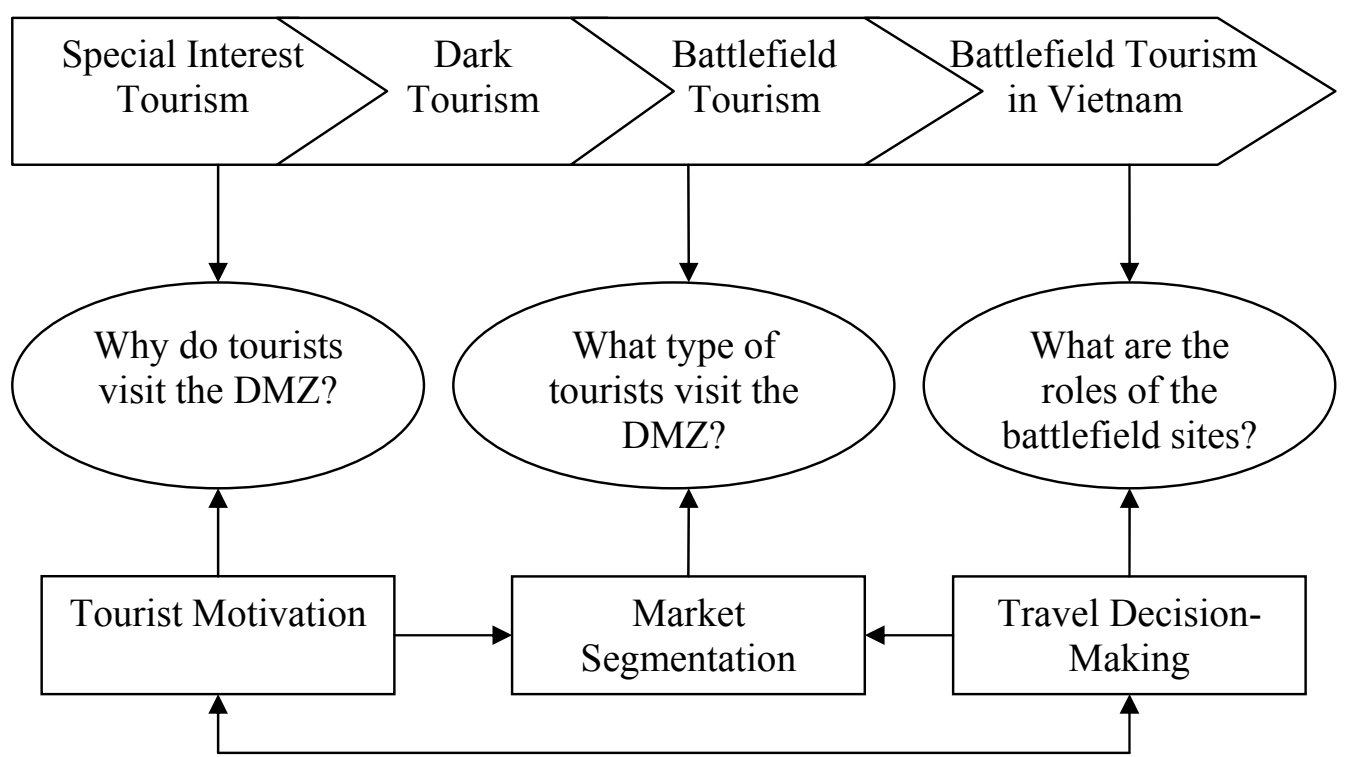

Figure 2-1: Summary of the tourism literature related to the study

\subsection{Special Interest Tourism}

Emerging trends in tourism research show a shift in interest from mass tourist attractions to alternative products and services and a demand for personalised and sophisticated tourism with a wide range of quality choices (Derrett, 2001). This phenomenon is often regarded as Special Interest Tourism (SIT) or niche tourism.

Several definitions of SIT have been proposed in tourism research. According to the World Tourism Organisation (1985, as cited in Hall \& Weiler, 1992, p.5):

"Special Interest Tourism is specialised tourism involving group or individual tours by people who wish to develop certain interests and visit sites and places connected with a specific subject."

Derrett (2001) defines SIT as:

"the provision of customised leisure and recreational experiences driven by the specific expressed interests of individuals and groups" (p.3).

These definitions suggest the important aspects of SIT are (1) driven by specific needs and interests, and (2) suitable for only certain individuals or groups. Yet they neither define these "particular individuals or groups" nor show how to differentiate between these tourists and general interest tourists. Hall and Weiler (1992), however, propose a tighter definition, in which SIT is believed to occur: 
"when the traveller's motivation and decision-making are primarily made by a particular interest" (p.5).

This definition implies SIT as "active" or "experiential" travel. It emphasises the participation and learning experiences aspect of the visit, i.e. the tourists are not just there but they also engage themselves in the activities at the place visited. However, again, it is difficult to determine which interest is "a particular interest". The two aspects (i.e. motivation and decision-making) are useful in defining a special interest tourist, however, other factors such as participation, experience and knowledge of a particular tourism activity also need to be considered.

As tourist motivation is complex and changes over time (Pearce, 1993), a wide range of activities has emerged to meet these needs. The increasing diversity of SIT is thus in line with the increasingly fragmented nature of tourism products. Special Interest Tourism appears in many forms, including cultural tourism, heritage tourism, rural tourism, educational tourism, aboriginal cultures and indigenous tourism, wine and food tourism, environmental tourism, and dark tourism. Among these, dark tourism or thanatourism has attracted much attention from tourists as well as tourism researchers due to the complexities of both its supply and demand side.

\subsection{Dark tourism}

\subsubsection{Definition of dark tourism and thanatourism}

Before defining dark tourism or thanatourism, it is worth mentioning the long standing phenomenon of travelling to sites associated with deaths and disasters. This phenomenon has existed for a long time (Lennon \& Foley, 2000). Seaton (1996) asserts that the ongoing thanatourism can be traced from the gladiatorial combats in the Roman Coliseum, through to the mediaeval Dance of the Death pilgrimages to sites of public execution, and assassination. To date, visitation to sites related to death and disasters is growing due to the strong influence of up-to-date information from the media (Dann, 2005). Examples of such sites include:

- $\quad$ The Holocaust Museums (see, for example, Miles, 2002; Yuill, 2003).

- War related sites all over the world such as those in Japan, Korea, Vietnam, and Singapore (see, for example, Agrusa, Tanner, \& Dupuis, 2006; Cooper, 2006; Lee et al., 2007; Lloyd, 1998; Seaton, 1999; Slade, 2003; Timothy et al., 2004). 
- Sites related to historic heroes or celebrities' deaths (see, for example, Frost, 2006; Lennon \& Foley, 2000).

In tourism research, travel associated with death, atrocity and disaster has been studied under different names (e.g. dark tourism, thanatourism, grief tourism, black spots tourism, etc.). Although there has been no clear definition of this tourism niche (Tarlow, 2005), the two most commonly used definitions are thanatourism and dark tourism, which are believed to have first entered the literature in 1996 (Seaton \& Lennon, 2004).

Originally, Seaton (1996) defines thanatourism as travel (1) to witness enactments of death, (2) to see the sites of mass or individual deaths, (3) to visit internment sites and memorials, (4) to view the material evidence of symbolic representations of death, and (5) for enactments of simulation of death. Later, the author uses the term "thanatourism" to portray this phenomenon in which people:

"travel to a location wholly, or partially, motivated by the desire for actual or symbolic encounters with death, particularly, but not exclusively, violent death, which may, to a varying degree be activated by the person-specific features of those whose deaths are its focal object" (Seaton, 1999, p. 240).

The second term, "dark tourism", is introduced by Lennon and Foley (2000, p. 198). The authors describe dark tourism as:

"the phenomenon which encompasses the presentation and consumption (by visitors) of real and commodified death and disaster sites".

Tarlow (2005) in his discussion of the appeal of the "dark" side of tourism, asserts that thanatourism or dark tourism relates to events, which are more than just tragedies in history, but rather touch our lives from an emotional perspective and impact our politics and social policies.

In this study, thanatourism and dark tourism are used interchangeably and refer to travel associated with death, disaster and atrocity. 


\subsubsection{The influence of media on the increasing phenomenon of dark tourism}

According to Gatewood and Cameron (2004), visitation to sites related to deaths and disasters is growing as it encourages reflections on the meaning of life and death. In addition to the push factors (motivations), the media plays an important role in promoting thanatourism (Dann, 2005; Lennon \& Foley, 2000). These authors suggest media such as film, television and the press are responsible for converting scenes of violent or premature death of celebrities into commodified tourist attractions. Other researchers' findings support this argument. In particular, Schwenkel (2006) finds that Hollywood movies such as Platoon, Good Morning Vietnam, and Heaven and Earth contributed to increase interest and curiosity about Vietnam and also created an image of the country for many people. In addition, Strange and Kempa (2003) believe Alcatraz and Robben Island were presented in such a sensational and curiously patriotic way in Hollywood blockbusters that they attract thousands of people to go to see the real place. Such movies also influence people's expectation when they visit Alcatraz.

\subsubsection{Levels of dark tourism: a supply perspective}

As mentioned, there is a diverse range of sites associated with death, disaster and atrocity. Some sites may be strongly related while the others are only slightly connected to the event. A question is raised if there are differences between visitations to these sites. Understanding these differences (if there are any) can provide better understanding of the visitors. Consequently it helps the tourism organisations to apply better suited strategies for each group of visitors. However, in order to understand the visitation pattern, first of all, these sites need to be categorised. How many types of sites associated with death and disaster are there, and what are the differences between these sites?

Several researchers have examined the questions above. Miles (2002) points out the differences between visits to sites $o f$ and sites associated with death, disaster and depravity. According to Miles, dark tourism is visits to sites associated with death and holocaust; whereas darker tourism refers to visit to actual sites of barbarism and genocide. The highest level, darkest tourism, "goes beyond both the spatial differences that distinguish dark from darker type and the time gap that separates both dark and darker from the remembered tragedy" (p.1176). The author believes 
that advances in media and internet help stimulate the phenomenon of darkest tourism.

Similarly, Stone (2006) argues that dark tourist sites can be categorised into different types according to their level of darkness. A dark tourism spectrum includes six levels: darkest, darker, dark, light, lighter and lightest. Accordingly, there are seven dark suppliers: Dark Camps of Genocide, Dark Conflict Sites, Dark Shrines, Dark Resting Places, Dark Dungeons, Dark Exhibitions, and Dark Fun Factories. Battlefield sites are placed in "Dark Conflict Sites". The author also notes that Dark Conflict Sites are becoming increasingly commercialised due to increasing tourism infrastructure.

Another author who examined the complexity of dark tourism is Tarlow (2005). Tarlow indicates that dark tourism exists in many forms, such as a pretext to understand our own age, romanticism, barbarism, part of national identity, a sign of decadence, a mystical experience and a spiritual experience. He notes four basic emotions of the visitors throughout those forms: a sense of insecurity, a sense of gratitude, feelings of humility, and feelings of superiority.

Although providing a good overview of dark tourism, Miles' and Stone's frameworks are only based on the characteristics of the sites (i.e. using a supply perspective). Can a similar framework be applied for the dark tourism consumers? Tarlow (2005) mentions the connection of the sites with the visitor's psychological state yet there was no further explanation regarding the tourist motivation and behaviour. Moreover, as Stone (2006) suggests, many dark tourism products are multi-layered and are perceived differently amongst different groups of people. The question to what extent a dark tourism consumer is a "dark tourist" still remains. Therefore, further investigation on the level of darkness from a tourist perspective (e.g. tourist motivation) is needed to provide a better picture of dark tourism. A study of visitors to a battlefield site thus can contribute to fill this gap.

\subsection{Battlefield tourism}

\subsubsection{Battlefield tourism and the role of war in tourism industry}

Battlefield tourism is a specific type of thanatourism (Ashworth, 2004; Seaton \& Lennon, 2004). It is about resolving grief, understanding and learning from what 
happened in the past, and sharing and sympathising with other people (Braithwaite \& Lee, 2006).

Seaton (1996) indicates that war has always been a major energiser of thanatourism in history and in recent times. It is believed to be "an important stimulus to tourism through shifts and technical innovation, and after the war, through nostalgia, memorabilia, honorifics and reunions" (Smith, 1998, p. 224). Despite the uncertainty about the appropriateness of battlefield travel, to date, battlefields remain important tourist attractions which play an important role in the tourism industry in many countries (Lloyd, 1998). One example is the case of Korea.

Lee (2006) believes that the impacts of the Korean War on the development of the South Korea's tourism industry were in line with the country's economic developmental drives. According to Lee, the war raised the country's determination to rebuild their society economically, which ultimately influenced the developmental patterns of the tourism industry. Tourists were obliged to act "the right way", in which the country could benefit either economically or by international reputation. On the other hand, battlefield tourist's satisfaction was found to be influenced by the perceived value such as functional, overall and emotional value (Lee et al., 2007). However, while understanding the motivations is important to better understand the tourist behaviour and satisfaction, the question of why tourists visit the battlefield sites in Korea (i.e. the Korean DMZ) was ignored.

\subsubsection{Battlefield tourism in Vietnam}

Being a small country that fought against the United States, Vietnam and the Vietnam War attracted much of the world's attention both during and since the war ended in 1975. The war has been marketed as a part of the country's tourism product (Schwenkel, 2006). However, as mentioned in Chapter One, there has been little research on Vietnam's tourism and even less research that has examined battlefield tourism. Only a few studies related to the present topic can be found (e.g. Alneng, 2002; Henderson, 2000; Schwenkel, 2006).

In their anthropological studies, Alneng (2002) and Schwenkel (2006) suggest that most tourists travelling to the country are looking for authenticity. Backpackers prefer to travel in the local buses, which are considerably less comfortable and relatively unsafe, as an effective way of securing a traveller identity (Alneng, 2002). According to Schwenkel (2006), experiences such as visiting the shooting range and 
firing a Soviet AK47 is considered to be unique and essential by many foreign visitors in Vietnam. However, reactions to the experience are different among visitors. On visiting the war related sites in Vietnam such as the $\mathrm{Cu}$ Chi tunnel and the War Remnants Museum, some have tears in their eyes, some pose smilingly for photos while some dismiss these sites as pure communist propaganda (Alneng, 2002). Alneng also states that:

"Hardly a homogeneous horde, some tourists are clearly infatuated by war while others have the 'war' prefix more reluctantly attached - if Vietnam is War then all visitors are war-tourists, like it or not." (p. 485).

According to Kugelmass (1996, as cited in Schwenkel, 2006), a journey to former war sites can help to heal a painful and formative past. Nonetheless, Agrusa et al. (2006) find that the American Vietnam War veterans do not have a high interest in returning to Vietnam as tourists. Their study shows that almost half of the veterans surveyed reported low interest in returning to Vietnam in any capacity, including very low or low interest in natural sightseeing, cultural sightseeing, industrial sightseeing, and recreational activity. However, as this study merely focuses on war veterans, studies on other groups of visitor are needed to better understand the international tourists in Vietnam.

Henderson (2000) studies the management challenges involved in wartime attractions with an example of recent conflicts in Vietnam. She believes it is a difficult question to satisfy the demands of Vietnamese visitors who experienced the war, the young generation, the returning foreign veterans and curious tourists while maintaining authenticity and integrity. Nonetheless, again her research is from a supply perspective and thus does not provide an understanding of the tourist motivation and behaviour in battlefield tourism.

A country with numerous famous battlefield sites left from the Vietnam War, Vietnam offers an ideal context for a study in battlefield tourism. However, research on tourism regarding war related sites in Vietnam is very limited and to date none has explored the battlefield tourist behaviour and motivation. Given the attraction of Vietnam War to the foreign visitors, it is critical to understand why tourists visit war related sites as well as how important these places are in their decision to travel to Vietnam. It is important also to define the customer segments of the war tourism market in Vietnam so as to provide better suited products for each particular type of 
tourist. In other words, segmentation of the battlefield tourist market in Vietnam is needed.

\subsection{Defining and segmenting the Special Interest Tourist}

As battlefield tourism is a type of SIT, an examination of the SIT framework is useful for the purpose of segmenting battlefield tourists. Given the diversity of special interest tourism activities, several frameworks have been proposed to examine different types of special interest tourists. This section introduces some typical examples of frameworks for the analysis of special interest tourists.

Trauer (2006) categorises special interest tourists into four groups, which are similar to those by Charters and Ali-Knight (2002), but based on frequency of SIT participation and level of involvement in special interest focus (Figure 2-2):

- The SIT experts are highly involved in the leisure interest and have strong travel experience. They are in the high challenge zone.

- The novices in SIT are called the "dabblers", who are seeking a change from General Interest Tourism and Mixed Interest Tourism. They look for "fashionable or popular" products as a means of self-expression. They are in the exploration zone.

- The collectors of SIT experiences participate in a variety of SIT experiences/products (e.g. cultural tourism, adventure tourism) but they may find themselves in the real risk/danger zone because of their limited experience in the special interest recreation activities.

- The travelling special interest experts are in contrast with the collectors. They are highly involved (specialist) in the leisure focus but do not have much experience in travelling. They are in the comfort zone. 


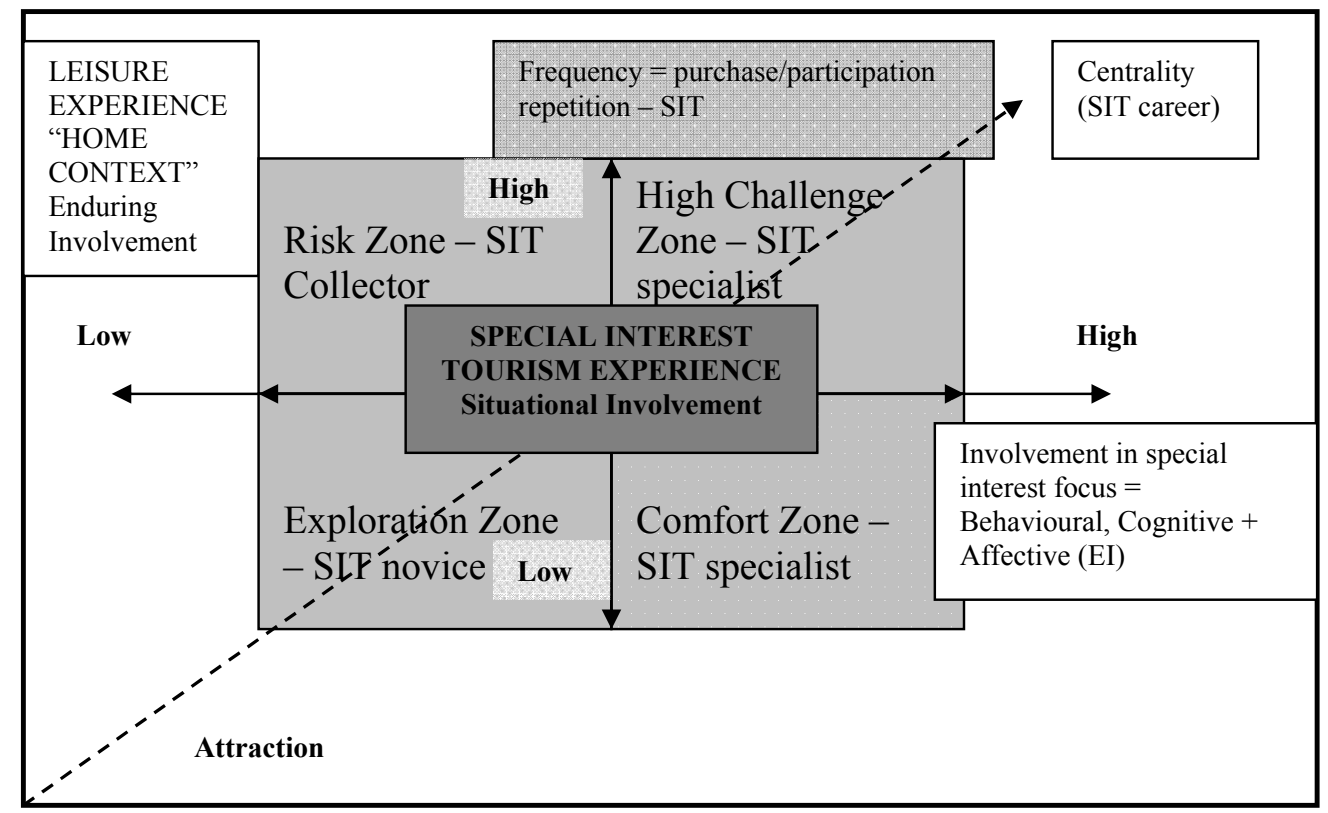

Source: Trauer (2006)

Figure 2-2: The "SIT experience"

However, the model by Trauer (2006) is limited in terms of the dimensions measured. It focuses mainly on the activities participated in by the tourist but does not take into account other critical factors such as the importance of that activity in the decision-making, and the level of interest in that particular activity.

In addition to Trauer's general SIT model, there are some models for a specific activity such as cultural tourism or wine tourism. Specifically, in a model examining cultural tourists proposed by McKercher (2002), two dimensions were used: the importance of cultural motives in the decision to visit a destination and depth of experience. The author identifies five different types of cultural tourists: (1) the purposeful cultural tourist, (2) the sightseeing cultural tourist, (3) the casual cultural tourist, (4) the incidental cultural tourist and (5) the serendipitous cultural tourist (Figure 2-3). These tourists show clearly different behaviour although their demographic and trip profiles are generally similar. 


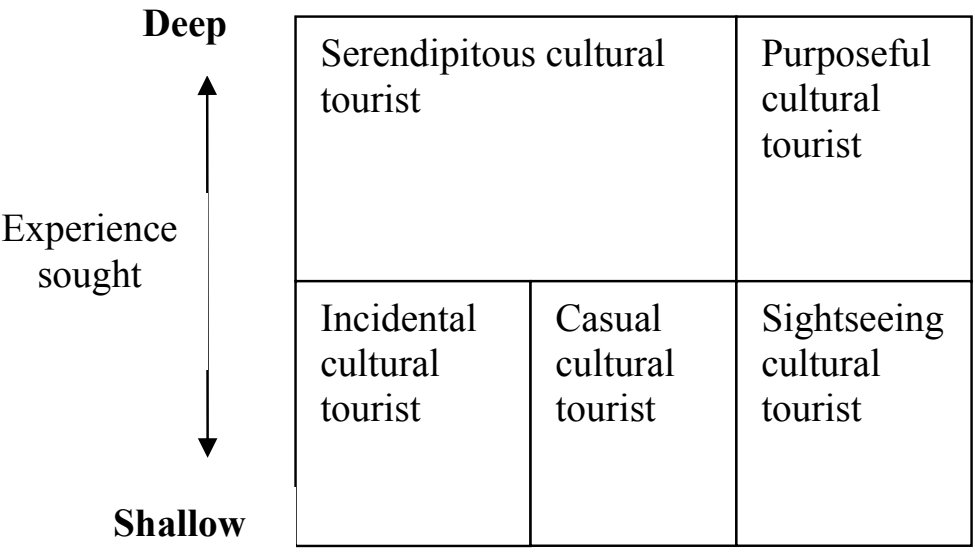 \\ Low $\longleftrightarrow$ High \\ Importance of cultural tourism in the decision to visit a destination}

Source: McKercher (2002)

Figure 2-3: Classification of cultural tourists

Likewise, Charters and Ali-Knight (2002) attempt to define what constitutes a wine tourist. The authors propose an analytical model which measures three dimensions: purpose of visit, general tourist motivation and relationship to other tourist activities. Respondents were asked to self-classify on the basis of their interest in wine (i.e. no interest, limited interest, interested and highly interested) and their knowledge of it. From there wine tourists are divided into wine lovers, wine interested and wine novices (Figure 2-4).

Although the model provides wine marketers with useful information on who the wine tourists are, its application to other SIT forms is questionable. While the factors of purpose of visit and motivation are concrete, the validity of the "relationship to other tourism activity" factor is uncertain. Choosing a totally different activity does not necessarily show any relation to primary motivation. Among a wide range of activities undertaken by tourists, many are directly related to the trip purpose while many more are additional or unimportant to the reason for travel (McKercher \& Chan, 2005). In addition, the similarity between activities is difficult to judge. 


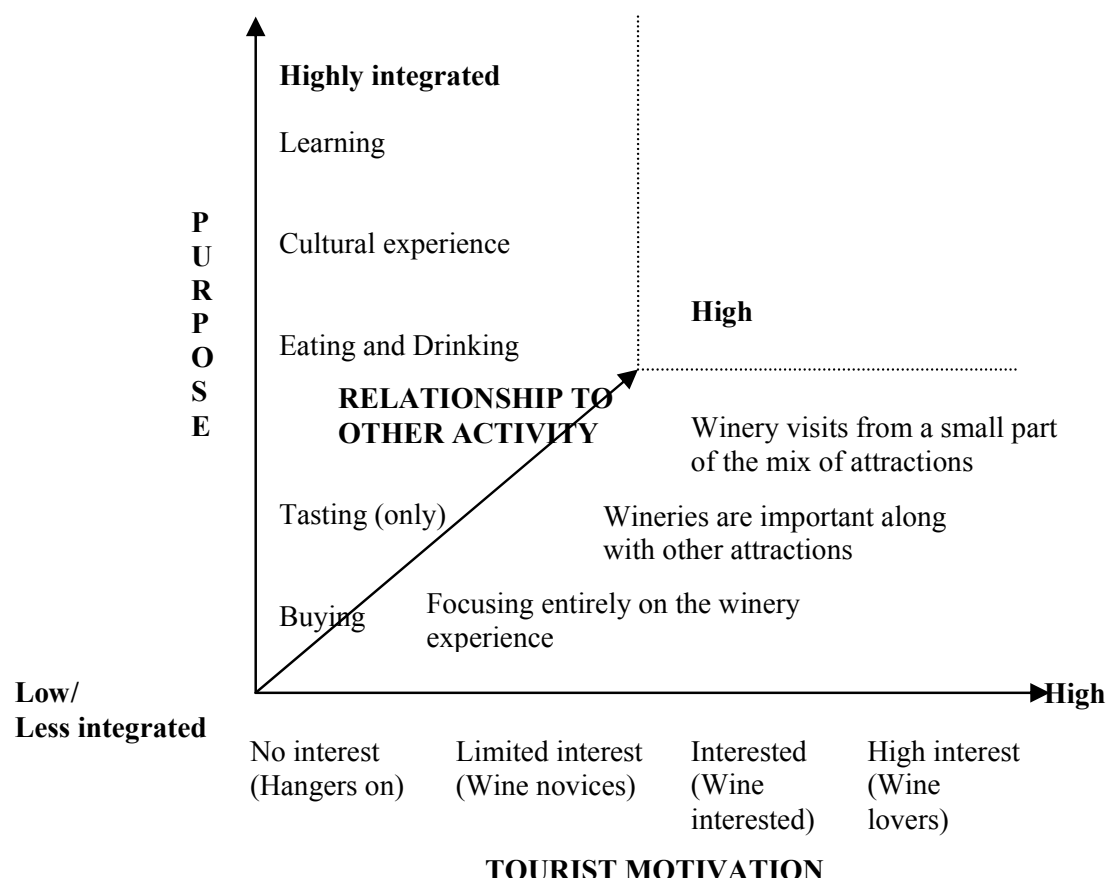

Source: Charters \& Ali-Knight (2002)

Figure 2-4: The Wine Tourist - a three dimensional analysis

As can be observed from the three models above, there have been several dimensions used to measure special interest tourist. While these dimensions are important in defining a special interest tourist, two imperative factors in defining special tourists were not included. They are: motivations for a particular activity or destination and the role of a specific activity or destination in the tourist's decision-making. Therefore, further research in SIT is needed to provide a better framework to define the special interest tourist. As Hall and Weiler (1992) suggest, the travellers' motivation and decision-making are critical in defining SIT. The next section discusses these two aspects.

\subsection{Tourist motivation}

Tourist motivation is a hybrid concept, "which is borrowed from the individual orientation of psychology" and "applied to a specific domain of human action" (Pearce, 1993, p.113). Though motivation is only one of many variables that are often used to explain consumer behaviour, it is an imperative factor as it is "the driving force behind all behaviour" (Fodness, 1994, p. 555).

Tourist motivation has been extensively examined in the literature and several models have been proposed to explain the complexity of tourist motivation. Some of 
the most recognised models of tourist motivation are described in chronological order below.

\subsubsection{Research models of tourist motivations}

\subsubsection{The Psychocentric-Allocentric typology}

Plog (1974) argues that personality and motivation of a person are interrelated with each other. The author divides personality into psychocentric and allocentric groups. The psychocentric is self inhibited, nervous and non-adventuresome. This type of personality tends to prefer familiar destinations and commonplace activities. Relaxation is their main motivation. On the other hand, the allocentric individual is adventuresome and self-confident. In terms of travelling, they are more attracted to non-touristy areas to seek out new experience, discovery and meeting and dealing with people from exotic places.

Plog's typology provides important insights into studying tourist motivation in general and dark tourism in particular. For example, Tarlow (2005) believes dark tourism is a form of virtual tourism nostalgia. He then suggests that theoretically the person who seeks tourism nostalgia is more likely to be found on the psychocentric side of Plog's continuum. Therefore, dark tourism must be presented in a way that mixes history with adventure so as to attract the allocentric type of travellers.

\subsubsection{The Push and Pull model}

One of the commonly used motivation models in tourism research is the Push and Pull model by Dann (1977). According to Dann, "pull" factors are "those which attract the tourist to a given resort (e.g. sunshine, sea, etc.), and those values are seen to reside in the object of travel" (p.186). Conversely, "push" factors "refer to the tourist as subject and deal with those factors predisposing him to travel (e.g. escape, nostalgia, etc.)" (p.186). Dann believes that the problem of motivation can be tackled more easily by focusing on "push" factors.

Crompton (1979) was among the first authors to classify motivations into push and pull factors and many researchers have been adopting the same approach (see, for examples, Bansal \& Eiselt, 2004; Correia, Oom do Valle, \& Moco, 2007; Goossens, 2000; Kozak, 2002). The Push-Pull model has been regarded as a standard theory for investigating tourist motivation as it is clear and relatively simple to apply. 


\subsubsection{The Extrinsic and Intrinsic Motivation Typology}

Having a similar approach to Dann (1977), Iso-Ahola (1982) suggests that leisure motivation in general and tourism motivation in particular have two components: seeking and escaping. The author believes that the forces driving tourists to travel are (1) the desire to leave the everyday environment (extrinsic), and (2) the desire to obtain psychological (intrinsic) rewards through travel in a different environment. Choosing one or both of these forces as primary reason(s) for travelling would influence the tourists' plans and behaviours.

\subsubsection{The Travel Career Ladder}

Another well-recognised tourist motivation model is the Travel Career Ladder by Pearce (1988). Based on Maslow's theory of hierarchical needs, Pearce describes five different levels of tourist motivation from low to high: relaxation needs, safety/security needs, relationship needs, self-esteem and development needs, and self-actualisation/fulfilment needs (Pearce, 1993; Pearce \& Lee, 2005). According to Pearce, motivation is dynamic, future oriented, socially influenced and evolving and people are likely to change their motivation over time. While being adopted and developed in several studies (e.g. Holden, 1999; Pearce \& Lee, 2005); this approach has received some criticism from tourism researchers. Ryan (1998) finds that people having experience with a destination or a holiday type show a better match between wants and an ability to meet their desires. This, however, is not a case of changing psychological needs resulting from past experience as suggested by the Travel Career Ladder, but rather a case of better meeting those needs.

In sum, motivation is an imperative factor in tourism research. Crompton (1979) notes that while it is possible to answer such questions of who, when, where and how in tourist behaviour, the "why" question remains the most difficult to tackle. Despite there being several models that have been proposed, to date there is a lack of agreement on a theoretical approach to this topic. Further research on tourist motivation is thus required in order to facilitate consensus among tourism researchers.

On the other hand, it can be seen that in spite of certain differences, most theories basically categorise motivations based on two extremes: novelty-seeking (risk tolerance) and familiarity (risk adverse). This is an important note for all studies in tourist motivation in general and special interest tourist in particular. 


\subsubsection{Motivations for special interest tourism}

Hall and Weiler (1992) suggest that special interest tourists are more concerned with the "seeking" behaviour. They tend to seek both personal and interpersonal opportunities rather than attempting to escape their environments. Hall and Weiler (1992) argue that special interest tourists can be defined according to whether the primary focus of their interest is on activities or on destinations. In any event, they often show a common desire for authenticity and like to immerse in the cultural and/or physical environment and pursue environmental and experiential quality (Derrett, 2001; Hall \& Weiler, 1992).

Generally speaking, special interest tourists are not homogeneous in their motivations (Yuan, Cai, Morrison, \& Linton, 2005) or in their socio-demographic characteristics (Weiler \& Hall, 1992). However, according to these authors, special interest tourists are more likely to be adults travelling without children, better educated, and on a higher income. They have a desire for novelty, quality and experiential travel. For special interest packages in particular, participants often assemble in small groups and are motivated by the activities more than the prices (Sorensen, 1993).

Several studies have identified a number of motivations related to specific interest activities. The next section discusses motivations for visiting thanatouristic sites.

\subsubsection{Motivations for visiting thanatouristic sites}

Motivation has been considered as the imperative element in examining dark tourism or thanatourism (Lennon \& Foley, 2000; Seaton, 1996; Yuill, 2003). Accordingly, several motivations for visiting thanatouristic sites and battlefield sites have been studied in the tourism literature. Some of the most often discussed motivations are described as follows.

\subsubsection{Education and exploration}

Improving knowledge and learning new things have always been important motivations for travelling (Crompton, 1979). After an atrocity or disaster has occurred, it is common that people are interested to know why it happened, how it ended and who was involved. Hence, it is no surprise that education together with exploration/discovery are some of the most common motivations for visiting sites associated with death and disasters (Best, 2007; Cooper, 2006; Strange \& Kempa, 
2003; Yuill, 2003). For example, Strange and Kempa (2003) indicate that people came to Robben Island to learn about Nelson Mandela and the political leadership of the resistance and to explore South African history and culture. Visitors showed strong, positive, and in most cases emotive behaviour, particularly respect and admiration for the prisoners who endured and overcame maltreatment.

\subsubsection{Historic interest}

It is believed that visitors to thanatouristic sites showed at least some degree of historic interest (Best, 2007; Gatewood \& Cameron, 2004). In a study of visitation to Norfolk Island, a site whose attractions stem from its convict history, apart from discovery, historic interest is found to be the main motivation attracting visitors (Best, 2007). Tourists to the Gettysburg National Military Park also indicated "a vague sense of its historic importance" as one of the reasons for their visiting the site (Gatewood \& Cameron, 2004).

\subsubsection{Remembrance}

Remembrance is a vital activity for human beings as connection with the past help to shape our present and future (Lennon \& Foley, 2000). It is also among the most important motivations for tourists visiting disaster and atrocity related sites (Cooper, 2006; Yuill, 2003). Yuill (2003) emphasises that current and future generations should learn and memorialise the lessons obtained from these sites so that such events never occur again.

Similarly, Cooper (2006) states that the nature of tourism to sites such as Nagasaki and Hiroshima is more of seeking education in the folly of war and remembrance. The younger Japanese generation and some of the remaining veterans no longer wanted to encourage silence about the past, rather, they were prepared to visit battlefields and enter into media debate in order to contribute to further understanding of how the dehumanising processes of war come about.

\subsubsection{Nostalgia}

Tarlow (2001) argues that it is critical to connect nostalgia in the understanding of dark tourism. The author suggests that dark tourism may be a form of virtual nostalgia in which the tourists vicariously visit the related scenes and experience the sites. According to the author, this does not mean all history is dark tourism, but rather all dark tourism is history. 


\subsubsection{Curiosity}

According to Ashworth (2004), tourists are attracted to atrocity partly because of curiosity. Cooper (2006) also indicates that in addition to education and remembrance motivation, some tourists visited the Nagasaki Peace Park because of curiosity or to view the macabre exhibits. Similarly Yuill (2003) believes that visitors to the Holocaust Museum in Houston exhibited motivations of a combination of curiosity and education. The curious defined by Agrusa et al. (2006) are those who had no personal involvement in the battlefield to distinguish with those who themselves or their friends or relatives served in the battlefield presented (the involved).

\subsubsection{Identity}

Ashworth (2004) asserts that all heritage tourism is a form of "roots" tourism where the tourists seek self-understanding and self-identity. The author suggests such motives arise from personal or family history or the desire to "pay respects" to those whom the visitor feels a connection. Slade (2003), for example, extends the understanding of tourist motivations to dark sites in a case study of Gallipoli tourism. He argues that the presence of people at places associated with death and disaster does not necessarily mean that their motivations are thanatouristic or they are thanatourists. His research shows that Australians and New Zealanders' motivations to visit Gallipoli were concerned with nationhood (e.g. to discover who they are, where they came from, and what the meanings of their nations might be in the modern world).

\subsubsection{Location}

The importance of location in influencing visitation to a battlefield site is emphasised by several authors (Hanink \& Stutts, 2002; Yuill, 2003). Hanink and Stutts (2002) find that battlefields which are in proximity to larger population centres have higher levels of use. The fact that the place is en route to somewhere else also contributes to influence the tourist's decision to visit the site (Gatewood \& Cameron, 2004). Thus it is critical to include the role of location in a study of visitations to thanatouristic site (Yuill, 2003). 


\subsubsection{Other motivations}

In addition, other motivations for visiting sites associated with atrocity, deaths and disasters include artefacts/exhibitions, relaxation (Yuill, 2003); spending time with friends and family, as part of a tour programme (Best, 2007); or visiting family and relative (Butler \& Hajar, 2005). Examples of studies which examined thanatouristic motivations are summarised in Table 2-1.

Table 2-1: Examples of thanatouristic motivations studied in the literature

\begin{tabular}{|c|c|c|}
\hline Author & Place & Main motivations \\
\hline Best (2007) & Norfolk Island & $\begin{array}{l}\text { Discovery and Historic interest } \\
\text { Other: Relaxation, Spending time with } \\
\text { friends and family }\end{array}$ \\
\hline $\begin{array}{l}\text { Cooper (2006) } \\
\text { Ashworth (2004) }\end{array}$ & Nagasaki Peace Park & $\begin{array}{l}\text { Education, Remembrance and Curiosity } \\
\text { Curiosity, Identity, Horror and Empathy }\end{array}$ \\
\hline Slade (2003) & Gallipoli & Nationhood \\
\hline Seaton (1999) & Waterloo & $\begin{array}{l}\text { "On the spot", Personal connection with } \\
\text { the battle, Recreation }\end{array}$ \\
\hline $\begin{array}{l}\text { Strange and } \\
\text { Kempa (2003) }\end{array}$ & Robben Island & Learning and Exploration \\
\hline Yuill (2003) & $\begin{array}{l}\text { Houston Holocaust } \\
\text { Museum }\end{array}$ & $\begin{array}{l}\text { Remembrance and Education } \\
\text { Other: Curiosity, Novelty seeking, } \\
\text { Nostalgia, Media, Survivor's guilt, } \\
\text { Death and dying, Artefacts/exhibitions, } \\
\text { Sight sacralisation, Hope, and Location }\end{array}$ \\
\hline
\end{tabular}

In summary, motivation is a critical factor when investigating visitors to thanatouristic sites. There are several reasons for visiting sites associated with death and disaster as discussed above. Although not all studies in motivation for dark tourism are about battlefield tourism, these findings provide useful insights into a study of motivation for visiting battlefield sites. It is also argued that not all visitors to sites associated with deaths and disasters are dark tourists (Slade, 2003). Similarly, visiting the battlefield sites does not make a tourist a battlefield tourist. Therefore, it is necessary to classify the visitors into different groups based on their motivations in order to better understand their behaviour. Accordingly, market segmentation on the motivation of battlefield tourists is essential to meet this need.

\subsubsection{Market segmentation on motivations}

Segmentation has been considered as one of the most important tools in marketing (Wedel \& Kamakura, 1999). It aims to divide the heterogeneous market into homogeneous subgroups for marketing and management purposes. 
Market segments are often defined based on various variables such as demographic, geographic, socio-economic and psychological characteristics, which can be categorised into two groups: the observable and unobservable (Wedel \& Kamakura, 1999). Of these, motivation is a valid variable that has been commonly used in tourism research (Bieger \& Laesser, 2002; Crompton, 1979). The usefulness of motivation as a variable for market segmentation has been widely recognised in the literature (Andreu, Kozak, Avci, \& Cifter, 2005; Cha, McCleary, \& Uysal, 1995; Kau \& Lim, 2005; Sirakaya, Uysal, \& Yoshioka, 2003). In the SIT market, motivation has also been commonly used for segmentation purpose. Some examples of research on SIT segmentation on motivations are displayed in Table 2-2. Despite having different SIT topics, these studies provide useful inputs for a study of battlefield tourism market segmentation especially regarding the segmentation methods.

Table 2-2: SIT market segments on motivations

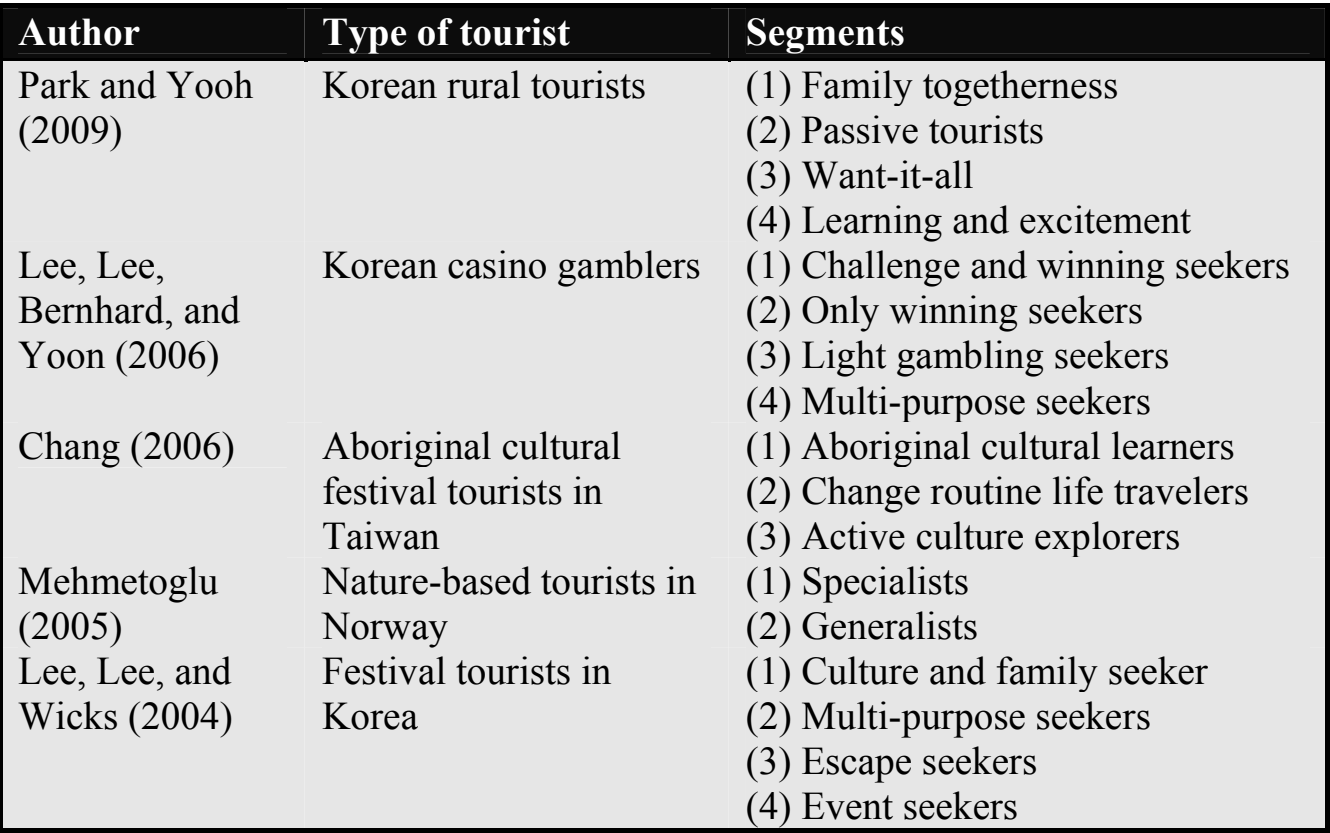

Segmentation methods can be categorised into A-priori descriptive method, post-hoc descriptive method, A-priori predictive method, post-hoc method and normative segmentation method (Wedel \& Kamakura, 1999), or as priori (criterion) method and posteriori (factor-cluster) method (Mazanec, 1992). Generally, with priori market segmentation method the market segments are pre-determined, which is less timeconsuming. However, this requires the researchers to identify the basis for 
segmenting in the outset. Conversely, the factor-cluster segmentation method works by delineating the existing segments on the selected set of variables. Further analysis can be done once the segment procedure is completed by a discriminant analysis to reveal the most discriminant factor as well as to validate the segment solution. This study adopts the factor-cluster segmentation approach using a list of motivational items for visiting battlefield sites in Vietnam.

Undoubtedly, motivation is a critical variable as it is the stage that triggers the whole decision process (Mansfeld, 1992). Motivation and destination choice are linked together through benefits and activities as the vacation benefits travellers seek are related to the activities they pursue (Moscardo, Morrison, Pearce, Lang, \& O'Leary, 1996). Understanding the motivations that influence tourists' travel pattern and habits is critical in predicting their future travel behaviour (Cha et al., 1995). However, decision-making is a complex process. Besides motivation, several other factors also play crucial roles.

\subsection{Travel decision-making}

\subsubsection{Travel decision-making models}

Decision-making behaviour is a sequential, dynamic, multifaceted, and multistage process (Fesenmaier \& Jeng, 2000; Jeng \& Fesenmaier, 2002). Although there have been considerable advances in the travel decision-making literature with several models having been proposed, most are very complex and comprise a variety of variables. Besides, most researchers tend to focus on choice of destination and emphasise the static nature of travel choice behaviour, which results in problematic and invalid estimations (Fesenmaier, 1990, as cited in Jeng \& Fesenmaier, 2002). Despite the fact that tourists' decisions are made in different stages of the travel trip, there has been little research on the decisions made en route.

In general, most of travel decision-making models recognise the complex nature of the decision making process. The travel planning process can be viewed as a threestage hierarchical process including an early stage where the core decision is made, a second stage involving less rigid decision and a last stage with peripheral decision (Fesenmaier \& Jeng, 2000; Jeng \& Fesenmaier, 2002). In addition, a trip decision comprises several sub-decisions or travel decision facets with characteristics of multidimensional, sequentiality and contingency (Ibid.). Bansal and Eiselt (2004), however, divide the travel decision-making process into two phases: (1) the planning 
process, where decisions are made before the trip, and (2) the modification phase, in which the details are determined.

As stated above, decision-making time reflects the importance of the travellers' choice. Destination choice is among the primary decisions, activities and attractions are considered to be in the secondary group (Fesenmaier \& Jeng, 2002). Participating in some activities and attractions does not necessarily show the level of interest by the traveller in doing such things. It is critical to know when the decision to participate in that activity was made in order to understand its importance to the traveller.

\subsubsection{Factors influencing the travel decision-making process}

Decision-making behaviour is influenced by many factors (see, for example, Fesenmaier \& Jeng, 2000; Jeng \& Fesenmaier, 2002; Moutinho, 1987; van Raaij \& Francken, 1984). Moutinho (1987) believes that travel decisions are more affected by external forces, including social influences, reference groups, social classes, culture and subculture. Other factors influencing the decision-making process include household related characteristics (van Raaij \& Francken, 1984); marketing variables, destination awareness, traveller variables (Woodside \& Lysonski, 1989), attitude (Um \& Crompton, 1990); and tourism product characteristics (Seddighi \& Theocharous, 2002).

From several factors examined in the literature, Jeng and Feseinmaier (2002) point out three components influencing the travel decision-making process:

- (1) The psychological/cognitive component establishes the travel needs and demand (e.g. value, knowledge, involvement, risk, attitude, and intention).

- (2) The second component identifies the behaviour decision process (e.g. information retrieval process, and information integration process).

- (3) The third component, the decision context, defines the environment where decision behaviour takes place, including macro-environments such as ethnicity, cultural background, social-demographics and micro-environment.

In sum, there are many factors influencing a travel decision. These factors can be categorised in three groups: (1) the traveller's characteristics (including demographic, social and psychological factors), (2) the characteristics of the object 
(i.e. destination or activity, whether it needs to be booked in advance or not, how much money, and effort needs to be involved) and (3) the external factors (including the environmental factors, marketing and influences from reference groups). As the decision-making process is complex, examining all of these factors in one single study is a difficult task. Given the scope of this study, only the most important factors of each group are examined. These factors include: the travellers' characteristics: demography and motivation, characteristics of the activity (packaged or independent arrangement, point of time making decision, duration, content, etc.), and information sources.

\subsection{Conclusion}

This chapter has reviewed the past work related to the topic of "segmenting the battlefield visitors in Vietnam based on their motivations for visiting the DMZ". It introduced the background information on special interest tourism before moving into details of dark tourism and battlefield tourism. It also explored the concept of motivation from the primary general motivation theories to a wide range of specific motivations for thanatourism. By reviewing the related studies according to the research questions, the research gaps are easily identified and some critical issues can be drawn from the literature review.

First, there is a need for continuing research on tourist motivation. Although many authors have attempted to investigate this topic, there are still many answers yet to be revealed (Fodness, 1994). Since tourists are heterogeneous and tourism activities diverse, still more explorations are needed to contribute to the body of knowledge of tourist motivation.

Second, defining the special interest tourist is a complex task. Research has identified several factors which constitute what makes a special interest tourist. Yet none has attempted to bring together all of these factors to provide a more comprehensive measure.

Third, there is a need for more empirical studies on thanatourism from the demand side. Seaton and Lennon (2004) state that the extent of thanatourism as consumer practice is unknown, since visitors to thanatouristic sites have hardly been profiled and much less has been revealed about their motivations. Many questions remain to be addressed, especially those regarding thanatouristic motivations and the thanatourist identities (Seaton \& Lennon, 2004). Furthermore, while there has been 
little research into the motivations of the consumers of thanatourism, even less is known about how they vary across social groups (Seaton \& Lennon, 2004). There may be no general thanatourism motive or set of motives, rather, people visit thanatouristic sites for a diversity of reasons (Ibid.). This point has important implications for the research methodology in that it suggests that there should not be a fixed motivation given to the visitors to identify. Instead, it is better to include the flexibility of a wide range of reasons in the survey.

Last but not least, there is an urgent call for research on battlefield tourism in Vietnam, especially from the visitors' perspective. As mentioned earlier, battlefield tourism has been considered an important element in the Vietnam's tourism marketing. However, to date, to the best of the researcher's knowledge, no research has investigated visitors to battlefield sites in Vietnam. Understanding the battlefield tourist motivation and behaviour is critical to provide better tourism marketing strategies to attract more tourists to the country. In addition, it would be useful to provide another dimension of battlefield tourism from a developing country to supplement for existing research in developed countries.

This study aims to contribute to filling the gaps in the literature as mentioned above by examining the visitors to the DMZ in Vietnam. Based on the theoretical background provided in this chapter, a research methodology is proposed, which is presented in the following chapter. 


\section{Chapter 3: METHODOLOGY}

\subsection{Introduction}

The previous chapter provided a theoretical background for this study. However, in order to conduct the empirical research successfully, an appropriate methodology is needed. To begin with, selecting an overall paradigm is a primary task for every researcher. Two paradigms often discussed in the literature are qualitative and quantitative (Creswell, 1994). Creswell defines qualitative research as an inquiry process of understanding a social or human problem conducted in a natural setting. It involves building a complex and holistic picture with detailed views of informants. Alternatively, the quantitative paradigm, also termed the positivist, experimental or empiricist paradigm, is based on testing a theoretical theorem by analysing quantifiable variables using statistical procedures. Quantitative methods are often used to determine the generalisability of a theory. Selecting a paradigm is based on the research's nature and objectives.

As shown in Chapter Two, research on market segmentation is often based on statistical and quantitative analysis (Cha et al., 1995; Chang, 2006; Sirakaya et al., 2003). This study seeks to understand the tourist motivations for visiting the DMZ and to identify groups of visitors based on their motivations. It also seeks to determine the importance battlefield sites play in tourists' decision to travel to Vietnam. To tackle this aim, a wide range of information and numerous responses are critical, which require a quantitative approach. However, given the complexity of tourist motivation and behaviour, qualitative data is also used to complement the statistical analysis. Therefore, this study adopts a quantitative method with complementary qualitative data.

This chapter provides information about the research methodology used in this study. It begins with a description of the selection of the study site. The survey design is then presented, going from the stage of questionnaire development, to data collection procedure and data preparation for analysis. This chapter also reports on the considerations for an effective method of collecting reliable data. Data collected is assessed, showing the strengths and limitation of the study methodology. An analytical framework is placed at the end of this chapter, indicating how the results are to be presented. 


\subsection{Selection of the study site}

One of the first major decisions to be made is the choice of a study site. This study investigates battlefield visitors, thus battlefields would be the most appropriate study sites. As mentioned in the introduction chapter, the DMZ was one of the major battlefields during the Vietnam War, which was well-known in the media. Therefore, investigating visitation to the DMZ is appropriate for a study of battlefield tourism in Vietnam. However, as there are several individual war related sites in the DMZ area, selecting one specific site to conduct the survey is critical. Given the time and human resource constraints (only one researcher conducting fieldwork in approximately two months), it was decided that the survey should be based at only one site that is most visited in order to capture the largest possible number of respondents.

According to Quảng Trị’s Historical Relics and Tourism Spots Management Office, as of May 2008, the top three historical sites in Quảng Trị are the Vịnh Mốc Tunnels, the Khe Sanh Museum (Khe Sanh Combat Base) and the Hien Luong Bridge, of which only the Hien Luong bridge is actually located in the former DMZ. Nevertheless, the Khe Sanh Museum and the Vịnh Mốc Tunnels, although not geographically located in the DMZ, are important sites and strongly related to the DMZ. As described in the introduction chapter, the former is one of the principal American Marine Bases during the War and the latter is the largest underground tunnels system in Vietnam built by the local people as a shelter from heavy bombs.

Reports provided by Quảng Trị’s Department of Tourism and visitor statistics at each site (i.e. Vịnh Mốc, Khe Sanh, and Hien Luong) show that the Vịnh Mốc Tunnels stands out with the largest number of visitors. As shown in Table 3-1, visitors to the Vịnh Mốc Tunnels outnumber those who visit Khe Sanh every year. For example, in 2007, there were 62,625 visitors at Vịnh Mốc, almost six times the visitors at Khe Sanh $(11,979)$. In the first half of 2008, Vịnh Mốc continued to hold the most visited position compared to Khe Sanh and Hien Luong (Table 3-2). On average, from January to June 2008, Vịnh Mốc welcomed 5,594 visitors compared to 921 of Khe Sanh and 1,194 of Hien Luong. However, it is noted that most of visitors to Hien Luong are domestic tourists due to the nature and position of the site (Ben Hai River and Hien Luong Bridge: Visitor Statistics, 2008). Furthermore, the Vịnh Mốc Tunnels are considered a must see attraction and the most important site in the popular DMZ tour (HRTSMO, 2006). Accordingly, the Vịnh Mốc Tunnels were chosen as the site at which to conduct the visitor survey. 
Table 3-1: Visitor Statistics from 2001-2007

\begin{tabular}{|lccccccc|}
\hline Year & $\mathbf{2 0 0 1}$ & $\mathbf{2 0 0 2}$ & $\mathbf{2 0 0 3}$ & $\mathbf{2 0 0 4}$ & $\mathbf{2 0 0 5}$ & $\mathbf{2 0 0 6}$ & $\mathbf{2 0 0 7}$ \\
\hline Vịnh Mốc & 27125 & 29791 & 25991 & 37677 & 37083 & 42153 & 62625 \\
Khe Sanh $^{10}$ & N/A & N/A & N/A & N/A & 11182 & 11197 & 11979 \\
\hline
\end{tabular}

Table 3-2: Visitors Statistics from Jan-June 2008

\begin{tabular}{|c|c|c|c|c|c|c|c|}
\hline \multirow[t]{2}{*}{ Month } & \multicolumn{3}{|c|}{ Vịnh Mốc Tunnels } & \multicolumn{3}{|c|}{ Khe Sanh Museum } & \multirow{2}{*}{$\begin{array}{l}\text { Hien } \\
\text { Luong }^{11} \\
\text { Total } \\
\end{array}$} \\
\hline & Domestic & Foreign & Total & Domestic & Foreign & Total & \\
\hline Jan & 301 & 3761 & 4062 & 29 & 930 & 959 & 361 \\
\hline Feb & 398 & 3002 & 3400 & 107 & 737 & 844 & 860 \\
\hline Mar & 1460 & 4617 & 6077 & 372 & 1038 & 1410 & 1721 \\
\hline Apr & 2286 & 6784 & 9070 & 272 & 747 & 1019 & 1057 \\
\hline May & 1895 & 4277 & 6172 & 227 & 504 & 731 & 988 \\
\hline Jun & 3279 & 1505 & 4784 & 71 & 495 & 566 & 2175 \\
\hline Jul & 3624 & 3218 & 6842 & 250 & 769 & 1019 & $\mathrm{~N} / \mathrm{A}$ \\
\hline
\end{tabular}

Source: (Ben Hai River and Hien Luong Bridge: Visitor Statistics, 2008; Khe Sanh Museum: Visitor Statistics, 2008; Vinh Moc Tunnels: Visitor Statistics, 2008)

In addition to the benefit of having more visitors to improve the sample size, choosing Vịnh Mốc as a study area has the following advantages:

- According to the local tour guides (personal communication) and the researcher's observation, visitors often spend more time in the Vịnh Mốc compared to other sites, which can increase tourists' participation in the survey.

- There are drink shops and hammocks hanging around the bamboo surrounding the tunnels, providing the tourists with some shade and resting places to answer the questionnaire. This is a big advantage compared to Khe Sanh or Hien Luong, which are quite remote and isolated and do not provide enough shelters for visitors.

- The Vịnh Mốc Tunnels were built by the Vietnamese as a place to shelter from the heavy bombing in the area, and witnessed much wartime hardship. They reveal the dark side of Vietnamese history and the miserable consequences of war. Therefore, it is expected that the site would attract visitors with numerous motivations, such as those with an interest in the Vietnam War, interest in learning about the Vietnamese history, wanting to

\footnotetext{
${ }^{10}$ The site was restored as a tourist spot and recorded visitor statistics from 2005.

${ }^{11}$ The site was built as a tourist spot and recorded visitor statistics from January 2008. Visitor statistics for domestic tourists and foreign tourists were not available.
} 
have a taste of how life was during the war, or merely out of curiosity and so on.

\subsection{The survey design}

Once the study site has been selected, it is critical to decide on the method of collecting primary data. A review of research on market segmentation, tourist motivation and tourist behaviour shows that questionnaire survey was among the most commonly used methods (Andreu et al., 2004; Bansal \& Eiselt, 2004; Molera \& Albaladejo, 2007; Pearce \& Lee, 2005). Accordingly, this method is also adopted in the present study.

The term "survey" refers to the collection of standardised information from a specific population usually by means of questionnaire or interview (Robson, 1993). The advantages of a survey are clear: (1) ability to cover a large sample size and increase the generalisability of results at low costs; (2) ability to distinguish small differences; (3) ease of administering, coding, analysing and interpreting; (4) capability of using a variety of statistical analysis, and (5) providing a relatively simple and straightforward approach to the study of attitudes, values, beliefs and motives (Hair, Bush, \& Ortinau, 2003; Malhotra, 2007; Robson, 1993).

Initially, an intercept administered survey method was planned. However, due to the practical conditions (the number of visitors per day at the selected study site was small, and most visitors came in groups and rather concentrated during a specific time of the day), a self-competed method was used in the actual survey instead.

\subsection{Questionnaire development}

A self-administered questionnaire was developed with the aim of getting information about tourist motivations for visiting the DMZ and the importance of the battlefield sites in tourists' decision to travel to Vietnam. Additional data includes the visitors' socio-demographic (e.g. age, gender, educational level, etc.) and trip-related characteristics (e.g. travel arrangement, travel partner, etc.)

The final questionnaire (Appendix 2) consists of 33 questions, including both closed (structured) and open-ended (unstructured) questions. Among 26 structured questions, six have 5-point Likert-scaled response options, ranging from 1 (minimum score) to 5 (maximum score). These Likert-scaled questions are used to measure (1) tourist motivations for visiting the DMZ, (2) tourists' level of knowledge about the 
DMZ, the importance of the DMZ in tourists' decision to travel to Vietnam, (3) the importance of the Vietnamese battlefield sites in tourists' decision, (4) tourists' level of interest in visiting Vietnamese battlefield sites, and (5) tourists' level of satisfaction of the DMZ trip experience.

Inputs from the literature were used to compose the motivational statements for the question about tourist motivation. Specifically, thanatouristic motivations identified in the literature such as education (Best, 2007; Cooper, 2006; Strange \& Kempa, 2003; Yuill, 2003), remembrance (Cooper, 2006; Yuill, 2003), identity (Slade, 2003), location (Hanink \& Stutts, 2002; Yuill, 2003), and curiosity (Ashworth, 2004; Cooper, 2006) were adapted and developed into a variety of motivational statements. Consequently, a list of 22 motivation items was finalised. The appropriateness of these items was pre-tested with a small number of tourists, which showed that all the statements were well-understood and relevant.

In addition, since tourist motivations and behaviours are complex, in most cases, respondents were asked to give comments for their answers to the closed-ended questions. The self-expressed responses are time-consuming to analyse yet they provide rich complementary information.

The questionnaire was laid out in four A4 size pages, and arranged in four sections:

- Section A (question 1 to 5) seeks to understand the tourists' travel patterns in Vietnam.

- Section B (question 6 to 21) aims to profile the tourists' trip to the DMZ, including travel patterns, motivations and decision-making.

- Section C (question 22 to 27) seeks to identify the importance of the battlefield sites in tourists' decision to travel to Vietnam.

- Section D (question 28 to 33) requests the tourists' personal information (respondent profile). 


\subsection{Ethical consideration}

The study questionnaire was submitted to the Human Ethics Committee (HEC) of Victoria Management School on April the $28^{\text {th }}, 2008$ and was approved on May the $8^{\text {th }}, 2008$.

Participants in the survey were given information handouts which outlined the research objectives and the interview's nature (Appendix 1). The handouts also provided respondents with the researcher's contact information.

\subsection{Primary data collection}

\subsubsection{Sample selection}

Initially both international and domestic visitors at the Vịnh Mốc Tunnels were included in the study. However the final study sample includes only international tourists due to the difficulties in approaching native Vietnamese tourists (to be described in the pilot test section).

Respondents were recruited using an intercept structured random approach. The researcher approached the tourists at the ticket booth, introducing and briefly outlining the research project. Visitors were then handed out the information sheets and questionnaires. It was up to the visitors where and when to answer, however, in most cases, questionnaires were completed at the end of the visit. Completed questionnaires were returned to the researcher when the visitors exited the tunnels. Alternatively, visitors could fill in the questionnaires on the bus and return the questionnaires to the tour guide and bus driver. Cooperation from the tour guides and drivers at MeKong Travel Company, Huong Binh Tourist Company, An Phu Tourist Company and other independent tour guides allowed the researcher to gain access to their clients at the end of the tour.

\subsubsection{Pilot test}

The research instrument was pre-tested on a smaller scale. This step is important to check the validity of the research instrument and to improve the data collection method. First, the researcher conducted informal interviews with tourists in the DMZ bar in Hue city in order to practise the researcher's interviewing skills as well as to estimate the time needed for each interview. This step was also useful in obtaining some initial inputs from the respondents. 


\subsubsection{Pilot test 1}

The first pilot test was conducted on June 6-7, 2008 at the Vịnh Mốc Tunnels with the initial proposed method of an administered-survey. The researcher stood near the entrance/exit of the Vịnh Mốc Tunnels asking random tourists to participate in the survey. Those who agreed were handed an information sheet while the objectives of the survey were explained to them. The researcher asked and recorded answers given by the participants. Eight interviews were conducted of which six were completed. The other two were half way through when the respondents had to leave to catch their bus. The pilot test showed that the administered method was not suitable for this study. Part of the explanation may be the fact that visitors often came in groups and followed a tour, thus it was difficult to approach them individually. The concentration of tourists at particular times (around late morning, noon time and early afternoon) also restricted the number of visitors that the researcher could interview. Furthermore, most tourists often spent only half an hour to an hour at the Tunnels, which is just enough time for them to explore the site. In addition, most visitors feel exhausted after a long walk around the tunnels in the summer's humid and hot weather. In order to overcome these challenges, a self-completed method was proposed. The information sheet was attached to the questionnaire (first page). Clear instructions were also added to the questionnaire to maximally avoid misunderstanding or confusion.

\subsubsection{Pilot test 2}

The second pilot test was conducted on June 8 and 12 on a DMZ bus tour. Fifteen questionnaires were collected $(100 \%$ response rate). Feedback from the tourists showed that most questions were clearly understood and answered. However, some changes were made to the questionnaire:

- Question 7 (How did you make your travel arrangement to the DMZ?): option 3 "bought a tour to the DMZ" was split into two options "bought a bus tour" and "bought a private tour". This was to differentiate between tourist travel in big and small groups as well as to complement the question regarding travel companion.

- Question 8 (Who are you travelling with to the DMZ?): the option of "tour group" was deleted as it may cause confusion for those who have companies travelling with them on a tour. 
- Question 18 (Which of the following sites have you or are you going to visit?): the $5^{\text {th }}$ option was corrected as "Doc Mieu" in stead of "Con Tien, Doc Mieu/Mc Namara Line" for Con Tien and Doc Mieu although are along the Mc Namara Line, they are different sites and tourists may only visit one of them.

\subsubsection{Pilot test 3}

The third pilot test was conducted at Vịnh Mốc Tunnels on June 19-20, 2008 with 32 questionnaires collected ( $70 \%$ response rate). During this stage, it was observed that Vietnamese visitors were either not familiar with the survey method or not willing to participate. The majority of Vietnamese visitors travelled in big tour groups organised by their companies (personal communication with the manager of Vịnh Mốc Tunnels and local tour operators). ${ }^{12}$ Most of the questionnaires collected from Vietnamese were left blank or only a few questions were filled in. In most cases, the respondents did not give answers that are relevant to the questions. It should be noted that in contrast to developed countries, quantitative self-completed questionnaire surveys have not been widely used in Vietnam. In addition, most Vietnamese people tend to be less open to disclosing their personal opinions regarding sensitive questions related to the Vietnam War. This may explain the low response rate from Vietnamese visitors. Therefore, in order to get a sufficient number of responses within a limited time using a consistent method, it was decided that the study sample would be narrowed to include only international visitors.

Only a small change was made after the third pilot test to the questionnaire: In question 30 about nationality of the respondents, "Other European" and "Other Asian" were merged to only one category "Other".

\subsubsection{Major survey}

Following the pilot tests, the actual survey was conducted in one month (from June 22 to July 22, 2008). Overall, 744 questionnaires were distributed and 488 were collected, resulting in a response rate of $66 \%$. Among the collected questionnaires, 481 were usable and seven were rejected as either the questionnaire was not properly completed or most of the important questions were skipped. The number of questionnaires distributed and collected were recorded each day and tabulated as shown in Appendix 3.

\footnotetext{
${ }^{12}$ It is common in Vietnam that the organisations organise summer holiday trips for their staff.
} 


\subsection{Secondary information sources}

In addition to the data collected from the survey, secondary data was also used in this study to provide a richer context for the primary data as well as to gain a better understanding of the survey information. Secondary information sources include journals, newspapers, internet, magazines, books and reports from tourism organisations in Vietnam. In particular, visitor statistics from the historical sites in Quảng Trị were used to support the choice of study area. Likewise, visitor reports from Vietnam National Administration of Tourism provided an overview of tourism in Vietnam as detailed in the Introduction chapter, and also provided a useful comparison for the respondent profiles.

\subsection{Data preparation}

\subsubsection{Data coding and entry}

In order to facilitate the data entry process, all closed questions in the questionnaire were pre-coded. The code for each answer/option was shown at the right corner of the tick box. Data from the questionnaires were entered to the computer by the researcher after the survey ended. For open-ended questions, every word written by respondents was firstly entered into the database. Common themes were then identified using content analysis. Next, these themes were named using short descriptions before being coded as numbers to be analysed in SPSS.

\subsubsection{Data screening}

After the first stage where information from 481 questionnaires was entered, data was screened to prepare for the analysis.

Accuracy of the data file

Data was proofread against the original questionnaire by the researcher and her assistant. Every questionnaire was checked against how it was entered in the database. This double-check step helped eliminate errors made during the data entry stage and to make sure the each answer was entered correctly.

\section{Outliers and recoding}

Following the manual double-check step, data was screened by the computer using SPSS (descriptive statistics) to provide an overview of the data as well as to find mistyped values. 
Testing of frequencies showed that some options were rarely reported by respondents (e.g. "Korean" in the Nationality question, and "primary school" in the question of highest formal of education). In order to facilitate the analysis and interpretation, data was recorded as followed:

- Age: there was only one respondent indicated age as 70+ thus the age group of 60-69 and 70+ were merged as group $60+$.

- Nationality: the question regarding nationality of respondents was designed with the assumption that having a connection with the Vietnam War, Korean Veterans would be interested in visiting battlefield sites in Vietnam. However, in the study sample, there was only one Korean respondent; therefore, he was moved to the group "Other". As there were a substantial number of visitors from Canada, the Netherlands and Denmark in the survey these three nationalities were made separate categories.

- Education level: given the number of respondents for each group (primary school, secondary school and high school) is small and in order to avoid confusion regarding the different education systems, all those three groups were merged as one group named secondary education. The Vocational option was merged with the Other category.

\subsection{Data analysis}

This study encompasses both quantitative and qualitative data. The Statistical Package for the Social Sciences (SPSS) version 16.0 was used to facilitate quantitative data analysis while the qualitative information was analysed using content analysis. A data analysis strategy was developed in order to achieve the research objectives as shown in Figure 3-1. 


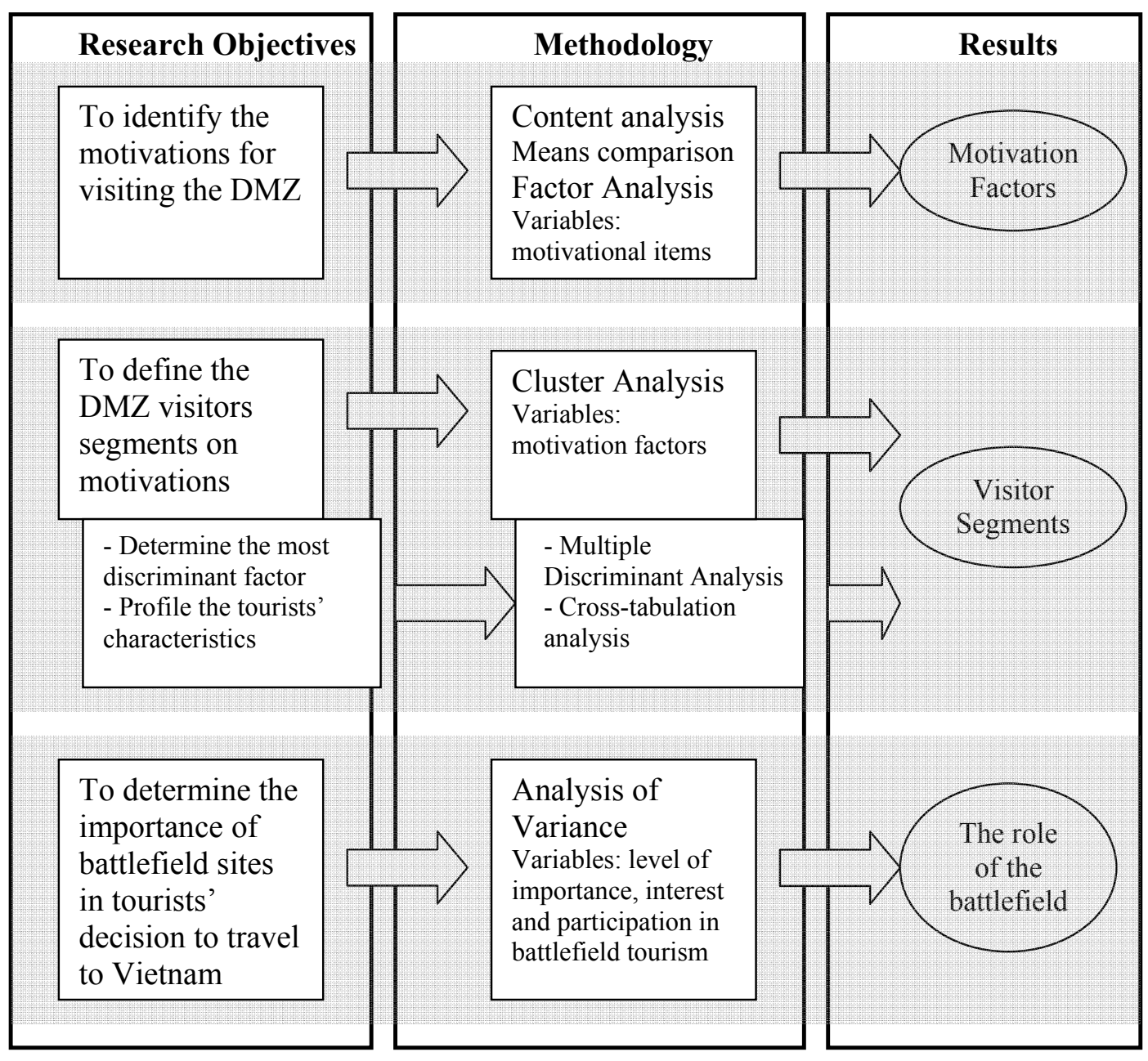

Figure 3-1: Data analysis strategy

Specifically, data in this study was analysed according to the following steps:

- Step 1 of the analysis is to achieve the first research objective: identifying the tourist motivations for visiting the DMZ. This can be done by performing means comparison and factor analysis on 22 motivational items and content analysis of respondents' self-expressed reasons for visiting the DMZ. The result of this step is the identification of the motivation factors.

- Step 2 relates to the second objective in which cluster analysis was run with the factor analysis-generated motivations as variables. As a part of this step, multiple discriminant analysis was performed to validate the cluster solution and to determine the most discriminant factor. In addition, cross-tabulation analysis with the Chi-square test $\left(\chi^{2}\right)$ was used to profile the cluster 
characteristics. This step resulted in the identification of the DMZ visitor segments, satisfying the second research objective.

- Step 3 of the analysis aims to achieve the third objective: determining the importance of battlefield sites in tourists' decision to travel to Vietnam. Specifically, Analysis of Variance (ANOVA) was performed on variables such as the importance of the DMZ and other Vietnamese battlefield sites, visitors' level of interest, level of knowledge and level of participation in battlefield tourism.

The next section provides technical details of the data analysis procedure.

\subsubsection{Statistical analysis}

\subsubsection{Data description}

Data was first summarised by the descriptive functions in SPSS (tests of frequencies, means, standard deviations and ranges). It is noted that mean values are used in this study since it is mostly used as a measure of central tendency in research (Punch, 2005; Robson, 1993). However, in order to better interpret the mean, standard deviations are included to help understand the variability of the scores. These descriptive statistics provide an overview of the respondents regarding their personal characteristics as well as trip related characteristics.

\subsubsection{Data comparison: Chi-square test and ANOVA}

Chi-square test and ANOVA were used to examine the relationships between variables. In particular, the Chi-square test was used in cross-tabulation analysis to test for independence between two nominal variables (e.g. demographic and trip related characteristics). Likewise, ANOVA was used in means comparison of metric variables (e.g. level of interest and level of importance) to see if differences existed between groups. The accepted level of significance is at $p<0.05$ (Cavana, Delahaye, \& Sekaran, 2001).

\subsubsection{Factor Analysis}

In tourism market segmentation, a factor-cluster integrated analysis approach has been broadly used (e.g. Cha et al., 1995; Kau \& Lim, 2005; Lee et al., 2006; Molera \& Albaladejo, 2007; Park \& Yoon, 2009; Sirakaya et al., 2003). In addition, according to Malhotra (2007), factor analysis has often been used to identify the 
underlying variables on which to group customers. The idea behind factor analysis is to reduce the original data into a small and easily understood number of factors based on the correlation between variables, that is, to group common factors together (Punch, 2005; Robson, 1993). Therefore, in order to delineate the underlying dimensions of the visitor motivation for visiting the DMZ, a factor analysis was performed on the set of 22 motivational statements.

However, it is important first to check the data's appropriateness for factor analysis. The study sample size (481) is more than 20 times the number of variables (22), which exceeds the minimum requirement that the number of observations should be at least five times the variables to be analysed (Hair, Anderson, Tatham, \& Black, 1998). In addition, as illustrated in Table 3-3, the Bartlett test of sphericity was significant at $p=0.000$ and Kaiser-Meyer-Olkin Measure of sampling adequacy at 0.761 meant that factor analysis could be applied (Hair et al., 1998; Sharma, 1996).

Table 3-3: KMO and Bartlett's Test

\begin{tabular}{|llr|}
\hline Kaiser-Meyer-Olkin Measure of Sampling Adequacy. & 0.761 \\
\hline Bartlett's Test of & Approx. Chi-Square & 1597.654 \\
Sphericity & df & 231 \\
& Sig. & 0.000 \\
\hline
\end{tabular}

The Principle Component Analysis with Varimax orthogonal rotation was used as the factor extraction method. This technique has been recognised as the most appropriate method for generating the most interpretable results (Field, 2005; Malhotra, 2007; Robson, 1993). It results in a factor structure in which each variable loads highly on one factor only.

\subsubsection{Cluster Analysis}

For the purpose of identifying groups of distinctive visitors to the DMZ, cluster analysis was performed. Cluster analysis is a useful and accessible method for classifying subjects into relatively homogeneous groups based on the set of variables considered (Malhotra, 2007; Weaver \& Lawton, 2005). It is used in many situations, particularly in market segmentation, experimentation and product position (Hair et al., 1998; Saunders, 1980). Similar to factor analysis, cluster analysis is an exploratory method that can help to identify patterns within data. However cluster analysis is used to group cases (instead of variables as in factor analysis) based on the characteristics they possess so that objects in one group have more similarities with each other than they do to objects in other groups. 
In general, most commonly used clustering algorithms can be classified into Hierarchical and Non-hierarchical clustering procedures (Bartholomew, Steele, Moustaki, \& Galbraith, 2002; Hair et al., 1998). The hierarchical method is often used in exploratory studies, where the researcher does not know the number of clusters to expect. However, hierarchical clustering can be misleading. Once an object is assigned to a cluster, it will never be reassigned. Hence, undesirable early combinations can eventually lead to artificial results (Hair et al., 1998). This method also has its drawback in not producing homogenous and well-balanced clusters and is not suitable for analysing large samples (Ibid.).

Conversely, non-hierarchical methods have been increasingly accepted and applied (Hair et al., 1998). In particular, they are commonly used in market segmentation studies (see, for example, Kau \& Lim, 2005; Lee et al., 2004; Sirakaya et al., 2003; Sung, 2004). A non-hierarchical algorithm is often referred to as K-means clustering (Hair et al., 1998). This method is widely used in marketing research as it provides better distinctive clusters by producing exactly $k$ different clusters of greatest possible distinction. K-means clustering is less sensitive to outliers in the data. It is also faster than other methods and thus more appropriate for large samples with more than 200 cases (Hair et al., 1998; Malhotra, 2007). This method can also be used for various types of data yet it is important to include variables measured by comparable scales. Given the nature of this study and the data collected, it was decided that the K-means method would be adopted for the segmentation purposes of this study. Specifically, the tourists in this study were classified into groups based on their motivations generated from the factor analysis.

\subsubsection{Multiple Discriminant Analysis}

After cluster analysis was done, multiple discriminant analysis (MDA) was performed for two purposes. First, it was needed to assess the accuracy level of classification of segment membership (Sirakaya et al., 2003). Cluster solution validation is important especially in $\mathrm{K}$-means cluster analysis where the number of clusters is determined by the researcher. Second, MDA was used to identify the factors that most discriminate the clusters (Sharma, 1996), to assign more appropriate labels according the clusters' outstanding characteristics. 


\subsubsection{Content analysis of qualitative data}

Qualitative data from open-ended questions was analysed using latent content analysis, which is the process of identifying, coding, and categorizing the primary patterns in the data (Patton, 1990, as cited in Cavana, 2001). The procedure followed Mayan's (2001) guidelines. First, data was coded by identifying persistent words, phrases, themes or concepts. The second step was to categorise the data by cutting out the highlighted sections of the text and classify them into groups. These groups are judged by internal and external factors later to confirm their consistency and distinction. The third step is to integrate and find themes by discovering the relationships among the groups and identifying common themes. Commonalities and differences were identified, creating theme categories.

\subsection{Overall data assessment}

To this point, an appropriate methodology has been developed for this study. However, before presenting the findings, it is worth making an overall evaluation of the data collected from the questionnaire survey. The results of this study then need to be viewed in light of the methodology's strengths and limitations.

To begin with, there are some limitations in the data collection procedure. First, the survey was conducted in the low season for international tourists in Vietnam in general and at the Vịnh Mốc Tunnels in particular. This may have affected the sample's size and characteristics and may be a reason for the lack of Vietnam War veterans. Second, for the reasons outlined earlier, this study is limited in its scope as it only focuses on international tourists. Excluding domestic Vietnamese tourists may lead to some limitations in interpreting and forecasting battlefield tourist behaviour. Furthermore, due to their personal connection with the War, domestic visitors may have distinctive motivations to visit the site, which would be very interesting to study. Third, the English-only-questionnaires would have excluded non-English speaking visitors because of language constraints. The fourth limitation relates to the disadvantages of self-completed survey. There may have been cases where respondents did not understand the questions clearly. Also, quantitative methods (i.e. survey) may have a disadvantage in capturing the complexities inherent in motivational research. However, in this study, open-ended questions and selfexpressed responses were useful in tackling part of this drawback. 
In spite of these limitations, this study has established an appropriate method for investigating the DMZ visitors. The data collection method adopted - an intercept questionnaire survey with a structured random sample - has resulted in an appropriate sample for the DMZ international visitor population. The sample size $(\mathrm{n}=481)$ is sufficient for the segmentation purposes. The rigorous data provided by the respondents and the use of a quantitative approach enables the researcher to quantify the motivations identified by previous studies. In addition, statistical analysis supported with qualitative data content analysis has provided structured and solid results with in-depth details. These strengths facilitate the analysis procedure and provide the conditions for robust and reliable results.

\subsection{Conclusion}

This chapter has presented the study methodology. The quantitative approach was used according to suggestions in the literature together with the requirements of the research objectives. The choice of the Vịnh Mốc Tunnels as the study site proved to be one of the most suitable places for a study of battlefield tourism in Vietnam. Given the need to gather a large number of visitors and numerous responses, the selfcompleted questionnaire survey method was most appropriate. The questionnaire designed covered all the variables that were needed for the purposes of this study, such as the tourists' motivations for visiting the DMZ, their level of interest in visiting battlefield sites in Vietnam as well as their personal and trip related characteristics. Based on the research objectives, a structured analytical framework was developed. In conclusion, despite some limitations regarding data collection, this study has built an appropriate and robust methodology to examine the visitors at the DMZ.

The results will be presented and interpreted in the following three chapters going from general description of the total sample to detailed analysis of visitor segments.

Chapter Four provides an overview of the respondents. It shows the respondents' socio-demographic characteristics as well as their travel patterns. What is more, the study sample and the total international tourist population in Vietnam are compared. Chapter Five focuses on the visitor segmentation procedure. It presents the process of identifying the tourist motivations for visiting the DMZ using both content analysis and statistical analysis. The delineated motivations are then used as variables to segment tourists to the DMZ in cluster analysis and multiple discriminant analysis. 
Chapter Six gives detailed analysis of the visitors' decision-making, information search, their interest in battlefield tourism along with the importance of the battlefield sites in the tourists' decision to travel to Vietnam. 


\section{Chapter 4: THE DMZ VISITORS' PROFILE: A DESCRIPTION OF THE STUDY SAMPLE}

\subsection{Introduction}

The findings of this study are organised according to the research objectives: motivations for visiting the $\mathrm{DMZ}$ are analysed first, followed by the identification of the visitor segments and the importance of the battlefield sites in tourists' decision to travel to Vietnam. However, before details of these analyses are presented, it is crucial to provide an overview of the total survey participants so that their motivation and behaviour can be better understood.

This chapter plays an introductory role to the findings sequence of this thesis with the aims of providing the basic profile of the DMZ visitors. Specifically, it portrays who the respondents are, where they are from and how they organise their travel. Beginning with their socio-demographic characteristics, this chapter describes the respondents' travel pattern in Vietnam before focusing on their DMZ trip related characteristics in particular.

\subsection{Respondents' demographic profile}

This section presents the survey participants' socio-demographic profile in order to gain understanding of the type of tourists that visit the DMZ. The profile includes, in particular, background information such as the respondents' gender, age, educational level, nationality, their connection with the Vietnam War, and whether or not they are member of any military related associations. It is noted that in this thesis, the figures are explained mostly in percentages rather than in quantities, and in some tables, the percentages may not add to $100 \%$ due to rounding.

As mentioned in Chapter Three, the survey includes 481 respondents. Just over half $(53.6 \%)$ of the survey participants are males (258 respondents) and $46.6 \%$ are females (253 respondents). This is in line with findings from other studies in battlefield tourism such as Gatewood and Cameron (2004), and Lee, Yoon, and Lee (2007), which may indicate that generally there are more men than women visiting battlefield sites. However, further analysis is needed to understand whether or not men are more interested in battlefield tourism than women. 
Similar to a study of visitors to the Korean DMZ (Lee et al., 2007), this study's sample appears to be dominated by younger tourists. As shown in Table 4-1, visitors in the 19-29 age group accounted for more than half of the total respondents $(53.2 \%)$, followed by those aged from 30 to 39 (23.1\%). In comparison, respondents in the $40-$ 49 age group represented a small number of visitors $(5.8 \%)$. Other age groups comprise less than $30 \%$ of the total sample. Specifically, there are $7.9 \%$ of respondents in their fifties, $7.1 \%$ in their sixties plus, and $2.9 \%$ of visitors in the group of 18 and below.

Table 4-1: Age group of respondents

\begin{tabular}{|lcc|}
\hline Category & $\begin{array}{c}\text { No. of } \\
\text { respondents }\end{array}$ & $\begin{array}{c}\% \\
(n=481)\end{array}$ \\
\hline 18 and below & 14 & 2.9 \\
$19-29$ & 256 & 53.2 \\
$30-39$ & 111 & 23.1 \\
$40-49$ & 28 & 5.8 \\
$50-59$ & 38 & 7.9 \\
$60+$ & 34 & 7.1 \\
\hline
\end{tabular}

Regarding educational level, visitors to the DMZ tend to be well-educated: more than three-quarters of the respondents $(76.1 \%)$ are university graduates or post graduates (Table 4-2). Specifically, 55.5\% of the sample have university/college degrees. The number of respondents who have post-graduate degrees makes up $20.6 \%$ of the sample, which is a similar percentage to the secondary education group (20.4\%). In addition, a small number of respondents indicated other forms of education as their highest level of formal school training (3.5\%). Again, these visitors to the Vietnamese DMZ demonstrated a shared characteristic with those of related studies in battlefield tourism: having a high level of education (Gatewood \& Cameron, 2004; Lee et al., 2007).

Table 4-2: Highest formal educational level of respondents

\begin{tabular}{|lcc|}
\hline Category & $\begin{array}{c}\text { No. of } \\
\text { respondents }\end{array}$ & $\begin{array}{c}\% \\
(n=481)\end{array}$ \\
\hline Secondary Education & 98 & 20.4 \\
College/University & 267 & 55.5 \\
Post Graduate & 99 & 20.6 \\
Other & 17 & 3.5 \\
\hline
\end{tabular}

In terms of nationalities, as presented in Table 4-3, British, Australian and American are the top three nationalities of the respondents. Specifically, $18.9 \%$ of respondents 
indicated their nationalities as British, $16.4 \%$ as Australian and 11\% as American. Dutch and Danish visitors correspond to $9.1 \%$ and $5.8 \%$ of the total respectively. Canadian, German and New Zealanders, each accounts for more than $4 \%$ of the sample (4.8\%, 4.4\% and 4.2\% respectively). Other minor nationalities included Irish (3.3\%), Japanese (2.7\%), French (2.1\%), Spanish (2.1\%) and Swedish (2.1\%). Nationalities with less than 10 respondents cover $13.1 \%$ of the total respondents.

Table 4-3: Nationality group of respondents

\begin{tabular}{|lcc|}
\hline Nationality & $\begin{array}{c}\text { No. of } \\
\text { respondents }\end{array}$ & $\begin{array}{c}\% \\
(n=481)\end{array}$ \\
\hline British & 91 & 18.9 \\
Australian & 79 & 16.4 \\
American & 53 & 11.0 \\
Dutch & 44 & 9.1 \\
Danish & 28 & 5.8 \\
Canadian & 23 & 4.8 \\
German & 21 & 4.4 \\
New Zealander & 20 & 4.2 \\
Irish & 16 & 3.3 \\
Japanese & 13 & 2.7 \\
French & 10 & 2.1 \\
Spanish & 10 & 2.1 \\
Swedish & 10 & 2.1 \\
Other & 63 & 13.1 \\
\hline
\end{tabular}

Unfortunately the Vịnh Mốc Tunnels visitor statistics by nationality were not available $^{13}$ so comparison between the study sample and the total visitors of the site was not possible. However, in order to provide a brief overview of the target markets for the DMZ, the sample is compared to the total number of international tourist arrivals in Vietnam in July $2008^{14}$ (Appendix 5).

As shown in Table 3-2, there were 6842 visitors to the Vịnh Mốc Tunnels in July 2008 among which 3218 were foreign visitors. Compared to the total foreign visitors to Vietnam in the same period (Table 4-4), the foreign visitors to the Vịnh Mốc Tunnels accounted for only a small fraction (less than 1\%). In addition, there are some differences between the two populations. While being dominant in the total number of international tourist arrivals to Vietnam, Asians (e.g. Chinese, South Korean, Taiwanese, Southeast Asian, etc.) are under-represented in the sample.

\footnotetext{
${ }^{13}$ The Vinh Moc visitor statistics only include the number of "domestic visitors" and "foreign visitors", information about specific nationalities was not recorded.

${ }^{14}$ Most of the questionnaires were collected in July 2008
} 
Japanese is the only Asian nationality recorded yet the proportion is small $(2.7 \%$ in comparison with $10.7 \%$ of total international visitors to Vietnam in July 2008). On the other hand, Europeans (except French) and Australasians were over-presented in the sample compared to total international tourists to Vietnam. The lack of Asians in the study sample may be related to the language barrier. Questionnaires were available only in English, which may have excluded the non-English speakers. However, the tourists' traditional travel patterns in Vietnam may be one of the main reasons. Despite being the major markets for Vietnam Tourism, the number of Asian visitors (e.g. Chinese, South Korean, Taiwanese) in Huế is relatively small (Thua Thien Hue's Department of Culture, Sports and Tourism (DCST), 2008). This is line with what explained in the Introduction chapter, there were a great number of Chinese tourists crossed the borders for a few hours shopping that were counted in the total foreign visitors to Vietnam. In addition, from the researcher's observation during the fieldwork, there were only a few Chinese, Korean and Japanese (major markets for Vietnam tourism) visitors at the Vịnh Mốc Tunnels. Instead, America, Europe and Australasia are traditional target markets for Central Vietnam and Huế in particular (DCST, 2008). Therefore, it can be seen that Asians in general may not be highly attracted to a DMZ tour. These reasons may explain the small proportion of Vịnh Mốc Tunnels' international visitors compared to the total Vietnam's international visitors in July 2008.

Table 4-4: Comparison of the study sample and total international visitors in Vietnam in July 2008 by nationalities

\begin{tabular}{|lcccc|}
\hline Category & \multicolumn{2}{c|}{$\begin{array}{c}\text { The study sample } \\
(n=481)\end{array}$} & \multicolumn{2}{c|}{$\begin{array}{c}\text { Vietnam's international } \\
\text { visitors }(n=330,000)\end{array}$} \\
\cline { 2 - 5 } & $\mathrm{n}$ & $\%$ & $\mathrm{n}$ & $\%$ \\
\hline British & 91 & 18.9 & 8,066 & 2.4 \\
Australian & 79 & 16.4 & 22,538 & 6.8 \\
American & 53 & 11.0 & 39,812 & 12.1 \\
Dutch & 44 & 9.1 & 4,555 & 1.4 \\
Danish & 28 & 5.8 & 2,279 & 0.7 \\
Canadian & 23 & 4.6 & 8,857 & 2.7 \\
German & 21 & 4.4 & 6,789 & 2.1 \\
New Zealander & 20 & 4.2 & 2,028 & 0.6 \\
Japanese & 16 & 2.7 & 27,165 & 8.2 \\
French & 13 & 2.1 & 13,611 & 4.1 \\
Spanish & 10 & 2.1 & 2,092 & 0.6 \\
Swedish & 10 & 2.1 & 1,679 & 0.5 \\
\hline
\end{tabular}


Of all 12 nationalities reported, Americans are the only visitor group that represents a similar structure compared to the total ( $11 \%$ compared with $12.1 \%)$. The reason may be because the U.S. is a major market for Central Vietnam tourism and American tourists have no language barrier to answering the questionnaire (unlike the French). This is also in line with the fact that American is generally seen to be the main target market for war tourism products in Vietnam (Schwenkel, 2006).

Being a battlefield related attraction, it was expected that the Vịnh Mốc Tunnels would attract a great number of visitors who are veterans of the Vietnam War or those who have some relation to the army. However, as presented in Table 4-5, only $3.3 \%$ of the respondents were members of some military related associations including Veterans Association (7 visitors), Military Association (4 visitors), Armed Forces Association (4 visitors) or other related Associations (1 visitor). The majority $(96.7 \%)$ of the respondents were not members of any military related associations. This may be due to the season in which the survey was conducted, which happened to be in the low season for international tourists in Vietnam in general and the Vịnh Mốc Tunnels in particular. According to the Vịnh Mốc Tunnels' manager and an American veteran tour leaders (personal communication), veteran groups often come during the period of Nov-Jan. However, the findings were also in line with Agrusa, Tanner, and Dupuis's (2006), who found that American Vietnam Veterans did not have a high level of interest in returning to Vietnam as tourists.

Table 4-5: Respondents' membership of military related association

\begin{tabular}{|lcc|}
\hline Category & $\begin{array}{c}\text { No. of } \\
\text { respondents }\end{array}$ & $\begin{array}{c}\% \\
(n=481)\end{array}$ \\
\hline $\begin{array}{l}\text { Member of military related } \\
\text { associations }\end{array}$ & 16 & 3.3 \\
$\begin{array}{l}\text { Non-member of any military } \\
\text { related associations }\end{array}$ & 465 & 96.7 \\
\hline
\end{tabular}

The lack of veterans and military related association members in the study sample may be related to the small number of visitors having connection with the Vietnam War as shown in Figure 4-1. The majority of visitors (93.5\%) stated that they did not have any personal connection with the Vietnam War as compared to $6.5 \%$ who felt personally connected. In addition, $13.1 \%$ of respondents indicated that they were closely related to someone who had connection with the Vietnam War. Conversely, 
$86.9 \%$ of respondents stated they were not closely related to anyone who had connection with the Vietnam War.

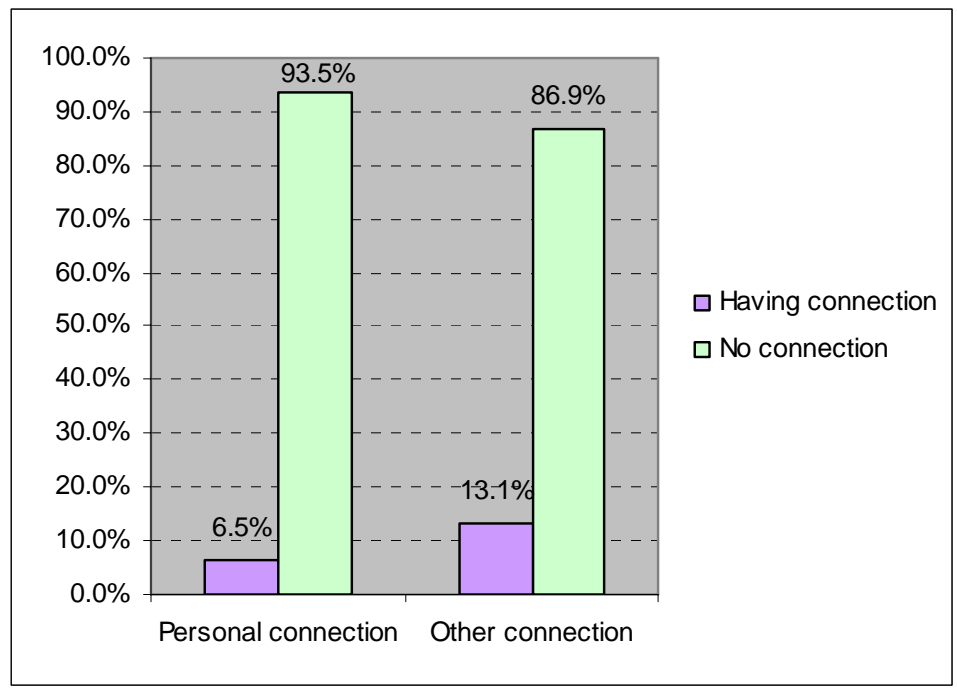

Figure 4-1: Respondents' connection with the Vietnam War

\subsection{Trip related characteristics}

\subsubsection{Visitors' trip to Vietnam}

Having the background information described, it is needed to next portray respondents' travel patterns before examining their motivation and behaviour. This study focuses on the international visitors to the DMZ. However, as the DMZ is likely to be a small part of visitors' bigger trip in Vietnam, it is crucial to understand the general characteristics of the Vietnam trip as a whole, before moving on to the DMZ trip in particular. This section, therefore, aims to provide a general description of visitors' Vietnam trip characteristics, including the number of visits to Vietnam, mode of travelling, purpose of visit and length of stay. It also presents the most important attributes of Vietnam that attracted tourists.

As shown in Table 4-6, the majority (92.3\%) of respondents were not travelling on package tours to Vietnam while only $7.7 \%$ were package tour travellers. The small number of package travellers may be related to their trip duration (i.e. tourists travelling on packages have shorter stay than independent travellers). Vietnam Visitor Statistics show that in 2005, package tourists in Vietnam had an average stay of 9.7 days while the number for independent travellers was 16.8 days (Yen, 2006). Therefore, package travellers may skip certain tourist sites such as the DMZ, which are not in the big cities. 
In addition, $86.5 \%$ visitors in the survey were on their first visit to Vietnam. In the case of repeat visitors, $5.4 \%$ were in their second visit to Vietnam, $4.6 \%$ were in their third or fourth visit. The rest (3.5\%) had visited Vietnam for up to 39 times. These findings reflect a similar pattern to the total Vietnam Visitor Statistics, which show that most incoming international tourists are visiting Vietnam for the first time (Pham, 2006; Yen, 2006).

Table 4-6: Respondents' mode of travel and type of visit to Vietnam

\begin{tabular}{|llcc|}
\hline & Category & $\begin{array}{c}\text { No. of } \\
\text { respondents }\end{array}$ & $\begin{array}{c}\% \\
(n=481)\end{array}$ \\
\hline Travel mode & Not on package tour & 444 & 92.3 \\
& Package tour & 37 & 7.7 \\
\hline Type of visit & First visit & 416 & 86.5 \\
& Repeat visit & 65 & 13.5 \\
\hline
\end{tabular}

Regarding the length of stay, on average, the tourists in the sample spent about 23 days in Vietnam. The most common lengths of stay are 30 days (20\%), 14 days $(15 \%)$ and 21 days (13\%). Some tourists spent as short as four days or in a few cases, up to 150 days in Vietnam. Unfortunately, statistics of international tourists coming to Vietnam during July 2008 by length of stay or number of visits were not available so comparison between the two was not possible.

In terms of the respondents' purposes for visiting Vietnam, holiday trip was dominant when compared to other purposes (e.g. VFR, business, and education), representing $85.7 \%$ of the total sample. Visiting friends and relatives is the main purpose for $2.3 \%$ of respondents while business trip was indicated by $1.7 \%$. The number of participants who visited Vietnam for education and other purposes accounts for $5.4 \%$ and $5 \%$ of the total sample respectively.

Figure 4-2 depicts a comparison between the study sample and the total international visitors to Vietnam in July 2008 in terms of trip purpose. As can be seen, the proportion of holiday takers in the study sample is higher than that of the total visitors to Vietnam (85.7\% compared to $51.5 \%)$. This leads to the underrepresentation of other purposes such as VFR and business (VFR and business trip account for $4 \%$ of the sample as compared to $39.6 \%$ of the total visitors in Vietnam). The lack of business tourists in the survey may due to the fact that the DMZ is distant from convention centres in Vietnam (e.g. Hanoi and Ho Chi Minh City). 
Furthermore, business tourists often have shorter stays, thus they may skip certain sites which are not conveniently located. Furthermore, Visitor Statistics recorded by VNAT include Overseas Vietnamese (Việt Kiều) as international tourists, which may result in a higher VFR portion in the total trip purposes. However, due to historical reasons, Overseas Vietnamese tend to be less interested in visiting war related sites (Vinh Moc Tunnels: Visitor Statistics, 2008). Regarding other purposes, "Education" was not recorded in the Vietnam Visitor Statistics so it was added to the Other category in this study to compare with the similar category in the total visitor population. As can be seen, other purposes account for a similar proportion in both the study sample and the total visitors in Vietnam ( $9.4 \%$ and $9 \%$ respectively).

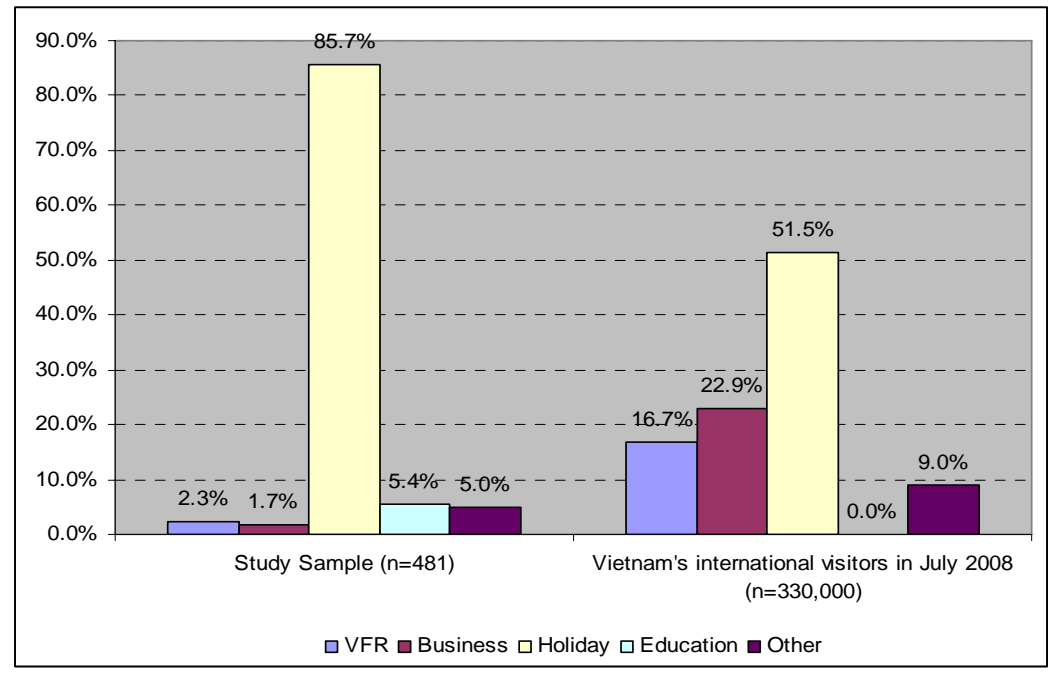

Figure 4-2: Comparison of purpose of visit between survey participants and the total international tourists to Vietnam in July 2008

In order to understand what attracts tourists to Vietnam, respondents were asked to select the top three important attributes from a list of 13 attributes. Table 4-7 shows that Culture, Landscape and History were the three most important factors that drew tourists to visit Vietnam, indicated by $64.7 \%, 64.1 \%$ and $60.3 \%$ of respondents respectively. Price (49.7\%) was also an important factor. In addition, the warm tropical climate was an important attraction for $12.5 \%$ of visitors. Likewise, Battlefield Sites were considered important by $12.3 \%$ of respondents. Other factors including service quality, infrastructure and tourism facilities, and safety were less important for most visitors (chosen by less than $10 \%$ of respondents). 
Table 4-7: Attribute of Vietnam attracting tourists

\begin{tabular}{|lccc|}
\hline Attribute & $\begin{array}{c}\text { No. of } \\
\text { responses }\end{array}$ & $\begin{array}{c}\% \text { of } \\
\text { responses } \\
(n=1404)\end{array}$ & $\begin{array}{c}\% \text { of } \\
\text { cases } \\
(n=481)\end{array}$ \\
\hline Culture & 310 & 22.1 & 64.7 \\
Landscape & 307 & 21.9 & 64.1 \\
History & 289 & 20.6 & 60.3 \\
Price & 238 & 17.0 & 49.7 \\
Climate & 60 & 4.3 & 12.5 \\
Battlefield sites & 59 & 4.2 & 12.3 \\
Local people's attitude towards tourists & 41 & 2.9 & 8.6 \\
Opportunities for outdoor activities & 29 & 2.1 & 6.1 \\
Accessibility & 16 & 1.1 & 3.3 \\
Infrastructure and tourism facilities & 13 & 0.9 & 2.7 \\
Safety & 10 & 0.7 & 2.1 \\
Service quality & 3 & 0.2 & 0.6 \\
Other & 29 & 2.1 & 6.1 \\
\hline
\end{tabular}

* Multiple responses

These findings are in line with Truong and Foster (2006) who found that the Vietnamese Culture and History were the most appealing factors for Australian visitors. Although Truong and Fosters solely focused on Australians whereas the present study includes a diversity of nationalities, the findings confirm the attractiveness of the Vietnamese Culture and History to tourists.

\subsubsection{Visitors' trip to the DMZ and the Vịnh Mốc Tunnels}

Moving from an overview of the respondents' trip to Vietnam as a whole, this section switches the focus to the DMZ trip in particular. It describes the visitors' number of visits to the DMZ, mode of travelling, travel companions, and their length of time exploring the area.

As can be seen from Table 4-8, the majority of respondents visited the DMZ for the first time, which is related to the fact that most tourists in the sample were on their first trip to Vietnam as mentioned earlier. However, while there are $86.5 \%$ of firsttime tourists to Vietnam (Table 4-6), the number of first-time visitors to the DMZ is $96.5 \%$. In other words, $10 \%$ of tourists did not visit the $\mathrm{DMZ}$ in their first visit to Vietnam. Conversely, there are a few cases where respondents had been to the DMZ more than once $(3.5 \%)$. Specifically, nine visitors were on their second visit to the site, six were on their third or fourth visit. One respondent had visited the DMZ five times and for one other it was his $10^{\text {th }}$ time. 
Table 4-8: Respondents' visits to the DMZ

\begin{tabular}{|lcc|lc|}
\hline Time of visit & $\begin{array}{c}\text { No. of } \\
\text { respondents }\end{array}$ & $\begin{array}{c}\% \\
(n=481)\end{array}$ & Measure of & \\
previous visits & \\
\hline First visit & 464 & 96.5 & Mean & 0.08 \\
Second visit & 9 & 1.9 & Median & 0 \\
Third visit & 3 & 0.6 & Mode & 0 \\
Fourth visit & 3 & 0.6 & Std. Deviation & 0.544 \\
Fifth visit & 1 & 0.2 & Minimum & 0 \\
Tenth visit & 1 & 0.2 & Maximum & 9 \\
\hline
\end{tabular}

Figure 4-3 shows that most of the respondents were visiting the DMZ on organised tours. Specifically, group bus tour represents $68 \%$ of the sample, followed by private tour $(14.1 \%)$. In contrast, around $12.5 \%$ of respondents travelled to the DMZ independently: either organising the trip on their own (10.6\%) or in a few cases, were taken by friends or relatives (1.9\%). Interestingly, while $7.7 \%$ of the respondents were travelling on package tours to Vietnam, only $3.7 \%$ indicated the DMZ as a part of their package trip. This is probably because package tourists may have some free or flexible days during the trip and the DMZ was one of the optional things they opted to visit on a separate short tour.

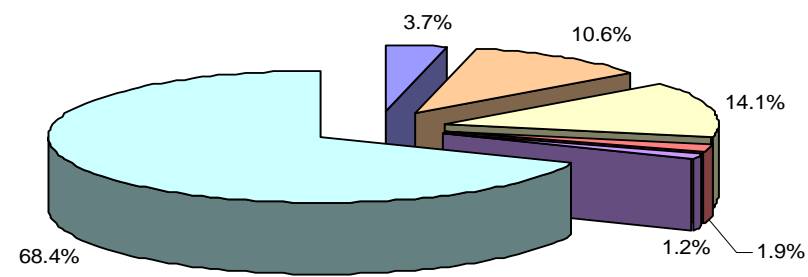

$$
\begin{array}{ll}
\square \text { Part of a package tour to Vietnam } & \square \text { Self-organised } \\
\square \text { Private tour } & \square \text { Taken by friends or relatives } \\
\square \text { Other } & \square \text { Group bus tour }
\end{array}
$$

Figure 4-3: DMZ tour travel arrangement

In general, respondents visited the DMZ with some travel companions. As illustrated in Table 4-9, 35.4\% of respondents were travelling with their friends, followed by those who were with their partners $(31.4 \%)$. The number of visitors travelling with their family and/or relatives makes up for $11.2 \%$ of the sample. There are also a small number of respondents having other companions $(2.7 \%)$. Conversely, one fifth of the visitors were travelling on their own (19.5\%). 
Table 4-9: Respondents' travel companions on the DMZ trip

\begin{tabular}{|lrr|}
\hline Travel company & $\begin{array}{c}\text { No. of } \\
\text { respondents }\end{array}$ & $\begin{array}{c}\% \\
(n=481)\end{array}$ \\
\hline Friends & 169 & 35.1 \\
Partner & 151 & 31.4 \\
Alone & 94 & 19.5 \\
Family and/or relatives & 54 & 11.2 \\
Other & 13 & 2.7 \\
\hline
\end{tabular}

Regarding the trip duration, the majority of respondents $(81.9 \%)$ spent one day exploring the area (Figure 4-4). As Quảng Trị is not a major tourist city, many tourists often choose nearby Huế as a base to visit the DMZ. For some respondents (16\%), half a day was enough to have a glimpse of the area. Nevertheless, some others preferred to spend two days exploring the area, however this number is small $(2.1 \%)$. No other trip durations were reported by respondents.

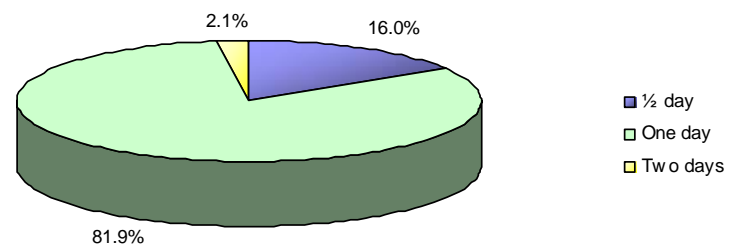

Figure 4-4: The DMZ trip's duration

\subsection{Conclusion}

This chapter has characterised the socio-demography and trip profiles of the respondents. It shows that visitors to the DMZ share some similarities with visitors to other battlefield sites described in previous studies (Gatewood \& Cameron, 2004; Lee et al., 2007). In conclusion, visitors to the DMZ included both males and females yet there were slightly more male visitors than female. They were likely to be young, well-educated and did not hold membership of any military related associations. The majority of survey participants were on their first visit to Vietnam and the DMZ. They tended to be independent travellers on holiday to Vietnam, and 
were mostly attracted to the country's culture, landscape and history. On average, the visitors spent three weeks in Vietnam. In terms of the trip to the DMZ, most visitors were visiting the area with their friends and/or partners. The majority of respondents travelled to the DMZ on a bus tour and spent approximately one day exploring the area.

Although descriptive and limited in nature, this profile information is critical to understanding the visitors' motivation and behaviour. Knowing who the tourists are, where they come from and how they travel provides useful insights into the study of why they visit the DMZ and how important the battlefield sites are in their decision to travel to Vietnam. This information will be presented in the next chapters. 


\section{Chapter 5: DMZ VISITOR SEGMENTATION ON MOTIVATIONS}

\subsection{Introduction}

The previous chapter provided a general overview of the total study sample. Visitors' socio-demographic and trip related characteristics were described; however, their travel motivation and behaviour has not yet been discussed. This chapter thus takes in the findings from the previous chapter to further analyse the tourists according to groups. It aims to address the first two objectives of this thesis: identifying the tourist motivations for visiting the DMZ and classifying the DMZ visitors based on their motivations, leaving the third objective for the next chapter.

As discussed in Chapter Two, motivation is an appropriate factor for tourism market segmentation (Bieger \& Laesser, 2002; Kozak, 2002; Lee et al., 2004; Sirakaya et al., 2003) and was chosen as a criterion for segmenting DMZ visitors in this study. The data about motivations for visiting the DMZ was analysed in two steps, each of which involves different types of data. The first step dealt with visitors' selfexpressed responses for the open ended question "Why did you visit the DMZ?". In the second step, pre-identified motivational statements were analysed using statistical tools (mean comparison and factor analysis). Generated motivational factors from factor analysis are then used to perform a cluster analysis to identify groups of visitors.

\subsubsection{Self-expressed reasons for visiting the DMZ}

Table 5-1 depicts the answers given by visitors for the question "Why did you visit the DMZ?" The numerous responses provided fruitful data for the motivational analysis. However, it is noted that managing and analysing respondents' own expressions is not a simple task. Generally, similar answers were put in groups so that major themes can be identified. Nevertheless, there are cases where it can also be challenging to correctly categorise the responses into suitable themes. Therefore, as a general rule, data was classified to the themes they are most closely related with. If two or more reasons were given by one respondent, all were recorded.

As can be seen, "interest in history and the Vietnam War" appears to be the most common reason for visiting the DMZ as indicated by $35.6 \%$ of respondents. This is consistent with the importance of the history of Vietnam amongst the country 
attributes that attract tourists as described earlier. Specifically, respondents reported that they were interested in history in general and the Vietnam War in particular. As a young Irish university graduate respondent pointed out:

"I visited the DMZ due to my interest in the history of Vietnam in regards to the American War".

The second most common reason for visiting the DMZ is "education", indicated by $27.1 \%$ of the visitors. It should be noted that a general historic interest may be related to an interest in learning about the history; however these two are not necessarily the same. "Education" here implies a desire to improve one's knowledge in general and knowledge about the Vietnamese history and the Vietnam War in particular. If respondents mentioned that their visit to the DMZ was to gain a better understanding of the history, the motivation was regarded as "education":

"I really enjoyed learning about history and wanted to learn more about the Vietnam War." said an Australian visitor, who was on a 2-week holiday trip in Vietnam with her partner.

Those who indicated interest in the history and the Vietnam War without stating a desire to learn were considered to have "interest in history and the Vietnam War" as mentioned above.

As a reason for visiting the $\mathrm{DMZ}$, the desire for firsthand experience was the second most selected response after intellectual motivations (i.e. interest in history and education). Respondents reported visiting the $\mathrm{DMZ}$ solely because they wanted to see the Vịnh Mốc Tunnels (12.3\% of visitors). While these visitors indicated that the Vịnh Mốc Tunnels was the only site that attracted them, other visitors wanted to see the whole DMZ area in real life (9.9\%). A middle-aged American, who is a member of the US Air Force, responded:

"I grew up in the US seeing images of Vietnam War on TV. Read lots of books about the war and battles. We wanted to see some of the sites for ourselves."

Beside a small number of visitors who showed an interest in seeing the war artefacts (3.1\%), there are participants visiting the DMZ mainly because it was an important site in the history of Vietnam (6.4\%). This reason was separated from a general interest in history because it elucidates the importance of the site per se. 
"I felt it was important to see the place that changed the national, regional and world history" said a young British independent traveller.

There also exists a small number of visitors ( $2.4 \%$ of the total sample) coming to the DMZ because it was recommended by others. As a Slovenian respondent put it "because our friends told us we have to visit it". In addition, the reasons could be simply because of curiosity and novelty seeking $(2.2 \%)$ or to see how life was in Vietnam during the war $(2.1 \%)$.

Table 5-1: Self-expressed reasons for visiting the DMZ

\begin{tabular}{|lrrr|}
\hline Reason & $\begin{array}{r}\text { No. of } \\
\text { responses }\end{array}$ & $\begin{array}{r}\text { \% of } \\
\text { responses }\end{array}$ & $\begin{array}{r}\text { \% of } \\
\text { cases }\end{array}$ \\
\hline Interest in history and the Vietnam War & 151 & 31.4 & 35.6 \\
Education & 115 & 23.9 & 27.1 \\
To see the Vịnh Mốc Tunnels & 52 & 10.8 & 12.3 \\
To see the DMZ in real life & 42 & 8.7 & 9.9 \\
The DMZ is an important site & 27 & 5.6 & 6.4 \\
To see the war artefacts & 13 & 2.7 & 3.1 \\
Recommended by others & 10 & 2.1 & 2.4 \\
Curiosity and novelty seeking & 9 & 1.9 & 2.2 \\
To see how life was during the war & 9 & 1.9 & 2.1 \\
Location and convenience & 8 & 1.7 & 1.9 \\
Personal involvement & 8 & 1.7 & 1.9 \\
It is part of a package tour & 7 & 1.5 & 1.7 \\
Other & 30 & 6.2 & 7.1 \\
Total & 481 & 100.0 & 113.4 \\
\hline
\end{tabular}

*Multiple responses

Other minor reasons indicated by less than $2 \%$ of the respondents include convenience $(1.9 \%)$, personal involvement $(1.9 \%)$, and as part of the package tour to Vietnam (1.7\%). Other reasons such as recalling memories, to get an impression from a Vietnamese perspective, and accompanying a partner account for $6.2 \%$ of the total responses. Examples include:

"My husband was connected to the war as an Australian soldier. We came to visit it together today." said an Australian woman, who was on her second visit to Vietnam with her husband.

However, it is noted that respondents often combined several reasons for visiting the DMZ. For example, a young Irish traveller who had a post graduate degree pointed out that: 
"I was curious to know the present situation, also growing up by youth culture was saturated with many films connected with the American War. It is also interesting to visit another country which has had to deal with conflict similar to mine (Northern Ireland)."

In short, respondents gave a variety of reasons for visiting the DMZ. Nevertheless, the dominant reasons are general historic interest and educational purposes, which account for more than half of the total responses (55.3\%). Interestingly, personal involvement was not among the most common reasons. This is related to the fact that most respondents did not have any connection with the Vietnam War as described in the previous chapter.

\subsubsection{Motivational statements}

\subsubsection{Mean comparison}

Moving on from an open-ended question, respondents were asked to rate on a 5-point Likert scale the importance level of each of the given motivational items for their visiting the DMZ. Level 1 indicates unimportant while level 5 means very important. Table 5-2 illustrates a comparison of the motivational statements by means, median and mode (in descending order by means). It is organised in three parts from highest to lowest mean scores (M), indicated by different shadings: $M>=3,3>M>=2$, and $2>M>=1$. Since these motivational items are generated into themes for comprehensive analysis later, this section only discusses the remarkable items such as the most important and the least important items.

As can be seen, the top two reasons are "to understand more about the Vietnam/American War" $(\mathrm{M}=4.47)$ and "Because I am interested in history" $(\mathrm{M}=4.24)$. This is in line with results from the open-ended question in which respondents indicated "interest in history and the Vietnam War" and "education" as the most important reasons for visiting the DMZ. The high means along with low standard deviation ( $\mathrm{SD}=0.78$ and $\mathrm{SD}=0.84$ respectively) shows the consistency among visitors, emphasising the importance of these two motivations.

Similarly, the fact that the DMZ "represents an important part in the Vietnam/American War" was also an important factor $(\mathrm{M}=3.96)$. This relates to the self-expressed motivation "because it is an important site", which again confirms the importance of the DMZ for the visitors. 
Conversely, the "curiosity" factor appears to be substantially important compared to the self-expressed responses. While only $2.2 \%$ of visitors claimed "curiosity and novelty seeking" as their reason for visiting the DMZ in the freely expressed question, this reason was rated important $(\mathrm{M}=4.00)$. This is probably because respondents tended to indicate their principal reasons when answering in their own words and "curiosity" may have been the secondary reason.

The second most important group of motivations (means vary from 2.26 to 2.99 ) includes a combination of novelty seeking, remembrance, interest in battlefield tourism, interest in the military motivations and location of the site. Interestingly, the least important reasons were found to be those related to the respondents' connection with the DMZ.

Table 5-2: Comparison of motivational items

\begin{tabular}{|c|c|c|c|c|}
\hline Motivational statement & Mean & Median & Mode & SD \\
\hline To understand more about the Vietnam & 4.47 & 5 & 5 & 0.78 \\
\hline Because I am interested in history & 4.24 & 4 & 5 & 0.84 \\
\hline Because I am curious & 4.00 & 4 & 4 & 1.00 \\
\hline Because it represents an important part in the & & & & \\
\hline Vietnam/American War & 3.96 & 4 & 4 & 1.01 \\
\hline To try something new and different & 2.99 & 3 & 4 & 1.33 \\
\hline To honour and pay tribute to the people whose & & & & \\
\hline lives were lost in the war & 2.95 & 3 & 3 & 1.34 \\
\hline To see the war artefacts & 2.82 & 3 & 3 & 1.18 \\
\hline Because the DMZ is a famous attraction & 2.60 & 3 & 3 & 1.19 \\
\hline Because I am interested in battlefield tourism & 2.41 & 2 & 1 & 1.30 \\
\hline Because I am interested in the military & 2.41 & 2 & 1 & 1.27 \\
\hline To see real places from the movies I watched & 2.38 & 2 & 1 & 1.23 \\
\hline Because it is on my way & 2.26 & 2 & 1 & 1.18 \\
\hline $\begin{array}{l}\text { To visit the places where someone I am closely } \\
\text { related to had connection with }\end{array}$ & 1.92 & 1 & 1 & 1.17 \\
\hline Because it is near other attractions & 1.80 & 1 & 1 & 1.01 \\
\hline To get away from my daily routine & 1.79 & 1 & 1 & 1.16 \\
\hline To learn about my heritage & 1.60 & 1 & 1 & 1.14 \\
\hline To accompany someone else & 1.56 & 1 & 1 & 0.98 \\
\hline Because I have no other activity to do & 1.49 & 1 & 1 & 0.90 \\
\hline Because it is a part of a package tour & 1.47 & 1 & 1 & 0.94 \\
\hline To remember the days of my youth & 1.28 & 1 & 1 & 0.79 \\
\hline To confront a painful part of my past & 1.27 & 1 & 1 & 0.81 \\
\hline Because I had personal connection with the DMZ & 1.20 & 1 & 1 & 0.65 \\
\hline Other & 1.20 & 1 & 1 & 0.77 \\
\hline
\end{tabular}

As shown in Table 5-2, the lowest rated motivational items are "because I had personal connection with the DMZ" $(\mathrm{M}=1.20)$, "to confront a painful part of my part" $(\mathrm{M}=1.27)$ and "to remember the days of my youth" $(\mathrm{M}=1.28)$. These are also the motivational items that have the smallest standard deviations $(\mathrm{SD}=0.65-0.81)$. 
Together with the small number of visitors indicated "personal involvement" as the main motivation in the open-ended question $(1.9 \%)$, this shows that a majority of visitors did not have a connection with the DMZ.

However, no pattern can be concluded at this stage regarding the tourist motivations for visiting the DMZ. In order to identify the dimensions underlying these motivational items, factor analysis was needed to reduce the original data into a small and easily understood number of factors based on the correlation between variables (Punch, 2005; Robson, 1993).

\subsubsection{Factor Analysis}

As described in the methodology chapter, data of this study was proven to be appropriate for factor analysis. However, it is important to determine the number of factors to extract. According to Hair et al. (1998), factor loading shows the correlation of each original variable and the factor. Higher loadings make the variable representative of the factor, and loadings from 0.5 are considered significant. Therefore, in this study, factor loadings less than 0.5 were omitted from the analysis. This resulted in a list of 20 valid variables, while two eliminated variables are:

+ To honour and pay tribute to the people whose lives were lost in the war

+ Because it is a part of a package tour

In deciding the number of factors, the most popular heuristic eigen-value-greaterthan-one rule was used (Hair et al., 1998; Sharma, 1996). Eigenvalue represents the amount of standardised variance in the variable accounted for by a factor. The sum of eigenvalues is the percentage of variance accounted for. Consequently, five factors with eigenvalue more than 1.0 were chosen, which explains $53.09 \%$ of the total variance.

In the next step, reliability of the factor generated was tested. Specifically, reliability analysis (Cronbach's alpha) was run to test the correlation between variables that constitute one factor. Results shows that variables within each factor were internally consistent $(\alpha>0.50$, which is the value accepted as an indication of reliability in basic research (Nunnally, 1967, as cited in Mehmet, 2005). Table 5-3 depicts results from factor analysis. 
Table 5-3: Factor analysis of tourist motivations for visiting the DMZ

\begin{tabular}{|lcc|}
\hline Motivation & Factor & Factor \\
& 1 & 2 \\
\hline Personal involvement & & \\
To remember the days of my youth & 0.809 & \\
Because I had personal connection & 0.792 & \\
with the DMZ & & \\
To confront a painful part of my past & 0.759 & \\
To visit the places where someone I & 0.689 & \\
am closely related to had connection & & \\
with & & \\
To learn about my heritage & 0.632 & \\
& & \\
Interest in war related sites and & & \\
exhibitions & & 0.777 \\
Because I am interested in the & \\
military & & 0.759 \\
Because I am interested in battlefield & & 0.602 \\
tourism & & 0.543 \\
To see the war artefacts & & \\
Because the DMZ is a famous & & \\
attraction & & \\
To see real places from the movies I & &
\end{tabular}

watched

\section{Education and exploration}

To understand more about the

Vietnam/American War

Because it represents an important

part in the Vietnam/American War

Because I am curious

0.777

0.759

0.602

0.543

0.501

Because I am interested in history

\section{Novelty seeking}

To try something new and different

To accompany someone else

To get away from my daily routine

actor Factor Factor

3

4

5

Because I have no other activity to do

0.751

0.715

0.645

0.602

Location and convenience

Because it is on my way

0.785

Because it is near other attractions

0.653

Eigenvalue

$3.11 \quad 2.63$

2.63
11.96

2.37

0.655

0.654

0.578

0.518

Variance (\%)

14.14

11.96

10.79

14.14

26.10

36.89

1.62

Cumulative variance (\%)

0.78

0.70

0.67

45.72

7.37

53.09

Reliability coefficient 
Once the factors were accepted, the final step was to interpret them. First of all, each factor was labelled according to the common characteristics of the motivational items it included, which are "Personal involvement", "Interest in war related sites and exhibition", "Education and Exploration", "Novelty seeking", and "Location and Convenience". It is noted that these motivations explain just over half of the total variance. However, complementary results from open-ended questions also provide useful inputs to the understanding of unexplained variance. On the other hand, the five factors reasonably reflect consistency with the results from open-ended questions and means comparison of individual motivational statements. The importance of "education" and "interest in history" motivations from self-expressed responses and mean comparison were reinforced in the "Education and Exploration" factor. Tourists' desire to see the war artefacts and the DMZ in real life was reflected in the "Interest in war related sites and exhibitions" factor. Likewise, the "Novelty seeking" and "Location and Convenience" factors mirror tourists' curiosity, their need to experience something new, and the location of the site. Interestingly, in spite of the relatively low means of individual items, "Personal involvement" appears as a significant factor for visiting the DMZ. Details of each of the five factors are discussed separately below.

The first factor, "Personal involvement", consists of five motivational items, which are "to remember the days of my youth", "because I had personal connection with the DMZ", "to confront a painful part of my past", "to visit the places where someone I am closely related to had connection with", and "to learn about my heritage". As can be seen in Table 5-3, the items constituting this factor have the highest loadings compared to other factors, which reflects a strong connection with the factor. In addition, variables under this factor are significantly intercorrelated with each other as shown by $\alpha=0.78$. With an eigenvalue of 3.11 , this factor accounts for the highest portion of variance explained (14.14\%).

The second factor includes four variables, which are "because I am interested in the military", "because I am interested in battlefield tourism", "because the DMZ is a famous attraction", and "to see real places from the movies I watched". Since these motivational statements show an interest in the military and war, this factor was labelled "interest in war related sites and exhibitions". The reliability alpha of this factor is 0.70 , indicating a strong correlation between variables under it. With an eigenvalue of 2.63 , this factor explains $11.96 \%$ of the total variance. 
"Education and exploration", the third factor, has an eigenvalue of 2.37 and explains $10.79 \%$ of the total variance. It consists of four motivational items such as "to understand more about the Vietnam/American War", "because it (the DMZ) represents an important part in the Vietnam/American War", "because I am curious", and "because I am interested in history". A reliability alpha of 0.67 shows that there is a relatively strong correlation between the variables constituting this factor.

The fourth factor was labelled "Novelty seeking" according to the variables it included, which are "to try something new and different", "to accompany someone else", "to get away from my daily routine", and "because I have no other activity to do". A reliability alpha of 0.57 indicates reasonable correlation between the four variables. The eigenvalue of the "novelty seeking" factor is 1.94 and it explains $8.83 \%$ of the total variance.

Labelled "Location and convenience", the last factor comprises two items: "because it is on my way" and "because it is near other attractions". With an eigenvalue of 1.62, this factor explains $7.37 \%$ of the total variance. The two variables constituted this factor are reasonably correlated with each other as shown by a reliability alpha of 0.53 .

In sum, five main motivations for visiting the $\mathrm{DMZ}$ were generated from the factor analysis, namely "Education and Exploration", "Interest in war related sites and exhibitions", "Novelty seeking", "Location and Convenience", and "Personal Involvement". However, these motivations may play different roles in each visitor, which may influence their travel decision-making and behaviour. Therefore, visitors to the DMZ are categorised based on these motivations to understand how they are diverse in terms of their socio-demographic characteristics as well as their travel behaviour.

\subsection{Cluster identification - Cluster analysis}

As mentioned in Chapter Three, this study uses K-means clustering method, in which the number of clusters had to be pre-determined. As this is an exploratory study, the cluster solution should be based on both theoretical and practical considerations. From a practical point of view, it is more manageable and interpretable if the number of clusters is from two to six. This is also in line with results from previous SIT market segmentation studies such as Charters and Ali-Knight's (2002), McKercher's (2002), Mehmetoglu's (2005), Sung's (2004) and Trauer's (2006). Findings from a 
range of solution (two to six clusters) were then retrieved from SPSS K-means cluster analysis. Table 5-4 shows the results (number of cases) for different solutions.

Table 5-4: Number of cases in different clustering solutions

\begin{tabular}{|c|c|c|c|c|c|}
\hline Formation & 2-cluster & 3-cluster & 4-cluster & 5-cluster & 6-cluster \\
\hline Cluster 1 & 329 & 74 & 66 & 48 & 77 \\
\hline Cluster 2 & 152 & 160 & 143 & 71 & 70 \\
\hline Cluster 3 & & 247 & 158 & 53 & 70 \\
\hline Cluster 4 & & & 114 & 164 & 49 \\
\hline Cluster 5 & & & & 145 & 39 \\
\hline Cluster 6 & & & & 176 \\
\hline
\end{tabular}

The cluster solution was then selected based on several factors such as distances between final clusters, final cluster centres, number of cases in clusters and ANOVA table (Weaver \& Lawton, 2005). As shown in Table 5-4, cluster memberships were relatively reasonably distributed in all the five solutions. However the 5-cluster and 6-cluster solutions are less favourable since they have relatively small clusters (the smallest cluster has less than $10 \%$ of the total sample). In particular, cluster 1 in a 5 cluster solution has 48 cases $(9.98 \%)$ and cluster 4 in a 6-cluster solution has 39 cases $(8.1 \%)$. Therefore, preferences are given to the other clusters whose number of cases in each cluster is large enough in order to increase the generalizability of the cluster solution.

Considering the distances between the final cluster centres, the 2-cluster and 3cluster solutions appear to provide most dissimilar clusters. Conversely, the distances between final cluster centres in the 4-cluster, 5-cluster and 6-cluster solutions are relatively smaller (Appendix 6). Specifically, the smallest distance in a 6-cluster solution is 1.667 (found between cluster 3 and 6), 1.618 in a 5-cluster solution (between cluster 2 and 4), and 1.440 in a 4-cluster (between cluster 2 and 3). Likewise, the smallest distance between clusters in a 3-cluster solution is 1.839 (between cluster 2 and 3) and 2.114 between 2 clusters in 2-cluster solution. Therefore, the 4-cluster, 5-cluster and 6-cluster solutions were rejected which left only two options: two clusters or three clusters. Eventually, the decision was given to the 3-cluster solution rather than the 2-cluster solution as the two-cluster solution failed to describe the complexity of the tourist motivations. In addition, when comparing the final cluster centres (i.e. means on the variables used to cluster) and ANOVA tables, the three-cluster solution appeared to yield the highest level of 
statistically significant differentiation, which indicates a strong level of "distance" between cluster (Weaver \& Lawton, 2005).

Table 5-5 illustrates one-way ANOVA results of motivation factors across clusters. The means of "Personal involvement" differs the most $(F=293.995)$, indicating a significant difference between the clusters. Specifically, Cluster 1 has a mean of 3.13, a difference of 2.00 compared to the other clusters. This may explain the low means of personal involvement related items as shown in Table 5-2. "Location and convenience" ( $F=266.393)$ is also a significant factor, followed by "Interest in war related sites and exhibitions" $(F=88.917)$ and "Novelty seeking" $(F=70.164)$. Conversely, "Education and Exploration" $(F=18.824)$ appears to make less contribution in characterising the clusters.

Table 5-5: Mean comparison of motivation factor by cluster

\begin{tabular}{|lrrrrr|}
\hline Factor & Cluster & Cluster & Cluster & $F$ ratio & $\begin{array}{c}\text { Sig. } \\
\text { level }\end{array}$ \\
& 1 & 2 & 3 & & \\
\hline Personal involvement & 3.13 & 1.15 & 1.05 & 293.995 & 0.000 \\
Interest in war related sites and & 3.58 & 2.62 & 2.21 & 88.917 & 0.000 \\
exhibitions & & & & & \\
Education and exploration & 4.57 & 4.17 & 4.05 & 18.824 & 0.000 \\
Novelty seeking & 2.47 & 2.58 & 1.67 & 70.164 & 0.000 \\
Location and Convenience & 2.03 & 3.00 & 1.45 & 266.393 & 0.000 \\
\hline
\end{tabular}

Note: The $F$ tests are used for descriptive purposes only because the clusters have been chosen to maximize the differences between cases in different clusters. The observed significance levels are not corrected for this and thus cannot be interpreted as a test of the hypothesis that the cluster means are equal.

In order to facilitate the interpretation of the cluster profile, clusters were labelled according to the importance of the motivation factors to each cluster. Inputs for the cluster labels were taken from the previous SIT studies such as Park and Yoon's (2009), and Weaver and Lawton's (2005). It is noted that having a label that covers all the characteristics of a cluster is impossible. Therefore, extreme labels were chosen to reflect the distinctive characteristics of the cluster only. Cluster 1 has highest means in three motivation factors namely "Personal involvement", "Interest in war related sites and exhibitions" and "Education and Exploration". Therefore this cluster was named "Battlefield Tourism Enthusiast" (or Enthusiast in short). Cluster 2 has the highest mean in the "Novelty seeking" factor and "Location and convenience" factor, thus was labelled "the Opportunist". The last cluster has the lowest means in all of the motivation factors; hence, it was called "the Passive Tourist". It is worth noting that visitors were not equally distributed across clusters 
(Table 5-4). The "Passive Tourist" cluster is the largest with 247 visitors, representing for more than half of the total sample $(51.4 \%)$. The second largest cluster, "Opportunist", consists of 160 visitors, accounting for one third of the sample (33.3\%). "Enthusiast" is the smallest cluster with 74 visitors $(15.4 \%)$.

Regarding the similarity of the cluster, Table 5-6 shows that the "Enthusiast" and "Passive Tourist" is furthest apart (2.722) while the "Opportunist" and "Passive Tourist" is closest to each other (1.839). Furthermore, the "Enthusiast" appears to be furthest from the other two clusters.

Table 5-6: Distances between final cluster centres

\begin{tabular}{|lrrc|}
\hline Cluster & Enthusiast & Opportunist & Passive Tourist \\
\hline Enthusiast & & 2.436 & 2.722 \\
Opportunist & 2.436 & & 1.839 \\
Passive Tourist & 2.722 & 1.839 & \\
\hline
\end{tabular}

At this point, it appears that the majority of visitors to the DMZ in this study were classified as "Passive Tourists", those who indicated the lowest ratings in all the five motivations. Conversely, there were some visitors who visited the DMZ for many motivations, especially for personal reasons, educational purposes and historical interest. These visitors made up the smallest group of visitors: the "Enthusiast". "Opportunist", the group of visitors that shares more similarities with the "Passive Tourist" than the "Enthusiast", also accounts for a significant number of visitors. These are the visitors who were looking for novelty and put high emphasis on the location of the site.

\subsection{Cluster validation - Discriminant analysis}

At this stage, a three-cluster solution was proposed but one remaining concern was how representative the clusters might be and which of the motivational factors best discriminated among the identified clusters. Therefore, a multiple discriminant analysis was needed to assess the classification accuracy of cluster membership as well as to identify which of the motivation factors was driving the differences (Hair et al., 1998; Sharma, 1996).

Discriminant analysis was performed with three cluster groups (dependent variable) and five motivational factors (independent variables). Due to the limited sample size of the study population, a holdout sample was not used, instead a classification 
matrix by using the entire sample was constructed for validating the results of clusters, which is acceptable in behavioural studies (Sirakaya et al., 2003).

The results of discriminant analysis (Table 5-7 and Table 5-8) show significant differences between the group characteristics. A Wilks' lambda test and a univariate $F$ test were performed to determine significance of each of the five motivation factors. Functions were interpreted using standardised structure coefficients, which represent the relative contribution of the associated variable to the discriminant function. As this is a three-group discriminant analysis model, two canonical discriminant functions were calculated (Hair et al., 1998). Significance levels of the resulting discriminant functions were determined using the Chi-square test. Table 5-7 shows that the two functions are statistically significant. Function 1 (Wilks' Lambda $=0.161, \chi^{2}=692.779, d f=10, p=0.000$ ), with an eigenvalue of 1.758 , explains $58.3 \%$ of the total variance. Function 2 (Wilks' Lambda $=0.443, \chi^{2}=308.264, d f=4$, $p=0.000$ ) has an eigenvalue of 1.255 , explaining $41.7 \%$ of the remaining variation. The canonical correlations are high $(0.798$ and 0.746$)$, indicating that the model explained a significant relationship between the function and the dependent variable.

Table 5-7: Summary of discriminant analysis results

\begin{tabular}{|crrrrrrrr|}
\hline $\begin{array}{l}\text { Discriminant } \\
\text { function }\end{array}$ & $\begin{array}{l}\text { \% of } \\
\text { variance }\end{array}$ & $\begin{array}{l}\text { Cumulative } \\
\%\end{array}$ & Eigenvalue & $\begin{array}{l}\text { Canonical } \\
\text { correlation }\end{array}$ & $\begin{array}{l}\text { Wilks' } \\
\text { Lambda }\end{array}$ & $\begin{array}{l}\text { Chi- } \\
\text { square }\end{array}$ & df & $\begin{array}{l}\text { Sig. } \\
\text { level }\end{array}$ \\
\hline 1 & 58.3 & 58.3 & $1.758^{\mathrm{a}}$ & 0.798 & 0.161 & 692.779 & 10 & 0.000 \\
2 & 41.7 & 100.0 & $1.255^{\mathrm{a}}$ & 0.746 & 0.443 & 308.264 & 4 & 0.000 \\
\hline
\end{tabular}

a. First 2 canonical discriminant functions were used in the analysis

In order to identify which predictor variable contributes the most to each function separately, F-ratios and discriminant loadings were examined. The loadings (or structure coefficients) are also helpful for assigning the label and for interpreting the contribution of each variable to the formation of the discriminant function (Sharma, 1996). The loading of a given discriminator variable is the correlation coefficient between the discriminant score and the discriminator variable. The closer the absolute value of the loading of a variable to 1.0, the more communality there is between the discriminating variable and the discriminant function and vice versa. As shown in Table 5-8, in Function 1, the "Location and Convenience" factor differentiates the clusters the most, followed by the "Novelty seeking", "Interest in war related sites and exhibitions", and "Education and Exploration" factors. Likewise, in Function 2, the "Personal involvement" factor is the differentiating factor. 
Table 5-8: Discriminant function loadings

\begin{tabular}{|c|c|c|}
\hline & $\begin{array}{c}\text { Function } \\
1 \\
\end{array}$ & $\begin{array}{c}\text { Function } \\
2 \\
\end{array}$ \\
\hline \multicolumn{3}{|l|}{ Motivation factors } \\
\hline Location and Convenience & $0.655^{\mathrm{a}}$ & -0.569 \\
\hline Novelty seeking & $0.373^{\mathrm{a}}$ & -0.142 \\
\hline Interest in war related sites and exhibitions & $0.348^{\mathrm{a}}$ & 0.170 \\
\hline Education and Exploration & $0.114^{\mathrm{a}}$ & 0.111 \\
\hline Personal involvement & 0.532 & $0.713^{\mathrm{b}}$ \\
\hline \multicolumn{3}{|l|}{ Centroids (group means) $^{\mathrm{c}}$} \\
\hline Battlefield tourism enthusiast & 2.336 & 2.669 \\
\hline Novelty and convenience seeker & 1.231 & -1.237 \\
\hline Passive tourist & -1.103 & 0.223 \\
\hline
\end{tabular}

Note: Pooled within-groups correlations between discriminating variables and standardised canonical discriminant functions. Variables ordered by absolute size of correlation within function.

${ }^{\text {a }}$ Four motivation factors discriminate the three clusters in Function 1.

${ }^{\mathrm{b}}$ Motivation factor discriminates the three clusters in Function 2.

${ }^{\mathrm{c}}$ Unstandardised canonical discriminant functions evaluated at group means

The classification matrix was examined to determine whether or not the Functions were valid predictors. As can be seen in Table 5-9, within Cluster $1(n=74)$, a total of 60 cases $(81.1 \%)$ were classified correctly, leaving 14 cases $(19 \%)$ misclassified. The number of cases correctly classified in Cluster 2 and 3 is 151 (94.4\%) and 238 (96.4\%) respectively. Overall, 449 out of 481 cases $(93.3 \%)$ were correctly classified, validating the results of the cluster analysis. Detailed descriptions of the three clusters are presented next.

Table 5-9: Classification results

\begin{tabular}{|crrr|}
\hline Cluster & \multicolumn{3}{c|}{ Predicted group membership } \\
\cline { 2 - 4 } membership & \multicolumn{3}{c|}{3} \\
\hline 1 & 60 & 7 & 7 \\
$(\mathrm{n}=74)$ & $81.1 \%$ & $9.5 \%$ & $9.5 \%$ \\
2 & 4 & 151 & 5 \\
$(\mathrm{n}=160)$ & $2.5 \%$ & $94.4 \%$ & $3.1 \%$ \\
3 & 4 & 5 & 238 \\
$(\mathrm{n}=247)$ & $1.6 \%$ & $2.0 \%$ & $96.4 \%$ \\
Percent of original grouped cases correctly classified: $93.3 \%$ \\
\hline
\end{tabular}




\subsection{DMZ visitor segments description}

\subsubsection{The clusters' demographic profile}

The previous analysis showed that there are three groups of visitors at the DMZ. Obviously, these visitor groups differ from each other regarding the motivations for visiting the DMZ. However, in order to better understand their dissimilarities, it is useful to consider some background information of these visitors segments. This section thus describes the visitor segments' socio-demographic profile.

Table 5-10 shows that the three visitor segments share some differences as well as similarities in terms of socio-demography. Specifically, there are significant differences across clusters regarding age group, nationality and connection with the Vietnam War. Conversely, no statistical significant differences can be found in terms of gender, educational level, or military related associations' membership. Examinations of these variables are presented below.

Table 5-10: Summary of the visitor segments' socio-demographic profiles

\begin{tabular}{|lrrr|}
\hline Profile attribute & $\chi^{2}$ & df & $\begin{array}{r}\text { Sig. } \\
\text { level }\end{array}$ \\
\hline Gender & 3.186 & 2 & 0.203 \\
Educational level & 10.270 & 6 & 0.144 \\
Age & 44.718 & 10 & 0.000 \\
Nationality & 40.550 & 20 & 0.004 \\
Military related associations' membership & 2.120 & 2 & 0.346 \\
Personal connection with the Vietnam War & 13.979 & 2 & 0.001 \\
Other connection with the Vietnam War & 28.855 & 2 & 0.000 \\
\hline
\end{tabular}

Generally, as displayed in Table 5-11, visitors aged 20-29 are dominant in all three clusters (33.8\% of Enthusiast, 58.8\% of Opportunist, and 55.5\% of Passive Tourist), followed by those in their thirties $(17.6 \%, 23.8 \%$ and $24.3 \%$ in three clusters respectively). Nevertheless, substantial differences are found in the age group of 5059 and $60+$. It appears that the Enthusiast group has the highest percentage of elderly visitors $(35.1 \%$ of the total visitors within the cluster), more than double those in the Opportunist and Passive Tourist group (8.8\% and 13\% respectively). 
Table 5-11: Age group by visitor segments

\begin{tabular}{|c|c|c|c|c|c|c|c|c|}
\hline \multirow[t]{2}{*}{ Age group } & \multicolumn{2}{|c|}{$\begin{array}{l}\text { Enthusiast } \\
(\mathrm{n}=74)\end{array}$} & \multicolumn{2}{|c|}{$\begin{array}{l}\text { Opportunist } \\
(\mathrm{n}=160)\end{array}$} & \multicolumn{2}{|c|}{$\begin{array}{c}\text { Passive Tourist } \\
(\mathrm{n}=247)\end{array}$} & \multicolumn{2}{|c|}{$\begin{array}{c}\text { Total } \\
(\mathrm{n}=481)\end{array}$} \\
\hline & $\mathrm{n}$ & $\%$ & $\mathrm{n}$ & $\%$ & $\mathrm{n}$ & $\%$ & $\mathrm{n}$ & $\%$ \\
\hline$<=18$ & 2 & 2.7 & 2 & 1.2 & 10 & 4.0 & 14 & 2.9 \\
\hline $19-29$ & 25 & 33.8 & 94 & 58.8 & 137 & 55.5 & 256 & 53.2 \\
\hline $30-39$ & 13 & 17.6 & 38 & 23.8 & 60 & 24.3 & 111 & 23.1 \\
\hline $40-49$ & 8 & 10.8 & 12 & 7.5 & 8 & 3.2 & 28 & 5.8 \\
\hline $50-59$ & 16 & 21.6 & 8 & 5.0 & 14 & 5.7 & 38 & 7.9 \\
\hline $60+$ & 10 & 13.5 & 6 & 3.8 & 18 & 7.3 & 34 & 7.1 \\
\hline$\chi^{2}$ & 44.718 & & & & & & & \\
\hline Sig. level & 0.000 & & & & & & & \\
\hline
\end{tabular}

Visitor segments also differ in respect of nationality $\left(\chi^{2}=40.550, p=0.004\right)$. It is noted that in order to simplify the comparison of visitor's nationality by clusters, nationalities which had 10 or fewer respondents were identified as "Other".

In general, British and Australians are the largest group of the total sample and also of the Opportunist and Passive Tourist segments (Table 5-12). However the number of British visitors ranks third in the group of Enthusiast (10.8\%), after Australian $(23 \%)$ and American (21.6\%). Obviously, Australians and Americans are more likely to have a personal connection and involvement with the Vietnam War. The U.S. and Australia were supporters of South Vietnam and their troops were directly involved in the war. In contrast, British and other nationalities (except for New Zealanders) were not involved directly in the Vietnam War. This could be the reason for Australians and Americans being dominant in the Enthusiast group (44.6\%). It is noted that despite having considerable historical connection with Vietnam, there is no Enthusiast French, compared to $2.5 \%$ of Opportunist and $2.4 \%$ of Passive Tourist. The reason may be because the French were involved in Vietnam much earlier (before 1954) and most of those involved may have passed away or be too old to travel or they could be more interested in sites such as Điện Biên Phủ instead.

The Opportunist segment has American as the third largest group (8.9\%), followed by Dutch $(7.5 \%)$ and Canadian (6.9\%). Nationality groups accounting for less than 5\% include Irish (4.4\%), New Zealander (3.8\%), and Japanese (3.1\%). Danish and German each makes up $2.5 \%$ of the cluster. Other nationalities comprise $19.4 \%$ of the Opportunist tourist. 
For the Passive Tourist, it is interesting that Dutch overtakes American in the position of third largest group (10.9\% compared to $9.3 \%)$. The number of Danish and German visitors represents $7.3 \%$ and $5.7 \%$ of this cluster respectively. Other nationalities accounting for less than $5 \%$ of the cluster include New Zealander (4.9\%), Canadian (4.5\%), Irish (3.2\%), and Japanese (1.2\%). Non-recorded nationality group corresponds to $21 \%$ of the Passive Tourist.

Table 5-12: Nationality of visitors by segments

\begin{tabular}{|c|c|c|c|c|c|c|c|c|}
\hline \multirow[t]{2}{*}{ Group } & \multicolumn{2}{|c|}{$\begin{array}{l}\text { Enthusiast } \\
(\mathrm{n}=74)\end{array}$} & \multicolumn{2}{|c|}{$\begin{array}{l}\text { Opportunist } \\
(\mathrm{n}=160)\end{array}$} & \multicolumn{2}{|c|}{$\begin{array}{c}\text { Passive Tourist } \\
(\mathrm{n}=247)\end{array}$} & \multicolumn{2}{|c|}{$\begin{array}{c}\text { Total } \\
(\mathrm{n}=481)\end{array}$} \\
\hline & $\mathrm{n}$ & $\%$ & $n$ & $\%$ & $\mathrm{n}$ & $\%$ & $\mathrm{n}$ & $\%$ \\
\hline British & 8 & 10.8 & 41 & 25.6 & 42 & 17.0 & 91 & 18.9 \\
\hline Australian & 17 & 23.0 & 25 & 15.6 & 37 & 15.0 & 79 & 16.4 \\
\hline American & 16 & 21.6 & 14 & 8.8 & 23 & 9.3 & 53 & 11 \\
\hline Dutch & 5 & 6.8 & 12 & 7.5 & 27 & 10.9 & 44 & 9.1 \\
\hline Danish & 6 & 8.1 & 4 & 2.5 & 18 & 7.3 & 28 & 5.8 \\
\hline Canadian & 1 & 1.4 & 11 & 6.9 & 11 & 4.5 & 23 & 4.8 \\
\hline German & 3 & 4.1 & 4 & 2.5 & 14 & 5.7 & 21 & 4.4 \\
\hline New Zealander & 2 & 2.7 & 6 & 3.8 & 12 & 4.9 & 20 & 4.2 \\
\hline Irish & 1 & 1.4 & 7 & 4.4 & 8 & 3.2 & 16 & 3.3 \\
\hline Japanese & 5 & 6.8 & 5 & 3.1 & 3 & 1.2 & 13 & 2.7 \\
\hline Other & 10 & 13.5 & 31 & 19.4 & 52 & 21.0 & 93 & 19.4 \\
\hline$\chi^{2}$ & 40.550 & & & & & & & \\
\hline Sig. level & 0.004 & & & & & & & \\
\hline
\end{tabular}

Interestingly, visitors show a significant difference in terms of personal connection $\left(\chi^{2}=13.979, p=0.001\right)$ as well as another connection with the Vietnam War $\left(\chi^{2}=28.855, p=0.000\right)$. As displayed in Table 5-13, Enthusiast visitors have more connection with the Vietnam War compared to those in other segments. Specifically, $16.2 \%$ of Enthusiasts have a personal connection and $30.1 \%$ are closely related to someone who had a personal connection with the Vietnam War. The Passive Tourist, however, appears to have the least connection, with only $4.1 \%$ having a personal connection and $8.7 \%$ having another connection with the Vietnam War. 
Chapter 5 - DMZ visitor segmentation on motivations

Table 5-13: Connection with the Vietnam War by visitor segments

\begin{tabular}{|c|c|c|c|c|c|c|c|c|}
\hline \multirow[t]{2}{*}{ Group } & \multicolumn{2}{|c|}{$\begin{array}{l}\text { Enthusiast } \\
\quad(\mathrm{n}=74)\end{array}$} & \multicolumn{2}{|c|}{$\begin{array}{l}\text { Opportunist } \\
(\mathrm{n}=160)\end{array}$} & \multicolumn{2}{|c|}{$\begin{array}{l}\text { Passive } \\
\text { Tourist } \\
(n=247)\end{array}$} & \multicolumn{2}{|c|}{$\begin{array}{c}\text { Total } \\
(\mathrm{n}=481)\end{array}$} \\
\hline & $\mathrm{n}$ & $\%$ & $\mathrm{n}$ & $\%$ & $\mathrm{n}$ & $\%$ & & \\
\hline $\begin{array}{l}\text { Personal connection } \\
\text { with the Vietnam War }\end{array}$ & 12 & 16.2 & 9 & 5.7 & 10 & 4.1 & 31 & 6.5 \\
\hline $\begin{array}{l}\text { No personal connection } \\
\text { with the Vietnam War }\end{array}$ & 62 & 83.8 & 148 & 94.3 & 235 & 95.9 & 445 & 93.5 \\
\hline$\chi^{2}$ & 13.979 & & & & & & & \\
\hline Sig. level & 0.001 & & & & & & & \\
\hline $\begin{array}{l}\text { Other connection with } \\
\text { the Vietnam War }\end{array}$ & 22 & 30.1 & 19 & 12.1 & 21 & 8.7 & 62 & 13.1 \\
\hline $\begin{array}{l}\text { No other connection } \\
\text { with the Vietnam War }\end{array}$ & 51 & 69.9 & 138 & 87.9 & 221 & 91.3 & 410 & 86.9 \\
\hline $\begin{array}{l}\chi^{2} \\
\text { Sig. level }\end{array}$ & $\begin{array}{r}28.855 \\
0.000\end{array}$ & & & & & & & \\
\hline
\end{tabular}

Conversely, there are no significant differences in terms of gender, educational level and military related associations' membership across clusters (Table 5-14). Overall, there are more males than females and the same pattern is found in all the three clusters. However, the difference between males and females for the Opportunist is higher than that of the other clusters $(18.8 \%$ compared to $2.8 \%$ of Enthusiast and $1.2 \%$ of Passive Tourist). The majority of respondents reported tertiary education as highest educational level: $41.9 \%$ of the Enthusiasts, $57.5 \%$ of the Opportunists and $58.3 \%$ of the Passive Tourists. In addition, most visitors are not members of any military related associations such as the Veteran Association, Military Association, and Armed Forces Association. Military related associations' membership holders account for a minor portion in all three clusters. However, it is noted that the Enthusiast has the highest percentage of membership holder (5.4\% compared to $1.9 \%$ of the Opportunist and $3.6 \%$ of the Passive Tourist).

To conclude, visitors to the DMZ include a relatively balanced proportion of males and females, they appear to be generally well-educated and not members of any military related associations. Nevertheless, there are significant differences across the three visitor segments on the other profile characteristics.

The Enthusiast visitors are more likely to be in the older age group. They are often of nationalities that were involved in the Vietnam War such as Australian and 
American. These visitors are also more likely to have connection with the Vietnam War than the other groups.

Table 5-14: Non-significant socio-demographic characteristics by visitor segments

\begin{tabular}{|c|c|c|c|c|c|c|c|c|}
\hline \multirow[t]{2}{*}{ Group } & \multicolumn{2}{|c|}{$\begin{array}{l}\text { Enthusiast } \\
\quad(n=74)\end{array}$} & \multicolumn{2}{|c|}{$\begin{array}{l}\text { Opportunist } \\
(\mathrm{n}=160)\end{array}$} & \multicolumn{2}{|c|}{$\begin{array}{l}\text { Passive } \\
\text { Tourist } \\
(n=247)\end{array}$} & \multicolumn{2}{|c|}{$\begin{array}{c}\text { Total } \\
(n=481)\end{array}$} \\
\hline & $\mathrm{n}$ & $\%$ & $\mathrm{n}$ & $\%$ & $\mathrm{n}$ & $\%$ & & \\
\hline \multicolumn{9}{|l|}{ Gender } \\
\hline Male & 38 & 51.4 & 95 & 59.4 & 125 & 50.6 & 258 & 53.6 \\
\hline Female & 36 & 48.6 & 65 & 40.6 & 122 & 49.4 & 223 & 46.4 \\
\hline \multicolumn{9}{|l|}{ Educational level } \\
\hline Secondary & 22 & 29.7 & 28 & 17.5 & 48 & 19.4 & 98 & 20.4 \\
\hline University/College & 31 & 41.9 & 92 & 57.5 & 144 & 58.3 & 267 & 55.5 \\
\hline Postgraduate & 20 & 27.0 & 34 & 21.2 & 45 & 18.2 & 99 & 20.6 \\
\hline Other & 1 & 1.4 & 6 & 3.8 & 10 & 4.0 & 17 & 3.5 \\
\hline \multicolumn{9}{|c|}{$\begin{array}{l}\text { Military related associations' } \\
\text { membership }\end{array}$} \\
\hline Non-membership holder & 70 & 94.6 & 157 & 98.1 & 238 & 96.4 & 465 & 96.7 \\
\hline Membership holder & 4 & 5.4 & 3 & 1.9 & 9 & 3.6 & 16 & 3.3 \\
\hline
\end{tabular}

The Opportunists include mostly young travellers, especially British and Australian. These visitors have less connection with the Vietnam War compared to the Enthusiast yet more connection than the Passive Tourist.

Similar to the Opportunist, the Passive Tourists are also in the younger age groups. However, this visitor segment includes a relatively more diverse range of nationalities compared to the other segments. Passive Tourists appear to have the least connection with the Vietnam War.

Thus far, the three visitor segments' socio-demography have been identified. However, the visitors' trip related characteristics are needed to better understand their typical travel patterns. Similar to the discussion of the total sample's general travel pattern, the visitors' Vietnam trip is described first before focusing on the $\mathrm{DMZ}$ aspect in particular.

\subsubsection{The Vietnam trip characteristics by clusters}

Table 5-15 demonstrates a summary of the visitor segments' Vietnam trip profiles. It shows that the three visitor segments are significantly different regarding time of visit (first time of repeat visit) to Vietnam and purpose of the trip but not in terms of 
the trip arrangement (package or independent) with $92.3 \%$ of all respondents not being on a package tour.

Table 5-15: Summary of the visitor segments' Vietnam trip profiles

\begin{tabular}{|lrrr|}
\hline Profile attribute & $\chi^{2}$ & df & $\begin{array}{r}\text { Sig. } \\
\text { level }\end{array}$ \\
\hline Time of visit to Vietnam & 9.015 & 2 & 0.011 \\
Type of trip & 4.195 & 2 & 0.123 \\
Purpose of trip & 26.613 & 8 & 0.001 \\
\hline
\end{tabular}

Overall, the majority of visitors are on their first visit to Vietnam. However, the Enthusiast's repeat visits are higher than that of the Opportunist and Passive Tourist (23\% compared to $15 \%$ and $13.5 \%$ ). As discussed earlier, visitors in this group have more connection with Vietnam, which may be the reason for their return to the country. The Passive Tourist, in contrast, has the smallest percentage of repeat visitors.

In addition, visitors across the three segments differ in purpose of visiting Vietnam $\left(\chi^{2}=26.613, p=0.001\right)$. Generally, the majority of participants visited Vietnam for holiday yet the percentage of Opportunist (87.5\%) and Passive Tourist $(88.5 \%)$ holiday takers outnumber that of the Enthusiast (73\%). In contrast, the number of Enthusiast visitors indicated education as their main purpose of Vietnam is $12.2 \%$, about four times that of Opportunist (3.1\%) and more than double that of Passive Tourist (4.9\%). This cluster also has a highest percentage of visitors on business trip (6.8\% compared to $1.2 \%$ of cluster 2 and $0.4 \%$ of cluster 3$)$. The Opportunist, however, has the highest portion of VFR tourists (3.8\%). In sum, most visitors were travelling on their holiday. However, Enthusiasts are more likely to be on Business and Education trips than the others. While the Opportunists are more likely to travel for VFR, the Passive Tourists tend to travel on holiday. 
Table 5-16: The visitors' Vietnam trip characteristics by clusters

\begin{tabular}{|c|c|c|c|c|c|c|c|c|}
\hline \multirow[t]{2}{*}{ Group } & \multicolumn{2}{|c|}{$\begin{array}{l}\text { Enthusiast } \\
(\mathrm{n}=74)\end{array}$} & \multicolumn{2}{|c|}{$\begin{array}{l}\text { Opportunist } \\
(\mathrm{n}=160)\end{array}$} & \multicolumn{2}{|c|}{$\begin{array}{c}\text { Passive Tourist } \\
(\mathrm{n}=247)\end{array}$} & \multicolumn{2}{|c|}{$\begin{array}{c}\text { Total } \\
(\mathrm{n}=481)\end{array}$} \\
\hline & $\mathrm{n}$ & $\%$ & $\mathrm{n}$ & $\%$ & $\mathrm{n}$ & $\%$ & $\mathrm{n}$ & $\%$ \\
\hline \multicolumn{9}{|l|}{ Time of visit } \\
\hline First visit & 57 & 77.0 & 136 & 85.0 & 223 & 90.3 & 416 & 86.5 \\
\hline Repeat visit & 17 & 23.0 & 24 & 15.0 & 24 & 9.7 & 65 & 13.5 \\
\hline$\chi^{2}$ & 9.015 & & & & & & & \\
\hline Sig. level & 0.011 & & & & & & & \\
\hline \multicolumn{9}{|l|}{ Type of trip } \\
\hline On package tour & 10 & 13.5 & 11 & 6.9 & 16 & 6.5 & 37 & 7.7 \\
\hline Not on package tour & 64 & 86.5 & 149 & 93.1 & 231 & 93.5 & 444 & 92.3 \\
\hline$\chi^{2}$ & 4.195 & & & & & & & \\
\hline Sig. level & 0.123 & & & & & & & \\
\hline \multicolumn{9}{|l|}{ Purpose of trip } \\
\hline VFR & 2 & 2.7 & 6 & 3.8 & 3 & 1.2 & 11 & 2.3 \\
\hline Business & 5 & 6.8 & 2 & 1.2 & 1 & 0.4 & 8 & 1.7 \\
\hline Holiday & 54 & 73.0 & 140 & 87.5 & 218 & 88.3 & 412 & 85.7 \\
\hline Education & 9 & 12.2 & 5 & 3.1 & 12 & 4.9 & 26 & 5.4 \\
\hline Other & 4 & 5.4 & 7 & 4.4 & 13 & 5.3 & 24 & 5.0 \\
\hline$\chi^{2}$ & 26.613 & & & & & & & \\
\hline Sig. level & 0.001 & & & & & & & \\
\hline
\end{tabular}

The differences in main purpose for visiting Vietnam across clusters may explain the dissimilarities in terms of attributes of Vietnam that attracted tourists. As displayed in Table 5-17, History (62.5\%) ranks as the most important attribute for the Enthusiast, followed by Culture (56.9\%) and Landscape (55.6\%). For the Opportunist, the order is Culture (65.6\%), Landscape (65\%) and Price (58.1\%). Likewise, in the case of Passive Tourist, Culture (66.4\%), Landscape (66\%) and History $(63.2 \%)$ are the most important attributes. It can be seen that while History is most important for the Enthusiast, it does not play a significant role for the Opportunist (fourth most important). Conversely, while Price was rated as the fourth most important attribute for the Enthusiast and Passive Tourist, it was better evaluated by the Opportunist (third most important). Ratings of the remaining attributes are similar for the three clusters (e.g. Battlefield sites in Vietnam ranks the sixth most important attribute across all three clusters). 
Chapter 5 - DMZ visitor segmentation on motivations

Table 5-17: Most important attributes of Vietnam by visitor segments

\begin{tabular}{|lrrrrrrrr|}
\hline Group & \multicolumn{2}{c}{$\begin{array}{c}\text { Enthusiast } \\
(\mathrm{n}=74)\end{array}$} & \multicolumn{2}{c}{$\begin{array}{c}\text { Opportunist } \\
(\mathrm{n}=160)\end{array}$} & \multicolumn{2}{c|}{$\begin{array}{c}\text { Passive Tourist } \\
(\mathrm{n}=247)\end{array}$} & \multicolumn{2}{c|}{$\begin{array}{c}\text { Total } \\
(\mathrm{n}=481)\end{array}$} \\
\cline { 2 - 11 } & $\mathrm{n}$ & $\%$ & $\mathrm{n}$ & $\%$ & $\mathrm{n}$ & $\%$ & $\mathrm{n}$ & $\%$ \\
\hline Culture & 41 & 56.9 & 105 & 65.6 & 164 & 66.4 & 310 & 64.7 \\
Landscape & 40 & 55.6 & 104 & 65.0 & 163 & 66.0 & 307 & 64.1 \\
History & 45 & 62.5 & 88 & 55.0 & 156 & 63.2 & 289 & 60.3 \\
Price & 35 & 48.6 & 93 & 58.1 & 110 & 44.5 & 238 & 49.7 \\
Climate & 8 & 11.1 & 19 & 11.9 & 33 & 13.4 & 60 & 12.5 \\
Battlefield & 10 & 13.9 & 19 & 11.9 & 30 & 12.1 & 59 & 12.3 \\
Local people's attitude & 13 & 18.1 & 13 & 8.1 & 15 & 6.1 & 41 & 8.6 \\
towards tourists & & & & & & & & \\
Outdoor activities & 5 & 6.9 & 11 & 6.9 & 13 & 5.3 & 29 & 6.1 \\
Accessibility & 0 & 0.0 & 7 & 4.4 & 9 & 3.6 & 16 & 3.3 \\
Tourism infrastructure & 5 & 6.9 & 1 & 0.6 & 7 & 2.8 & 13 & 2.7 \\
and facilities & & & & & & & & \\
Safety & 0 & 0 & 4 & 2.5 & 6 & 2.4 & 10 & 2.1 \\
Service quality & 2 & 2.8 & 0 & 0 & 1 & 0.4 & 3 & 0.6 \\
Other & 5 & 6.9 & 8 & 5 & 16 & 6.5 & 29 & 6.1 \\
\hline
\end{tabular}

In general, except for the trip arrangement in which most visitors were not travelling on package tour, the three visitor segments are significantly different regarding the trip related variables. Specifically, the Enthusiast visitors are more likely to visit Vietnam more than once compared to the other two groups. They tend to visit Vietnam for several purposes and more likely to travel on education and business purposes than the Opportunist and the Passive Tourist. The Vietnamese History is the outstanding factor that attracted the Enthusiast to visit Vietnam.

Although less than the Enthusiast, the Opportunist is more likely to visit Vietnam more than once when compared to the Passive Tourist. Apart from holiday purposes, Opportunists tend to be on VFR trips to Vietnam. For the Opportunist, Culture and Landscape are the most important attributes of Vietnam. However, in opposite to the Enthusiast and Passive Tourist, Price plays a significant role for the Opportunist while History was considered less important.

In contrast to the Enthusiast, the Passive Tourists are less likely to have visited Vietnam more than once. They are often tourists on holiday trip, who were attracted to Vietnam mainly for the Culture and Landscape.

\subsubsection{Description of the DMZ trip characteristics by clusters}

Despite having considerable differences regarding the Vietnam trip as a whole, the three visitor segments appear to share more similarities in their trip to the DMZ as demonstrated in Table 5-18. In general, the visitor clusters do not differ significantly 
regarding the number of visits to the $\mathrm{DMZ}$, their travel companions on the trip to the $\mathrm{DMZ}$ and the DMZ trip duration. Most visitors were in their first visit to the DMZ. They tend to travel with some companions and spend about one day exploring the DMZ. However, statistical differences were found between visitor segments in terms of the trip arrangement. Passive Tourists are more likely to travel on group bus tour while Enthusiasts tend to prefer the private tour trip than the others.

Table 5-18: Summary of the visitor segments' DMZ trip profiles

\begin{tabular}{|lrrr|}
\hline Profile attribute & $\chi^{2}$ & df & $\begin{array}{r}\text { Sig. } \\
\text { level }\end{array}$ \\
\hline Time of visit to the DMZ & 2.688 & 2 & 0.261 \\
Trip arrangement & 18.304 & 8 & 0.019 \\
Travel companion & 11.602 & 8 & 0.170 \\
Trip duration & 3.277 & 4 & 0.513 \\
\hline
\end{tabular}

Table 5-19 shows that group bus tour is the single largest travel arrangement for all the three clusters. However, while this type of arrangement accounts for over half of the Enthusiasts, these visitors were more likely to make other forms of travel arrangements than the other segments. Specifically, the number of Enthusiasts (20.3\%) travelling on private tours to the DMZ were double the Passive Tourists $(10.1 \%)$. In addition, this type of visitors had the highest percentage of respondents visiting the $\mathrm{DMZ}$ as a part of their package tour to Vietnam (6.8\% compared to $5.6 \%$ of Opportunist and $1.6 \%$ of Passive Tourist). Again, this is related to the earlier discussion that Passive Tourists are more likely to be older, thus they may prefer private tours for comfort and convenience. The Passive Tourist, on the contrary, has the highest percentage of visitors following a group bus tour to the DMZ $(74.5 \%$ compared to $54.1 \%$ of Enthusiast and $65.6 \%$ of Opportunist). They are also more likely to organise the trip independently ( $14.9 \%$ compared to $8.8 \%$ of cluster 2 and $10.5 \%$ of cluster 3 ). Interestingly, while being closer to the Passive Tourists in most respects, the Opportunists were more similar to the Enthusiasts than regarding the DMZ trip arrangement. 
Table 5-19: The DMZ trip travel arrangement by visitor segments

\begin{tabular}{|lrrrrrrrr|}
\hline Group & $\begin{array}{c}\text { Enthusiast } \\
(\mathrm{n}=74)\end{array}$ & $\begin{array}{c}\text { Opportunist } \\
(\mathrm{n}=160)\end{array}$ & \multicolumn{2}{c}{$\begin{array}{c}\text { Passive } \\
\text { Tourist } \\
(\mathrm{n}=247)\end{array}$} & $\begin{array}{c}\text { Total } \\
(\mathrm{n}=481)\end{array}$ \\
\cline { 2 - 12 } & $\mathrm{n}$ & $\%$ & $\mathrm{n}$ & $\%$ & $\mathrm{n}$ & $\%$ & $\mathrm{n}$ & $\%$ \\
\hline As part of a package & 5 & 6.8 & 9 & 5.6 & 4 & 1.6 & 18 & 3.7 \\
tour to Vietnam & & & & & & & & \\
Self-organised & 11 & 14.9 & 14 & 8.8 & 26 & 10.5 & 51 & 10.6 \\
Group bus tour & 40 & 54.1 & 105 & 65.6 & 184 & 74.5 & 329 & 68.4 \\
Private tour & 15 & 20.3 & 28 & 17.5 & 25 & 10.1 & 68 & 14.1 \\
Other & 3 & 4.1 & 4 & 2.5 & 8 & 3.2 & 15 & 3.1 \\
\hline$\chi^{2}$ & 18.304 & & & & & & & \\
Sig. level & 0.019 & & & & & & & \\
\hline
\end{tabular}

Conversely, there are no significant differences among visitors in the three segments regarding the number of previous visits to the DMZ, travel companions, and trip duration (Table 5-20). The majority of visitors are on their first trip to the DMZ, which includes $93.2 \%$ of Enthusiast visitors, $96.9 \%$ of the Opportunist, and $97.2 \%$ of the Passive Tourist. About one third of respondents in each cluster travelled with friends $(28.4 \%$ of the Enthusiast, $36.9 \%$ of the Opportunist and $36 \%$ of the Passive Tourist). There is also another third of each cluster who had their partner as company $(25.7 \%, 29.4 \%$, and $34.4 \%$ respectively). Nonetheless, the number of Enthusiasts travelling on their own is higher than that of the other visitors $(29.7 \%$ compared to $19.4 \%$ of Opportunist and $16.6 \%$ of Passive Tourist). Most of visitors explored the DMZ for one day (85.1\% of Enthusiast, $81.9 \%$ of Opportunist and $81 \%$ of Passive Tourist).

Table 5-20: Time of visit, travel companion, and DMZ trip duration by segments

\begin{tabular}{|lrrrrrrrr|}
\hline Group & $\begin{array}{c}\text { Enthusiast } \\
(\mathrm{n}=74)\end{array}$ & $\begin{array}{c}\text { Opportunist } \\
(\mathrm{n}=160)\end{array}$ & $\begin{array}{c}\text { Passive } \\
\text { Tourist } \\
(\mathrm{n}=247)\end{array}$ & $\begin{array}{c}\text { Total } \\
(\mathrm{n}=481)\end{array}$ \\
\cline { 2 - 10 } & $\mathrm{n}$ & $\%$ & $\mathrm{n}$ & $\%$ & $\mathrm{n}$ & $\%$ & $\mathrm{n}$ & $\%$ \\
\hline Time of visit & 69 & 93.2 & 155 & 96.9 & 240 & 97.2 & 464 & 96.5 \\
First visit & 5 & 6.8 & 5 & 3.1 & 7 & 2.8 & 17 & 3.5 \\
Repeat visit & & & & & & & & \\
Travel companion & 22 & 29.7 & 31 & 19.4 & 41 & 16.6 & 94 & 19.5 \\
By oneself & 21 & 28.4 & 59 & 36.9 & 89 & 36.0 & 169 & 35.1 \\
Friends & 19 & 25.7 & 47 & 29.4 & 85 & 34.4 & 151 & 31.4 \\
Partner & 10 & 13.5 & 21 & 13.1 & 23 & 9.3 & 54 & 11.2 \\
Family and relatives & 2 & 2.7 & 2 & 1.2 & 9 & 3.6 & 13 & 2.7 \\
Other & & & & & & & & \\
Trip duration & 9 & 12.2 & 24 & 15.0 & 44 & 17.8 & 77 & 16.0 \\
Half day & 63 & 85.1 & 131 & 81.9 & 200 & 81.0 & 394 & 81.9 \\
One day & 2 & 2.7 & 5 & 3.1 & 3 & 1.2 & 10 & 2.1 \\
Two days & & & & & & & \\
\hline
\end{tabular}




\subsection{Conclusion}

This chapter has described the procedure for defining the visitor segments based on their motivations for visiting the DMZ. Five motivation factors identified from the factor analysis are: Personal involvement, Interest in war related sites and exhibition, Education and Exploration, Novelty seeking, and Location and Convenience. Based on these factors, cluster analysis was performed, resulting in three visitor segments: the Battlefield Tourism Enthusiast, the Opportunist and the Passive Tourist. The Enthusiast tourists visited the DMZ for several reasons, similarly, the Opportunist placed high emphasis on the location of the site and the convenience for the trip. The Passive Tourist, however, did not have any important reasons for visiting the DMZ. Rather, it was just among other tourist attractions during their trip.

This chapter also presented the similarities and differences regarding sociodemographic and trip related characteristics of the three visitor segments. Overall, the Enthusiast visitors appear to be the most different compared to the others while the Opportunist and Passive Tourist tend to share more similarities. However, are their travel decision-making and behaviour distinctive from each other? The following chapter provides the information to address this question. 


\section{Chapter 6: DMZ VISITORS' DECISION- MAKING AND INTEREST IN BATTLEFIELD TOURISM}

\subsection{Introduction}

This chapter analyses the tourists' decision to visit the DMZ based on several factors. It aims to address the third objective of this study, which is to determine the importance of the DMZ and other Vietnamese battlefield sites in tourists' decision to visit Vietnam. Specifically, it discusses the point of time when tourists make the decision to visit the DMZ and their level of knowledge about the site. It also reports on visitors' level of participation in battlefield tourism by identifying the number of battlefield sites they visited and were going to visit in the DMZ and in Vietnam, as well as other battlefields sites in the world they had visited over the last two years. The data about visitors' level of interest in battlefield tourism and the importance of battlefield sites in their decision to travel to Vietnam are subsequently analysed. A description of the visitor's level of satisfaction in their DMZ tour, featuring their most interesting experience and their suggestions for things to be improved is placed at the end of the chapter.

\subsection{Visitors' decision-making stages}

Information about how far the decision was made in advance is critical in understanding the tourist's decision-making procedure (Fesenmaier \& Jeng, 2000). It shows the level of visitors' pre-planning for their trip, which consequently give insights into their behaviour and motivation for conducting particular activities.

In this study, the point of time when the respondents made the decision to visit the DMZ was divided into four stages ranging from the furthest to the closest point of time prior to visiting the area (refer to Figure 6-1): (1) before the tourists came to Vietnam, (2) during their trip in Vietnam but before reaching Huế/Quảng Trị/Quảng Bình - the cities where the DMZ tour is popular, (3) during their stay in Huế/Quảng Trị/Quảng Bình and (4) on their way to somewhere else when they decide to stop by to visit the DMZ. The advantages of having theses stages are twofold. First, counting the number of days in advance may show that visitors staying longer have made their decision earlier than those planning a shorter stay. However, this may lead to the misinterpretation that the DMZ was not important for shorter stay visitors when actually there are cases where the visitors came to Vietnam on a short stay primarily 
to visit the DMZ and other battlefield sites. Thus, even though it was a short trip, the DMZ played a critical role. Second, categorising the visitor's stage of travelling according to where they were staying provides important information about how external factors during the visitors' trip can affect their choice of destinations and activities (Fesenmaier \& Jeng, 2000).

As illustrated in Table 6-1, most respondents decided to visit the DMZ in the early stage of their trip, which suggests the significant position of the DMZ in the tourists' travel plans. In particular, $39.7 \%$ of respondents decided to visit the DMZ before their trip to Vietnam and $26.4 \%$ made up their mind before arriving the area. Conversely, one third of the respondents $(31.2 \%)$ only decided to visit the DMZ during their stay in the area, while visiting the DMZ

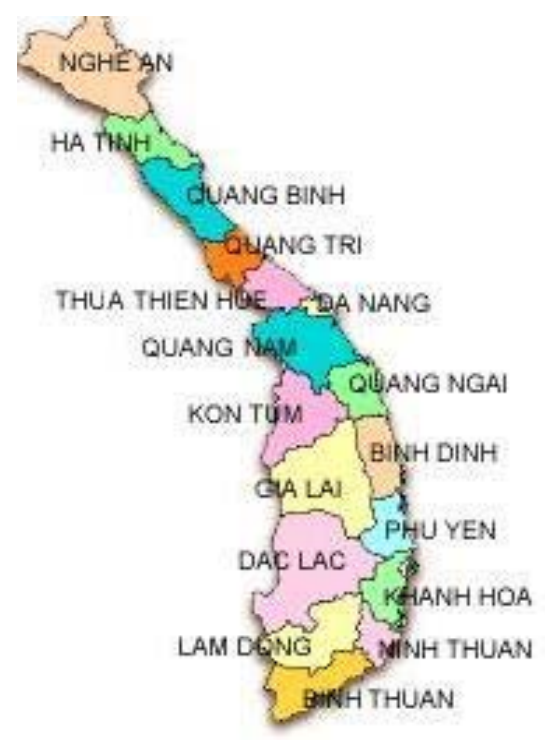

Figure 6-1: Map of Central Vietnam Source: http://www.vnn.vn is a spontaneous decision for only a small number of visitors $(2.7 \%)$ during their trip to somewhere else.

Comparing between the three segments, it can be seen that there are significant differences regarding the point of time when the decision to visit the DMZ is made $\left(\chi^{2}=18.515, p=0.005\right)$. As shown in Table 6-1, Enthusiasts tend to make the decision before their trip to Vietnam (58.1\%). The Opportunists are more likely to make the decision closer to the time they visit the site. Specifically, the Opportunists have the lowest percentage of visitors making the decision in the first stage $(33.8 \%)$ yet the highest in the two latest stages $(34.4 \%$ made the decision while in the area and 5\% decided spontaneously on the way to somewhere else). The Passive Tourists seem to be less different regarding their decision-making point of time as displayed by the relatively similar percentage of visitors making decision at the first stage $(38.1 \%)$, second stage (28.7\%) and third stage (32\%). Nevertheless, the proportion of visitors in this group making the decision at the latest stage is smallest $(1.2 \%$ compared to $2.7 \%$ of cluster 1 , and $5 \%$ of cluster 2 ). In short, the Enthusiasts are likely to make 
the decision before their trip to Vietnam, the Opportunists decide closer to the time they visit the site, and the Passive Tourists make their decision during the trip. This implies that visiting the $\mathrm{DMZ}$ appears to be more important for the Enthusiast when compared to the Opportunist and the Passive Tourist. Conversely, the Opportunists' decision-making point of time reflects their emphasis on location of the sites (i.e. convenience for the trip). The Passive Tourists, however, do not show any particular consistency: these tourists tended to make their decision evenly between stages.

Table 6-1: Stage of decision-making by segments

\begin{tabular}{|lrrrrrrrr|}
\hline Group & \multicolumn{2}{c}{$\begin{array}{c}\text { Enthusiast } \\
(\mathrm{n}=74)\end{array}$} & \multicolumn{2}{c}{$\begin{array}{c}\text { Opportunist } \\
(\mathrm{n}=160)\end{array}$} & $\begin{array}{c}\text { Passive Tourist } \\
(\mathrm{n}=247)\end{array}$ & \multicolumn{2}{c|}{$\begin{array}{c}\text { Total } \\
(\mathrm{n}=481)\end{array}$} \\
\cline { 2 - 10 } & $\mathrm{n}$ & $\%$ & $\mathrm{n}$ & $\%$ & $\mathrm{n}$ & $\%$ & $\mathrm{n}$ & $\%$ \\
\hline $\begin{array}{l}\text { Before the trip to } \\
\text { Vietnam }\end{array}$ & 43 & 58.1 & 54 & 33.8 & 94 & 38.1 & 191 & 39.7 \\
$\begin{array}{l}\text { Before the trip to } \\
\text { Huế/QT/QB }\end{array}$ & 13 & 17.6 & 43 & 26.9 & 71 & 28.7 & 127 & 26.4 \\
$\begin{array}{l}\text { During the trip in } \\
\text { Huế/QT/QB } \\
\text { On the way to } \\
\text { somewhere else }\end{array}$ & 16 & 21.6 & 55 & 34.4 & 79 & 32.0 & 150 & 31.2 \\
\hline $\begin{array}{l}\chi^{2} \\
\text { Sig. level }\end{array}$ & 2 & 2.7 & 8 & 5.0 & 3 & 1.2 & 13 & 2.7 \\
\hline
\end{tabular}

\subsection{Level of knowledge of the DMZ by clusters}

The previous section showed that the majority of respondents made their decisions to visit the DMZ prior to their trip. This may help to explain the high rate of awareness of the DMZ among the respondents. As shown in Table 6-2, 67.2\% of visitors were aware of the existence of the DMZ before their trip to Vietnam. However, there are significant differences between the three visitor segments $\left(\chi^{2}=8.010, p=0.018\right)$. The Enthusiasts appear to be more informed about the DMZ than the other visitors. This group has a great number of visitors being aware of the DMZ before their visit to the site $(81.1 \%)$, almost $20 \%$ higher than that of the Opportunist and Passive Tourist (66.2\% and 63.6\% respectively). Together with the fact that Enthusiast visitors tend to make the decision to visit the DMZ earlier than the other two groups, the high level of awareness suggests that the Enthusiasts may be more interested in visiting the DMZ. 
Chapter 6-DMZ visitors' decision-making and interest in battlefield tourism

Table 6-2: Awareness of the DMZ by visitor segments

\begin{tabular}{|c|c|c|c|c|c|c|c|c|}
\hline \multirow[t]{2}{*}{ Group } & \multicolumn{2}{|c|}{$\begin{array}{l}\text { Enthusiast } \\
(\mathrm{n}=74)\end{array}$} & \multicolumn{2}{|c|}{$\begin{array}{l}\text { Opportunist } \\
(\mathrm{n}=160)\end{array}$} & \multicolumn{2}{|c|}{$\begin{array}{l}\text { Passive Tourist } \\
(\mathrm{n}=247)\end{array}$} & \multicolumn{2}{|c|}{$\begin{array}{c}\text { Total } \\
(n=481)\end{array}$} \\
\hline & $\mathrm{n}$ & $\%$ & $\mathrm{n}$ & $\%$ & $\mathrm{n}$ & $\%$ & $\mathrm{n}$ & $\%$ \\
\hline $\begin{array}{l}\text { Aware of the } \\
\text { DMZ }\end{array}$ & 60 & 81.1 & 106 & 66.2 & 157 & 63.6 & 323 & 67.2 \\
\hline $\begin{array}{l}\text { Unaware of } \\
\text { the DMZ }\end{array}$ & 14 & 18.9 & 54 & 33.8 & 90 & 36.4 & 158 & 32.8 \\
\hline $\begin{array}{l}\chi^{2} \\
\text { Sig. level }\end{array}$ & $\begin{array}{l}8.010 \\
0.018\end{array}$ & & & & & & & \\
\hline
\end{tabular}

Although a great number of survey participants had heard of the DMZ before their trip, this may include those who only have vague knowledge and those who know a lot about the site. Further understanding of the tourists' knowledge of the DMZ is thus critical. Therefore, visitors being aware of the DMZ (323 respondents) were asked to rate their knowledge of the DMZ on a 5-point Likert scale. Level 1 indicates minimal knowledge and level 5 represents a very good knowledge, with corresponding values representing levels in between.

Table 6-3 shows that in general, respondents have a relatively modest knowledge of the DMZ before visiting the site (average score of 2.3). In fact, there are few tourists in the very good knowledge level. Specifically, while $31.6 \%$ of visitors had a level 1 knowledge, the number goes down to $30.3 \%$ at level $2,21.4 \%$ at level $3,12.1 \%$ at level 4 , and dropped to $4.6 \%$ at level 5 . Although the measurement is subjective, it contributes to understanding how interested the visitors are in learning of the DMZ and how familiar they are with the place.

Table 6-3: Respondents' knowledge of the DMZ

\begin{tabular}{|lrr|lr|}
\hline Level of DMZ knowledge & $\begin{array}{c}\text { No. of } \\
\text { respondents }\end{array}$ & $\begin{array}{c}\% \\
(n=323)\end{array}$ & Measure & Value \\
\hline Level 1: Minimal knowledge & 102 & 31.6 & Mean & 2.3 \\
Level 2 & 98 & 30.3 & Median & 2 \\
Level 3 & 69 & 21.4 & Mode & 1 \\
Level 4 & 39 & 12.1 & SD & 1.159 \\
Level 5: Very good & 15 & 4.6 & & \\
\hline
\end{tabular}

An examination of the relationship between age and knowledge of the DMZ shows that these two variables are strongly related as displayed in Table 6-4. Since the number of respondents aged 18 and below is negligible (9), this group is excluded from further analysis. Comparing between age groups (from 19 years old), it can be seen that the older the respondents, the higher their knowledge of the DMZ. In 
particular, respondents in their twenties reported the lowest level of knowledge $(M=1.94)$, followed by the 30-30 age group $(M=2.29)$. Respondents in their forties and fifties indicated an average score of 2.64 and 2.64 respectively. The oldest group of respondents $(60+)$ showed the highest level of DMZ knowledge $(\mathrm{M}=3.06)$. This can be related to the time of the Vietnam War: respondents who are now in the age of 30-39 were newly born during the War and those aged 19-29 were born after the War ended. Therefore, these respondents may not have given much attention to the War. The fifties and sixties plus, however, were adults during the period of the War. For these respondents, whether they had a connection with the War or not, most of them were surrounded by the media reporting on the War.

Table 6-4: Respondents' knowledge of the DMZ across age groups

\begin{tabular}{|lrrr|}
\hline Age group & $\mathrm{N}$ & Mean & SD \\
\hline 18 and below & 9 & 2.78 & 1.394 \\
$19-29$ & 159 & 1.94 & 0.966 \\
$30-39$ & 75 & 2.29 & 1.100 \\
$40-49$ & 22 & 2.64 & 1.432 \\
$50-59$ & 34 & 2.62 & 1.303 \\
$60+$ & 31 & 3.06 & 1.209 \\
\hline$F$ & 7.636 & & \\
Sig. level & 0.000 & & \\
\hline
\end{tabular}

However, it should be emphasised again that the knowledge measurement above is subjective as it was self-measured. Thus it is critical to take into account other information to better justify the visitors' knowledge level of the DMZ. For this purpose, respondents were asked to indicate the main aspects (not a whole detailed description) of the DMZ they were aware of. This open-ended question did not aim to test the level of respondents' knowledge. Rather, it seeks to determine if the respondents had accurate and reasonable information regarding the DMZ.

As displayed in Table 6-5, the most well-known aspect of the DMZ was its role as the border between North and South Vietnam during the Vietnam War, which was indicated by $34.4 \%$ of the total sample, followed closely by "the tunnels" $(31.8 \%)$. "The tunnels" mentioned here refers to the tunnel system in the area in general and the Vịnh Mốc Tunnels in particular. Respondents had also heard of the DMZ as a major battlefield of the Vietnam War (13\%). Some visitors had general knowledge of the Vietnam War $(7.5 \%)$, which provided them with some information about the DMZ. In addition, a small number of visitors indicated that they knew about the 
history of the DMZ (2.6\%) or its importance in the Vietnam War (4.0\%). The rest of the answers given provided only vague information of the DMZ such as "it was a war related site" (2.9\%), "there was Agent Orange, bombings, spraying, and landmines in the area" $(4.6 \%)$ or "it has some historical value" $(2.6 \%)$. Overall, no respondent gave any inaccurate information. Although the answers were quite diversified, most of them showed basic information about the DMZ.

Table 6-5: The main aspects of the DMZ known by respondents

\begin{tabular}{|c|c|c|c|}
\hline & $\begin{array}{l}\text { No. of } \\
\text { responses }\end{array}$ & $\begin{array}{l}\% \text { of } \\
\text { response } \\
\mathrm{s} \\
(\mathrm{n}=411)\end{array}$ & $\begin{array}{l}\% \text { of } \\
\text { cases } \\
(n=345 \\
)\end{array}$ \\
\hline Border area between North and South Vietnam & 119 & 29.0 & 34.4 \\
\hline Tunnels/Vịnh Mốc Tunnels & 110 & 26.8 & 31.8 \\
\hline Major battlefield & 45 & 10.9 & 13.0 \\
\hline General knowledge of the war & 26 & 6.3 & 7.5 \\
\hline Agent Orange, spraying, bombing and landmines & 16 & 3.9 & 4.6 \\
\hline Khe Sanh & 16 & 3.9 & 4.6 \\
\hline Its importance in the Vietnam War & 14 & 3.4 & 4.0 \\
\hline Military bases & 12 & 2.9 & 3.5 \\
\hline War related & 10 & 2.4 & 2.9 \\
\hline Historical value & 9 & 2.2 & 2.6 \\
\hline History of the DMZ & 9 & 2.2 & 2.6 \\
\hline Ho Chi Minh Trail & 6 & 1.5 & 1.7 \\
\hline Other & 19 & 4.6 & 5.5 \\
\hline
\end{tabular}

An examination of the level of knowledge of the DMZ between visitor segments shows that the three segments are significantly different $(F=6.800, p=0.001)$. Table 6-6 depicts the mean comparison between the three visitor segments. As can be seen, Enthusiast visitors indicated the highest level of knowledge of the DMZ (M=2.73), followed by the Passive Tourist $(\mathrm{M}=2.22)$ and the Opportunist $(\mathrm{M}=2.07)$. This relates to the previous discussion in which Enthusiasts were found to be more aware of the DMZ than the others. Despite having a higher proportion of visitors being aware of the DMZ than the Passive Tourists (Table 6-2), the Opportunists appear to have relatively lower level knowledge of the DMZ. However, since this remains a subjective self-measurement, further information is needed to better understand the visitors' knowledge of the DMZ, among which the information search provides a useful hint. 
Chapter 6-DMZ visitors' decision-making and interest in battlefield tourism

Table 6-6: Level of knowledge of the DMZ by visitor segments

\begin{tabular}{|lrrrrrr|}
\hline & $\begin{array}{c}\text { Enthusiast } \\
(\mathrm{n}=74)\end{array}$ & $\begin{array}{c}\text { Opportunist } \\
(\mathrm{n}=160)\end{array}$ & $\begin{array}{c}\text { Passive } \\
\text { Tourist } \\
(\mathrm{n}=247)\end{array}$ & $\begin{array}{c}\text { Total } \\
(\mathrm{n}=481)\end{array}$ & $F$ & $\begin{array}{c}\text { Sig. } \\
\text { level }\end{array}$ \\
\hline Mean & 2.73 & 2.07 & 2.22 & 2.26 & 6.800 & 0.001 \\
SD & 1.287 & 1.068 & 1.127 & 1.159 & & \\
\hline
\end{tabular}

\subsection{Information search}

Information sources suggest the time spent, financial cost and effort required by tourists (Gursoy \& McCleary, 2004), which consequently contributes to better understanding tourists' interest in a particular destination or activity. In this study, respondents were asked to select the three most important information sources for the DMZ from a list of 16 items. Table 6-7 shows that visitors used a wide range of sources to search for information about the DMZ.

As displayed in Table 6-7, travel guidebooks were found to be the dominant source of information about the DMZ, indicated by $66.6 \%$ of the tourists, a much higher frequency than the remaining channels. This may be because a majority of the respondents are independent travellers, and travel guidebooks are likely to be one of their must-have companions. Furthermore, travel guidebooks often provide a short description of the sites, mostly including the easy-to-remember facts and figures, thus they encourage tourists to read and remember basic information. The second most important information source for the respondents is movies about the War (30.4\%). Although movies are often set on a background of a reality, they are generally fictionalised, thus creating more interest for the audience. It can be seen that travel guidebooks and movies are the most convenient source of information and require the least amount of effort from travellers. These findings are similar to Alneng (2002) who found that the first information source for tourists about Vietnam is Hollywood movies about the Vietnam War with the Lonely Planet guidebook being second. These top two information sources may explain the respondents' general and basic knowledge of the DMZ.

Conversely, the next most important sources tend to provide more formal information, such as documentaries about the Vietnam War (25.9\%), books (24.4\%), the internet (19.6\%) and school education (17.7\%). Obviously, these sources require more effort from visitors to retrieve the information they need, which implies that the visitors have a more serious interest in knowing more about the Vietnam War. 
Word-of-mouth also appears to be a crucial information source, including other travellers $(21.1 \%)$, friends $(15.7 \%)$, family and relatives $(11.9 \%)$. Again, this may due to the fact that most of respondents were travelling independently. Therefore, they are more likely to be influenced by other travellers during the trip.

The last group of information sources includes travel related organisations, such as local travel agents $(10.6 \%)$, visitor centres $(7.1 \%)$, accommodation providers $(4.6 \%)$, and transportation providers (4.7\%). Newspapers and magazines, and travel agents in the tourists' home countries appear to be the least important sources $(4.7 \%$ and $1.7 \%$ respectively).

Table 6-7: Information sources for the DMZ by visitor segments

\begin{tabular}{|c|c|c|c|c|c|c|c|c|}
\hline \multirow{2}{*}{ Sources } & \multicolumn{2}{|c|}{$\begin{array}{c}\text { Enthusiast } \\
\quad(n=74)\end{array}$} & \multicolumn{2}{|c|}{$\begin{array}{l}\text { Opportunist } \\
(\mathrm{n}=160)\end{array}$} & \multicolumn{2}{|c|}{$\begin{array}{l}\text { Passive Tourist } \\
\qquad(\mathrm{n}=247)\end{array}$} & \multicolumn{2}{|c|}{$\begin{array}{c}\text { Total } \\
(\mathrm{n}=481)\end{array}$} \\
\hline & $\mathrm{n}$ & $\%$ & $\mathrm{n}$ & $\%$ & $\mathrm{n}$ & $\%$ & $\mathrm{n}$ & $\%$ \\
\hline Travel guidebooks & 36 & 50.0 & 105 & 69.5 & 168 & 69.7 & 309 & 66.6 \\
\hline $\begin{array}{l}\text { Movies about the } \\
\text { Vietnam War }\end{array}$ & 20 & 27.8 & 51 & 33.8 & 70 & 29.0 & 141 & 30.4 \\
\hline $\begin{array}{l}\text { Documentaries about the } \\
\text { Vietnam War }\end{array}$ & 21 & 29.2 & 32 & 21.2 & 67 & 27.8 & 120 & 25.9 \\
\hline $\begin{array}{l}\text { Books about the Vietnam } \\
\text { War }\end{array}$ & 30 & 41.7 & 28 & 18.5 & 55 & 22.8 & 113 & 24.4 \\
\hline Other travellers & 8 & 11.1 & 34 & 22.5 & 56 & 23.2 & 98 & 21.1 \\
\hline Internet & 16 & 22.2 & 40 & 26.5 & 35 & 14.5 & 91 & 19.6 \\
\hline School education & 16 & 22.2 & 25 & 16.6 & 41 & 17 & 82 & 17.7 \\
\hline Friends & 5 & 6.9 & 26 & 17.2 & 42 & 17.4 & 73 & 15.7 \\
\hline Family and relatives & 13 & 18.1 & 18 & 11.9 & 24 & 10 & 55 & 11.9 \\
\hline Vietnamese travel agents & 6 & 8.3 & 17 & 11.3 & 26 & 10.8 & 49 & 10.6 \\
\hline $\begin{array}{l}\text { Visitor } \\
\text { centre/Information centre }\end{array}$ & 6 & 8.3 & 9 & 6.0 & 18 & 7.5 & 33 & 7.1 \\
\hline $\begin{array}{l}\text { Accommodation } \\
\text { providers }\end{array}$ & 5 & 6.9 & 14 & 9.3 & 12 & 5.0 & 31 & 6.7 \\
\hline Transportation providers & 1 & 1.4 & 6 & 4.0 & 19 & 7.9 & 26 & 5.6 \\
\hline $\begin{array}{l}\text { Newspaper and } \\
\text { magazines }\end{array}$ & 5 & 6.9 & 6 & 4.0 & 11 & 4.6 & 22 & 4.7 \\
\hline $\begin{array}{l}\text { Travel agents in home } \\
\text { countries }\end{array}$ & 2 & 2.8 & 2 & 1.3 & 4 & 1.7 & 8 & 1.7 \\
\hline Other & 4 & 5.6 & 3 & 2.0 & 8 & 3.3 & 15 & 3.2 \\
\hline
\end{tabular}

Nevertheless, differences were found when comparing between visitor segments. In particular, the top five information sources for the Enthusiasts are travel guidebooks 
(indicated by $50 \%$ of the visitors), books about the Vietnam War $(41.7 \%)$, documentaries (29.2\%), movies about the Vietnam War $(27.8 \%)$, and the internet $(22.2 \%)$. In the case of Opportunists, the order is travel guidebooks $(69.5 \%)$, movies about the Vietnam War (33.8\%), the internet (26.5\%), other travellers $(22.5 \%)$ and documentaries about the Vietnam War (18.5\%). Likewise, the five most important sources for the Passive Tourist include travel guidebooks (69.7\%), movies about the Vietnam War (29\%), documentaries about the Vietnam War (27.8\%) and books about the Vietnam War (22.8\%).

As can be seen, the travel guidebook is the most important information source for visitors in all the three segments. However, while books about the Vietnam War are the second most important information source for the Enthusiast, they rank only sixth for the Opportunist and fifth for the Passive Tourist. The internet appears to be highly important for the Opportunist group but relatively unimportant for the Enthusiast and especially for the Passive Tourist. Similarly, while there is significant number of Opportunist and Passive Tourists who consider "other travellers" as important; this information channel is less favoured by the Enthusiast.

In conclusion, most visitors to the $\mathrm{DMZ}$ were aware of the area before their trip. Despite not having profound knowledge of the site, the survey participants appear to have the most basic and general information relating to the DMZ. Most visitors tend to use easy and convenient sources to search for information about the DMZ, such as travel guidebooks, which are the most important information source for the respondents while the media also plays a significant role.

Comparing between segments, Enthusiast visitors tend to be more aware of the DMZ than the other two groups. Apart from travel guidebooks, this type of tourists considers more serious and profound sources such as books and documentaries important for gaining information about the DMZ. Conversely, the Passive Tourist appears to be the least aware of the DMZ. These tourists prefer media channels such as movies and documentaries for their DMZ information search. The Opportunists have a similar level of awareness and knowledge of the DMZ with the Passive Tourists; however, besides travel guidebooks and movies, these tourists often refer to other travellers as an important information source. Relating back to the decisionmaking stage, this explains the high percentage of Opportunist visitors making their 
decision during their trip in Vietnam. It appears that other travellers they met during the trip might have been an influence on their decision-making process.

\subsection{The importance of battlefield sites in tourists' decision to travel to Vietnam}

\subsubsection{The importance of the DMZ}

The previous analysis provided indirect measurement of the importance of the DMZ for the respondents based on several factors such as decision-making stages, level of knowledge and information sources. It shows that despite having planned to visit the DMZ early in their trips, visitors did not tend to have much information about the site. Enthusiasts tended to make their decision at the earliest stage; does this imply visiting the DMZ is most important for these tourists? A direct question was needed to check this preliminary assessment. Accordingly, respondents were asked to rate from one (unimportant) to five (very important) the importance level of the DMZ in their travel decision to visit Vietnam.

Table 6-8 shows that in general, the DMZ was of little importance in the respondents' decision to travel to Vietnam $(M=2.09)$. Almost half of the respondents (48.1\%) considered the DMZ to be of little to moderately importance in their decision. A substantial number of respondents (37.6\%) stated the DMZ was unimportant in their decision. However, for a small number of visitors (11.6\%), the DMZ played a crucial role (important to very important) in their decision to travel to Vietnam.

Table 6-8: The importance of the DMZ in visitors' decision to travel to Vietnam

\begin{tabular}{|lrr|lr|}
\hline Level of importance & Frequency & $\begin{array}{c}\% \\
(n=468)\end{array}$ & Measure & Value \\
\hline Unimportant & 181 & 37.6 & Mean & 2.09 \\
Of little importance & 136 & 28.3 & Median & 2.00 \\
Moderately important & 95 & 19.8 & Mode & 1.00 \\
Important & 43 & 8.9 & SD & 1.097 \\
Very important & 13 & 2.7 & & \\
\hline
\end{tabular}

It is expected that the more important the $\mathrm{DMZ}$ is for the visitor, the earlier the decision to visit the site will be made. However, as can be seen in Table 6-9, those who decided to visit the $\mathrm{DMZ}$ at the latest stage stated a highest importance level $(\mathrm{M}=2.54)$. However, given the small number of visitors (13) and a high standard 
deviation ( $\mathrm{SD}=1.330)$, the results may be been biased. In contrast, the numbers of respondents making decisions in other three stages are relatively equal. Therefore, the importance of the DMZ is to be examined with relevance to the three first decision-making stages only.

Table 6-9 shows that the decision-making stages are strongly related to the importance of the DMZ in visitors' travel decision. As expected, the more important the DMZ was for the respondents, the earlier the decision to visit was made. Specifically, the DMZ appeared to be moderately important for those who decided to visit the site before they came to Vietnam $(M=2.53)$ while it was of little importance for those who made the decision before arriving in Huế/Quảng Trị/Quảng Bình $(\mathrm{M}=1.82)$ and during their stay in the area $(\mathrm{M}=1.72)$.

Table 6-9: The DMZ's level of importance across decision-making stages

\begin{tabular}{|lrrr|}
\hline Decision-making stage & N & Mean & \multicolumn{1}{l|}{ SD } \\
\hline Before coming to Vietnam & 182 & 2.53 & 1.086 \\
Before coming to Hué/QT/QB & 123 & 1.82 & 0.975 \\
During the stay in Huế/QT/QB & 149 & 1.72 & 0.985 \\
On the way to somewhere else & 13 & 2.54 & 1.330 \\
\hline$F$ & 20.665 & & \\
Sig. level & 0.000 & & \\
\hline
\end{tabular}

An examination of the three clusters in Table 6-10 shows that there are significant differences concerning the importance of the DMZ in visitors' decisions to travel to Vietnam $(F=6.113, p=0.002)$. In particular, the DMZ has the highest level of importance for the Enthusiast $(\mathrm{M}=2.51)$ compared with the other visitors. A Spanish Enthusiast visitor explained:

"The DMZ was important because it was a significant part of the most recent history in Vietnam and I chose Vietnam because of its history."

However, for the Opportunist and the Passive Tourist, the DMZ did not play a crucial role in their decisions to travel to Vietnam $(\mathrm{M}=2.01)$. Most Opportunist visitors indicated that they did not come to Vietnam for a particular individual site, but rather it was the country as a whole that attracted them. The DMZ was of little importance to most visitors in this segment and in most case, was made for convenience. 
"I am travelling to Hanoi from Ho Chi Minh City, the DMZ is on the way and I am interested to find out more about the war", said a young British traveller.

Table 6-10: The importance of the DMZ in the visitor' decision-making

\begin{tabular}{|lrrrrrr|}
\hline Value & $\begin{array}{c}\text { Enthusiast } \\
(\mathrm{n}=74)\end{array}$ & $\begin{array}{c}\text { Opportunist } \\
(\mathrm{n}=160)\end{array}$ & $\begin{array}{l}\text { Passive } \\
\text { Tourist } \\
(\mathrm{n}=247)\end{array}$ & $\begin{array}{c}\text { Total } \\
(\mathrm{n}=481)\end{array}$ & $F$ & $\begin{array}{c}\text { Sig. } \\
\text { level }\end{array}$ \\
\hline Mean & 2.51 & 2.01 & 2.01 & 2.09 & 6.113 & 0.002 \\
SD & 1.290 & 1.044 & 1.047 & 1.097 & & \\
\hline
\end{tabular}

Likewise, the Passive Tourist stated that they visited Vietnam for a variety of reasons such as culture, landscape, and history, and would have come to Vietnam in any event regardless of the DMZ. However, the DMZ was believed to be an interesting part, which could add another dimension to the usual relaxing and sightseeing trip historical dimension, as a young British woman indicated:

"I am interested in the history of the country as a whole, rather than the DMZ specifically. The DMZ was on my way and an interesting addition to my itinerary."

The Passive Tourists often made their final decision to visit the DMZ closer to the site and in some cases were influenced by others. An example is a twenty-something Australian visitor who revealed:

"I had only the vaguest notion of going to the DMZ before coming to Vietnam. The decision was finalised here as I have a friend who really wanted to see it."

\subsubsection{The importance of the battlefield sites in Vietnam in general}

Similar to the DMZ, Vietnamese battlefield sites in general also appear to be of reasonably little importance to the tourists' decision to visit Vietnam $(M=2.22)$. Table 6-11 shows that battlefields were unimportant to $34.7 \%$ of visitors and of little or moderate importance to about half the total visitors $(51.1 \%)$. Nonetheless, for a minority $(14.2 \%)$, the battlefields in Vietnam played important to very important roles in their decision to visit the country. 
Table 6-11: The importance of battlefield sites visitors' decisions to travel to Vietnam

\begin{tabular}{|lrr|lr|}
\hline Level of importance & Frequency & $\begin{array}{c}\% \\
(n=467)\end{array}$ & Measure & Value \\
\hline Unimportant & 162 & 34.7 & Mean & 2.22 \\
Of little importance & 130 & 27.8 & Median & 2.00 \\
Moderately important & 109 & 23.3 & Mode & 1.00 \\
Important & 40 & 8.6 & SD & 1.173 \\
Very important & 26 & 5.6 & & \\
\hline
\end{tabular}

When examining the visitors according to segments, it can be seen from Table 6-12 that a significant difference exists between the visitors in terms of the importance of battlefield sites in Vietnam in their decision to travel to Vietnam ( $F=16.074$, $p=0.000)$. Specifically, the battlefield sites played a moderately important role in the Enthusiast's decision-making $(\mathrm{M}=2.90)$. For the Opportunist, the battlefields are of little importance $(M=2.21)$ yet they are least important for the Passive Tourist $(\mathrm{M}=2.03)$. These findings are comparable to the previous section regarding the importance of the DMZ in decision-making. Again, visiting battlefield sites in Vietnam (including the DMZ) is more important for the Enthusiast than the other visitors. A Dutch visitor in this cluster indicated:

"It is an important part to Vietnam and has had an incredible effect on what Vietnam is today. It is good to learn from previous actions so hopefully we can prevent them in the future."

For most Opportunists, again, battlefield sites were of little importance and the decision to visit was often made during the trip:

"If we happened to pass through or travel near we would visit [the battlefield sites] but it was a deciding factor on where we were." stated an American visitor.

Likewise, battlefields were believed to not influence the Passive Tourists' decision to travel to Vietnam. The majority of visitors were attracted to Vietnam by multiple dimensions, not only the battlefield sites in particular, as one of the Dutch female visitors explained:

"I see that the war has had a big influence on the Vietnamese, but actually I was more interested in the overall identity of Vietnamese, especially because in Europe, Vietnam is mostly known by the impression of the Vietnam War." 
Table 6-12: The importance of battlefield sites in Vietnam in visitors' decision-making

\begin{tabular}{|lrrrrrr|}
\hline & $\begin{array}{c}\text { Enthusiast } \\
(\mathrm{n}=74)\end{array}$ & $\begin{array}{c}\text { Opportunist } \\
(\mathrm{n}=160)\end{array}$ & $\begin{array}{c}\text { Passive } \\
\text { Tourist } \\
(\mathrm{n}=247)\end{array}$ & $\begin{array}{c}\text { Total } \\
(\mathrm{n}=481)\end{array}$ & $F$ & $\begin{array}{c}\text { Sig. } \\
\text { level }\end{array}$ \\
\hline Mean & 2.90 & 2.21 & 2.03 & 2.22 & 16.074 & 0.000 \\
SD & 1.523 & 1.075 & 1.039 & 1.173 & & \\
\hline
\end{tabular}

To sum up, battlefield sites in general and the DMZ in particular appear to be of relatively little importance to the tourists' decision to visit Vietnam. Similar to the findings about the decision-making stage, Enthusiast visitors appear to place the highest emphasis on the DMZ and other Vietnamese battlefield site, while these sites were considered less important for the Opportunist and Passive Tourist. This may suggest that Enthusiasts are more interested in battlefield tourism than their counterparts. The following section examines this assumption.

\subsection{Level of interest in battlefield tourism}

Earlier discussion shows that battlefield sites did not play a significant role in the respondents' decision to visit Vietnam. Interestingly, a majority of the respondents indicated some interest in visiting the battlefield sites in Vietnam (94.3\%). However, the level of interest was generally moderate $(M=3.12)$. As shown in Table 6-13, $24.8 \%$ of respondents were slightly interested in visiting Vietnamese battlefields and $34.8 \%$ were moderately interested. The interested and very interested respondents account for $34.6 \%$ of the total sample, as opposed to $5.7 \%$ of those who had no interest at all.

Table 6-13: Respondent's level of interest in visiting the battlefield sites in Vietnam

\begin{tabular}{|lrr|lr|}
\hline \multicolumn{1}{|c|}{ Level of interest } & Frequency & $\begin{array}{c}\% \\
(n=471)\end{array}$ & Measure & Value \\
\hline Level 1: Not interested at all & 27 & 5.7 & Mean & 3.12 \\
Level 2: Slightly interested & 117 & 24.8 & Median & 3.00 \\
Level 3: Moderately interested & 164 & 34.8 & Mode & 3.00 \\
Level 4: Interested & 98 & 20.8 & SD & 1.107 \\
Level 5: Very interested & 65 & 13.8 & & \\
\hline
\end{tabular}

Nonetheless, the levels of interest in visiting battlefield sites in Vietnam differ considerably between visitor segments $(F=11.533, p=0.000)$. As displayed in Table 6-14, the Enthusiasts appear to have the highest level of interest in visiting the battlefield sites in Vietnam $(\mathrm{M}=3.68)$. The Opportunist and Passive Tourist, 
however, are quite similar as shown by means of 3.03 and 3.01 respectively. These findings are relevant to previous discussions. The Enthusiasts tend to be more aware of the DMZ and consider the DMZ most important compared to other groups, thus obviously these visitors are more interested in visiting the battlefield sites in Vietnam. Likewise, the Opportunist and Passive Tourists' relatively lower level of interest confirms the lesser importance of the DMZ and battlefield sites in their decision to visit Vietnam.

Table 6-14: Level of interest in visiting battlefield sites in Vietnam by visitor segments

\begin{tabular}{|lrrrrrr|}
\hline & $\begin{array}{c}\text { Enthusiast } \\
(\mathrm{n}=74)\end{array}$ & $\begin{array}{c}\text { Opportunist } \\
(\mathrm{n}=160)\end{array}$ & $\begin{array}{c}\text { Passive } \\
\text { Tourist } \\
(\mathrm{n}=247)\end{array}$ & $\begin{array}{c}\text { Total } \\
(\mathrm{n}=481)\end{array}$ & $F$ & $\begin{array}{c}\text { Sig. } \\
\text { level }\end{array}$ \\
\hline Mean & 3.68 & 3.03 & 3.01 & 3.12 & 11.533 & 0.000 \\
SD & 1.195 & 1.015 & 1.091 & 1.107 & & \\
\hline
\end{tabular}

In sum, visitors indicated a moderate level of interest in visiting battlefield sites. However, their actual visitation needs to be investigated to better understand their interest in battlefield tourism. It is expected that given the visitors' fair amount of interest in visiting battlefield sites, they will have relatively little experience in battlefield tourism.

\subsection{Level of participation in battlefield tourism}

According to Trauer (2006), the level of involvement in a particular activity is related to the level of interest. Trauer believes that a high frequency of participation shows high interest in that activity. Hence, participants in this study were asked to indicate the battlefield sites they had visited and were going to visit in Vietnam in general and in the DMZ in particular. In addition, they were also asked to list the battlefield sites in the world they had visited over the last two years. The information is needed to better understand the visitors' overall interest in battlefield tourism.

\subsubsection{Battlefield sites in the DMZ}

Table 6-15 shows that on average, respondents visited five battlefield sites in the DMZ area. Specifically, $26.6 \%$ of respondents visited five sites and a similar number visited six sites $(25.6 \%)$. One explanation for this may be the fact that a great number of visitors were travelling on organised tours as explained in the previous chapter. These visitors followed the fixed itineraries, which normally included five to six typical sites (Rockpile, Khe Sanh, Dakrong Bridge, Vịnh Mốc Tunnels, Doc Mieu, 
and sometimes Ben Hai River). In other cases, one third of the survey participants $(29.5 \%)$ visited three or four sites in the area and $10.4 \%$ visited only one or two sites. A small number of visitors $(8.1 \%)$, however, had been to seven to thirteen sites.

Surprisingly, most respondents $(82.3 \%)$ did not show any intention to visit any more sites in the DMZ (Table 6-15). However, this is probably because the respondents were following the tour and were not sure about the itineraries. Moreover, in the common group bus tour's itinerary, the Vịnh Mốc Tunnels is the last stop. Accordingly, respondents were not going to any further battlefield sites.

Table 6-15: The number of battlefield sites visited and to be visited in the DMZ by respondents

\begin{tabular}{|r|rr|rr|}
\hline & \multicolumn{2}{|c|}{ Visited } & \multicolumn{2}{|c|}{ To be visited } \\
\cline { 2 - 5 } No. of & No. of & $\%$ & No. of & $\%$ \\
sites & respondents & $(n=481)$ & respondents & $(n=481)$ \\
\hline 0 & 0 & 0.0 & 396 & 82.3 \\
1 & 29 & 6.0 & 23 & 4.8 \\
2 & 21 & 4.4 & 15 & 3.1 \\
3 & 55 & 11.4 & 16 & 3.3 \\
4 & 87 & 18.1 & 5 & 1.0 \\
5 & 128 & 26.6 & 9 & 1.9 \\
6 & 122 & 25.4 & 6 & 1.2 \\
7 & 23 & 4.8 & 6 & 1.2 \\
8 & 8 & 1.7 & 1 & 0.2 \\
9 & 3 & 0.6 & 3 & 0.6 \\
10 & 1 & 0.2 & 1 & 0.2 \\
12 & 2 & 0.4 & 0.0 & 0.0 \\
13 & 2 & 0.4 & 0.0 & 0.0 \\
\hline Mean & 4.72 & & 0.60 & \\
Median & 5 & & 0.0 & \\
Mode & 5 & & 0.0 & \\
SD & 1.771 & & 1.630 & \\
\hline
\end{tabular}

Table 6-16 provides more details about the number of sites respondents visited and were going to visit for each particular site in the DMZ area. As expected, all respondents had been to the Vịnh Mốc Tunnels because that is where the survey was conducted. Yet this is compounded by the fact that the Vịnh Mốc Tunnels are considered to be a must-see as the most attractive site in the DMZ area, as explained in the Introduction and Methodology chapters.

The next most visited sites are the Dakrong Bridge, Rockpile, and Khe Sanh Marine Base, which were visited by $79 \%, 76.1 \%$ and $70.5 \%$ of the participants respectively. Other sites which attracted about half of the respondents were the Ben Hai River 
(58.4\%) and Doc Mieu Firebase (48.9\%). These five sites together with the Vịnh Mốc Tunnels are included in the popular DMZ tour as mentioned earlier. Given a great number of respondents were travelling on tour, it would appear that these sites rank as the top most visited among the survey participants.

The rest of the listed sites were not included in the group tour, thus the choice to visit was optional and tailor-made for customers with special needs. These include North Vietnam-related sites such as Truong Son National Cemetery (10.6\%) and the Quảng Trị Citadel (9.1\%). Conversely, the other three sites are American bases that attract mostly international visitors, especially veterans groups.

Table 6-16: List of sites in the DMZ tour and their popularity

\begin{tabular}{|lrrrrr|}
\hline & \multicolumn{3}{c}{ Visited } & \multicolumn{2}{c|}{ To be visited } \\
\cline { 2 - 6 } Site & \multicolumn{1}{c}{$\begin{array}{c}\% \\
(n=481)\end{array}$} & $\mathrm{n}$ & $\begin{array}{c}\% \\
(n=481)\end{array}$ \\
\hline Vịnh Mốc Tunnels & 481 & 100.0 & 0 & 0.00 \\
Ho Chi Minh Trail and Dakrong Bridge & 380 & 79 & 32 & 7.7 \\
Rockpile & 366 & 76.1 & 24 & 5.7 \\
Khe Sanh Marine Base & 339 & 70.5 & 20 & 4.8 \\
Ben Hai river and Hien Luong bridge & 281 & 58.4 & 14 & 3.3 \\
Doc Mieu & 235 & 48.9 & 15 & 3.6 \\
Truong Son National Cemetery & 51 & 10.6 & 34 & 8.1 \\
Thach Han river & 33 & 6.9 & 25 & 6.0 \\
Ai Tu Base and Airfield & 31 & 6.4 & 21 & 5.0 \\
Quảng Trị Citadel & 28 & 5.8 & 38 & 9.1 \\
A Sau Valley and Hamburger Hill & 18 & 3.7 & 34 & 8.1 \\
Lang Vay Special Forces Camp & 14 & 2.9 & 25 & 6.0 \\
Other & 7 & 1.5 & 7 & 1.7 \\
\hline
\end{tabular}

Surprisingly, there is no significant difference between visitors in the three clusters regarding the number of DMZ sites visited $(F=0.283, p=0.754)$ and those planned to visit $(F=1.342, p=0.262)$. As shown in Table 6-17, Enthusiasts, Opportunists and Passive Tourists had visited about 4-5 sites in the DMZ and did not have plans to visit more sites. 
Chapter 6-DMZ visitors' decision-making and interest in battlefield tourism

Table 6-17: The number of sites visited and to be visited in the DMZ by segments

\begin{tabular}{|lrrrrrr|}
\hline & $\begin{array}{c}\text { Enthusiast } \\
(\mathrm{n}=74)\end{array}$ & $\begin{array}{c}\text { Opportunist } \\
(\mathrm{n}=160)\end{array}$ & $\begin{array}{c}\text { Passive } \\
\text { Tourist } \\
(\mathrm{n}=247)\end{array}$ & $\begin{array}{c}\text { Total } \\
(\mathrm{n}=481)\end{array}$ & $F$ & $\begin{array}{c}\text { Sig. } \\
\text { level }\end{array}$ \\
\hline Visited & & & & & & \\
$\quad$ Mean & 4.65 & 4.80 & 4.68 & 4.72 & 0.283 & 0.754 \\
SD & 1.824 & 1.906 & 1.667 & 1.771 & & \\
\hline To be visited & & & & & & \\
Mean & 0.34 & 0.71 & 0.61 & 0.60 & 1.342 & 0.262 \\
SD & 1.101 & 1.806 & 1.639 & 1.630 & & \\
\hline
\end{tabular}

\subsubsection{Battlefield sites in Vietnam}

Regarding battlefield sites in Vietnam in general, Table 6-18 shows that more than half of the respondents have neither been to nor planned to visit any other battlefield sites in Vietnam. The number of visitors who had been to at least one other site (apart from the DMZ) accounted for $46.7 \%$ of the total respondents; $31.6 \%$ indicated their intention to visit at least one more site. The number of respondents appears to have an inverse relationship with the number of the battlefield sites visited and to be visited. That is, there were fewer respondents to visit more sites. Specifically, while $27.2 \%$ of respondents had visited one other battlefield site in Vietnam, there were only $11 \%$ who visited two sites, and $4.6 \%$ who visited three sites. A similar pattern applies when considering tourists' intention to visit, where the number is $15.4 \%$ for one site, $10.2 \%$ for two sites and $0.2 \%$ for ten sites.

Table 6-18: The number of battlefield sites visited and to be visited in Vietnam

\begin{tabular}{|c|c|c|c|c|}
\hline \multirow[b]{2}{*}{$\begin{array}{r}\text { No. of } \\
\text { sites }\end{array}$} & \multicolumn{2}{|c|}{ Visited } & \multicolumn{2}{|c|}{ To be visited } \\
\hline & $\begin{array}{r}\text { No. of } \\
\text { respondents }\end{array}$ & $\begin{array}{r}\% \\
(n=481) \\
\end{array}$ & $\begin{array}{r}\text { No. of } \\
\text { respondents }\end{array}$ & $\begin{array}{r}\% \\
(n=481) \\
\end{array}$ \\
\hline 0 & 257 & 53.4 & 330 & 68.6 \\
\hline 1 & 131 & 27.2 & 74 & 15.4 \\
\hline 2 & 53 & 11.0 & 49 & 10.2 \\
\hline 3 & 22 & 4.6 & 18 & 3.7 \\
\hline 4 & 9 & 1.9 & 2 & 0.4 \\
\hline 5 & 4 & 0.8 & 3 & 0.6 \\
\hline 6 & 2 & 0.4 & 1 & 0.2 \\
\hline 7 & 2 & 0.4 & 1 & 0.2 \\
\hline 8 & 1 & 0.2 & 2 & 0.4 \\
\hline 9 & 257 & 53.4 & 1 & 0.2 \\
\hline 10 & 131 & 27.2 & 330 & 68.6 \\
\hline Mean & 0.83 & & 0.60 & \\
\hline Median & 0.0 & & 0.0 & \\
\hline Mode & 0.0 & & 0.0 & \\
\hline SD & 1.256 & & 1.229 & \\
\hline
\end{tabular}


Table 6-19 shows some specific battlefield sites in Vietnam and their popularity among the respondents. It is noted that there are numerous battlefield related sites throughout Vietnam as a result of the several wars in its history. However, only the ten most famous and relevant (based on their connections to the wars and recommendations from guidebooks) were selected for the study.

Table 6-19: List of some battlefield sites in Vietnam and their popularity among respondents

\begin{tabular}{|lrrrr|}
\hline \multirow{2}{*}{ Site } & \multicolumn{2}{c}{ Visited } & \multicolumn{2}{c|}{ To be visited } \\
\cline { 2 - 6 } & \multicolumn{1}{c}{$\begin{array}{c}\% \\
(n=481)\end{array}$} & \multicolumn{1}{c|}{$\mathrm{n}$} & $\begin{array}{c}\% \\
(n=481)\end{array}$ \\
\hline War Remnants Museum & 123 & 25.6 & 207 & 43.0 \\
Cu Chi Tunnels & 90 & 18.7 & 173 & 36.0 \\
Hoa Lo Prison & 90 & 18.7 & 108 & 22.5 \\
My Lai Village & 26 & 5.4 & 63 & 13.1 \\
Vietnam Gulf of Tonkin & 20 & 4.2 & 36 & 7.5 \\
Dien Bien Phu & 16 & 3.3 & 37 & 7.7 \\
Ia Drang Valley & 9 & 1.9 & 19 & 4.0 \\
Pleime, Dak To & 6 & 1.2 & 14 & 2.9 \\
Ve River (Quang Ngai Province) & 5 & 1.0 & 11 & 2.3 \\
Other & 13 & 2.7 & 20 & 4.2 \\
\hline
\end{tabular}

As can be seen, the War Remnants Museum in Ho Chi Minh City appears to be the most popular site among the respondents. Despite not being an actual battlefield, the Museum was included as it is strongly related to the Vietnam War. As displayed in Table 6-19, the Museum occupies first place regarding the number of respondents who had visited as well as those who had the intention to visit. The next top two sites were the Củ Chi Tunnels and Hỏa Lò Prison, each visited by $18.7 \%$ and to be visited by approximately one third of the respondents. All the other listed sites attracted a smaller number of visitors (below 6\% of respondents had visited and less than $14 \%$ were going to visit). It is noteworthy that the top three most visited sites are located in or close to the two main tourist centres in Vietnam. The War Remnants Museum is located in the centre of Ho Chi Minh City while Hoa Lo Prison is located at the heart of Hanoi, the capital city of Vietnam. The $\mathrm{Cu}$ Chi Tunnels are also close to Ho Chi Minh City (70 km northwest of the city). In contrast, other listed battlefield sites are located in much less travelled places, either in the central highlands (Ia Drang Valley and Pleime Dak To), the poor coastal provinces (Ve River and My Lai Village), or in the northern mountainous area (Dien Bien Phu). The locations of these places could be one of the factors that make these sites less attractive to tourists. However, it 
implies that respondents in the sample have a reasonably low level of interest in visiting battlefield sites in Vietnam, i.e. they tend to visit those that are most conveniently located. This is consistent with findings about respondents' interest in visiting battlefield sites in Vietnam, as discussed earlier (Table 6-13). As can be seen, visitors' relatively low level of participation in battlefield tourism is related to their moderate interest $(\mathrm{M}=3.12)$ in visiting battlefield sites in Vietnam.

Interestingly, significant differences can be found between visitor segments with regards to the number of battlefield sites visited in Vietnam $(F=7.419, p=0.001)$. On average, the Enthusiast had visited at least one other battlefield site in Vietnam $(\mathrm{M}=1.30)$. The Opportunist and Passive Tourist showed less participation $(\mathrm{M}=0.86$ and $\mathrm{M}=0.67$ respectively). Nevertheless, there is no significant difference between the visitors regarding their intention to visit more battlefield sites in Vietnam $(F=1.190, p=0.305)$. Overall, only a few visitors intended to visit more battlefield sites in Vietnam $(\mathrm{M}=0.61)$. In general, when combined with results from the previous discussions about the importance of the DMZ and other Vietnamese battlefield sites in tourists' decision-making and visitors' level of interest in battlefield tourism, it appears that the Enthusiast tend to be more attracted to battlefield sites in Vietnam than their counterparts.

Table 6-20: The number of battlefield sites visited and to be visited in Vietnam by segments

\begin{tabular}{|lrrrrrr|}
\hline & $\begin{array}{c}\text { Enthusiast } \\
(\mathrm{n}=74)\end{array}$ & $\begin{array}{c}\text { Opportunist } \\
(\mathrm{n}=160)\end{array}$ & $\begin{array}{c}\text { Passive } \\
\text { Tourist } \\
(\mathrm{n}=247)\end{array}$ & $\begin{array}{c}\text { Total } \\
(\mathrm{n}=481)\end{array}$ & $F$ & $\begin{array}{c}\text { Sig. } \\
\text { level }\end{array}$ \\
\hline Visited & & & & & & \\
$\quad$ Mean & 1.30 & 0.86 & 0.67 & 0.83 & 7.419 & 0.001 \\
SD & 1.515 & 1.405 & 1.016 & 1.257 & & \\
\hline To be visited & & & & & & \\
Mean & 0.50 & 0.72 & 0.56 & 0.61 & 1.190 & 0.305 \\
SD & 1.063 & 1.546 & 1.027 & 1.230 & & \\
\hline
\end{tabular}

\subsubsection{Battlefield sites in the world}

Following on from consideration of battlefield sites in a particular area (DMZ) and in a particular a country (Vietnam), this section enhances the discussion about visitors' level of participation in battlefield tourism at a world level. As there are too many battlefield sites in the world to name specific ones, it was decided that the question of the respondents' experience in battlefield tourism around the world should be left open. Respondents were asked to list the sites they had visited over the last two years 
only. A wide range of answers was collected from the survey participants, however, the percentage of responses are very low.

Table 6-21 shows that European battlefield sites attract the greatest number of respondents compared to other continents' (approximately 102 responses compared to 70 in Asia, 11 in America, 9 in Australia and 4 in Africa). European sites listed related mostly to the First and Second World Wars, among which Normandy (France) and Auschwitz (Poland) rank the first with 3.1\% of respondents having visited one or the other. Other WWII battlefield sites in total attract $8.5 \%$ of respondents and the number for WWI sites is 3.5\%.

Asian battlefield sites also attracted a significant number of respondents: the Killing Fields - Cambodia (4.2\%), the River Kwai - Thailand (2.3\%), Hiroshima and other World War II sites in Japan (2.7\%), Changi - Singapore (1.2\%), the others (4.2\%). Some reasons for the popularity of European and Asian battlefield sites may be because European visitors account for a significant fraction of the total sample. Together with the ease of travelling within Europe, it is not surprising that European sites are the most visited among the respondents. Additionally, according to Tarlow (2005), Europe may be a model for dark tourism. Tarlow states that death dominates much of European tourism, from visits to the graves of poets and kings, to the mass graves of soldiers who died in Europe's many wars. Likewise, the fact that Asia has become a popular destination for Western tourists may explain the high number of respondents visiting Asian battlefield sites. Furthermore, it is likely that the respondents visited Vietnam as part of their South East Asia trip, which is why the Killing Fields, River Kwai and Changi are most visited.

Conversely, the other three continents (America, Australia, and Africa) only have a small number of visitors (less than 3\% visitors each). One explanation may be that there were fewer battles that occurred in America and Australasia compared to Europe and Asia, while Africa is still considered to be a less travelled destination due to the instability in several nations. 
Table 6-21: Battlefield sites in the world and their popularity among the respondents

\begin{tabular}{|l|c|c|}
\hline Site & $\begin{array}{c}\text { No. of respondents } \\
\text { visited }\end{array}$ & $\begin{array}{c}\% \\
(n=481)\end{array}$ \\
\hline Normandy (France) & 15 & 3.1 \\
Auschwitz (Poland) & 15 & 3.1 \\
Other European World War II battlefield sites & 41 & 8.5 \\
World War I battlefield sites & 17 & 3.5 \\
Other battlefield sites in Europe & 14 & 2.9 \\
Killing Fields (Cambodia) & 20 & 4.2 \\
River Kwai (Thailand) & 11 & 2.3 \\
Changi (Singapore) & 6 & 1.2 \\
Hiroshima and other Japanese battlefield sites & 13 & 2.7 \\
Other battlefield sites in Asia & 20 & 4.2 \\
American Civil War & 11 & 2.3 \\
War related sites in Australia & 9 & 1.9 \\
Other battlefield sites in Africa & 4 & 0.8 \\
\hline
\end{tabular}

In short, respondents indicated having visited a diversity of battlefield sites throughout the world, yet that the number of responses (per site and total) is small. In other words, few respondents appear to have visited sites in other countries. Together with the small number of battlefield sites visited in Vietnam, it can be seen that respondents generally did not show a high level of participation in battlefield tourism. Due to the small percentage of responses per international site, comparison between the three visitor segments was not analysed. However, information about the respondents' experience in world battlefield sites provides an overview of the battlefield tourism trends among the survey participants.

\subsection{Satisfaction of the DMZ trip experience}

The previous discussions suggest that the DMZ was of little importance in tourists' decision-making. However, once the tourists made their visit to the site, it is critical to understand if they were satisfied with the trip. It is also useful to understand what was and was not appreciated so that improvements can be made. Therefore, respondents were asked to indicate their level of satisfaction with the DMZ experience, what they found most interesting and what could be improved.

As shown in Table 6-22, visitors seemed to be satisfied with their DMZ trip $(M=3.64)$. A majority of respondents reported a positive experience in the DMZ $(88.2 \%)$. In particular, $30 \%$ of respondents indicated their trips were rather good, $39.5 \%$ stated good and $18.6 \%$ rated very good. There was only a small number of 
respondents who considered the DMZ experience were not good at all $(0.4 \%)$ or not very $\operatorname{good}(11.4 \%)$.

Table 6-22: Respondent's satisfaction of the DMZ experience

\begin{tabular}{|lrr|lr|}
\hline Level of importance & Frequency & $\begin{array}{c}\% \\
(n=473)\end{array}$ & Measure & Value \\
\hline Not good at all & 2 & 0.4 & Mean & 3.64 \\
Not very good & 54 & 11.4 & Median & 4.00 \\
Rather good & 142 & 30.0 & Mode & 4.00 \\
Good & 187 & 39.5 & SD & 0.926 \\
Very good & 88 & 18.6 & & \\
\hline
\end{tabular}

When examining the level of satisfaction by clusters, statistical difference between visitors can be found. The Enthusiasts tend to be more satisfied with their DMZ trip experience than the Opportunists and Passive Tourists. Table 6-23 shows that Enthusiasts considered their DMZ trip as $\operatorname{good}(\mathrm{M}=3.97)$ while Opportunists and Passive Tourists gave a moderately lower rate $(\mathrm{M}=3.59$ and $\mathrm{M}=3.58$ respectively).

Table 6-23: Level of satisfaction of the DMZ trip by visitor segments

\begin{tabular}{|lcrrrrr|}
\hline & $\begin{array}{c}\text { Enthusiast } \\
(\mathrm{n}=74)\end{array}$ & $\begin{array}{c}\text { Opportunist } \\
(\mathrm{n}=160)\end{array}$ & $\begin{array}{l}\text { Passive } \\
\text { Tourist } \\
(\mathrm{n}=247)\end{array}$ & $\begin{array}{c}\text { Total } \\
(\mathrm{n}=481)\end{array}$ & $F$ & $\begin{array}{c}\text { Sig. } \\
\text { level }\end{array}$ \\
\hline Mean & 3.97 & 3.59 & 3.58 & 3.64 & 5.526 & 0.004 \\
SD & 0.833 & 0.933 & 0.930 & 0.926 & & \\
\hline
\end{tabular}

With respect to the most interesting experience in the DMZ trip, respondents reported a variety of answers, including both tangible and intangible aspects. Table 6-24 shows that the Vịnh Mốc Tunnels stood out as the most interesting thing in the $\mathrm{DMZ}$ trip as indicated by $73.5 \%$ of the visitors. Most respondents were impressed by the time and efforts in constructing the Tunnels. They also respected the hardship the local people had been through.

"The Tunnels was amazing. I enjoyed walking through it and feel a bit of what the Vietnamese had to go through in several years." stated an Australian visitor.

The Khe Sanh Museum, which once was a principal American base during the Vietnam War, was also among the most interesting parts of the DMZ trip, as indicated by $6.7 \%$ visitors. While some visitors reported satisfaction in being able to 
see and observe the site they had long heard about, others were stunned by the greenness of the area, which shows a positive healing from the past.

In addition, visitors found improving their knowledge of Vietnam satisfying. Specifically, 6.2\% respondents enjoyed learning how the Vietnamese people lived during the War and 5\% were satisfied with better understanding of the Vietnam War while $4.7 \%$ greatly evaluated the historical information they gained. Other highly rated aspects of the trip include the countryside landscape (3.5\%) and the opportunity to witness war artefacts and the place in "real life" (4.2\%). The tour guides were also well-complimented by a small number of visitors $(4 \%)$.

Table 6-24: Most interesting aspect in the DMZ trip

\begin{tabular}{|lrrr|}
\hline Aspect & $\begin{array}{c}\text { No. of } \\
\text { respondents }\end{array}$ & $\begin{array}{c}\text { \% of } \\
\text { responses } \\
(\mathrm{n}=478)\end{array}$ & $\begin{array}{c}\% \text { of } \\
\text { cases } \\
(\mathrm{n}=403)\end{array}$ \\
\hline The Vịnh Mốc Tunnels & 296 & 61.9 & 73.5 \\
Khe Sanh & 27 & 5.6 & 6.7 \\
How Vietnamese people lived during the war & 25 & 5.2 & 6.2 \\
Better understanding of the Vietnam War & 20 & 4.2 & 5.0 \\
Historical information & 19 & 4.0 & 4.7 \\
The tour guide & 16 & 3.3 & 4.0 \\
The countryside landscape & 14 & 2.9 & 3.5 \\
Seeing the war artefacts & 17 & 3.6 & 4.2 \\
Other & 44 & 9.2 & 10.9 \\
\hline
\end{tabular}

However, visitors also suggested some improvements for the DMZ trip. As shown in Table 6-25, the majority of respondents (likely to be those travelling on the group bus tour) were concerned with the tour's organisation (38.1\%). Typically, visitors were not satisfied with the length of the tour (12 hours), the long bus ride and the short time spent at each site. In addition, most respondents would have preferred better and more information in English (20.9\%) since most of the signs, maps and information at the sites were in Vietnamese with little English translation. A faster and more modern bus was suggested by $9.4 \%$ of the visitors. Interestingly, while some respondents were happy with the tour guides as mentioned earlier, about $8.8 \%$ of the visitors expressed a preference for a better English speaking tour guide. Better museums and more genuine war artefacts were also among things to be improved as indicated by $13.5 \%$ the respondents. Apart from weather, other things that could be improved included better food, more interaction with the local people, better facilities at the attractions and more information about both sides of the War. 
Conversely, $8.1 \%$ of the respondents stated the trip was good as it was and had no need to improve anything.

Table 6-25: Things to be improved for the tour

\begin{tabular}{|lrrr|}
\hline & $\begin{array}{r}\text { No. of } \\
\text { respondents }\end{array}$ & $\begin{array}{c}\text { responses } \\
(n=388)\end{array}$ & $\begin{array}{c}\% \text { of } \\
\text { cases } \\
(n=320)\end{array}$ \\
\hline Better tour organisation & 122 & 31.4 & 38.1 \\
Better and more information in English & 67 & 17.3 & 20.9 \\
Better transportation & 30 & 7.7 & 9.4 \\
Better English-speaking tour guide & 28 & 7.2 & 8.8 \\
More genuine war artefacts & 23 & 5.9 & 7.2 \\
Better museums & 20 & 5.2 & 6.3 \\
Cooler weather & 15 & 3.9 & 4.7 \\
Better food & 12 & 3.1 & 3.8 \\
Contacts with local people & 11 & 2.8 & 3.4 \\
Better facilities at sites & 5 & 1.3 & 1.6 \\
Stories from both sides & 4 & 1.0 & 1.3 \\
Nothing & 26 & 6.7 & 8.1 \\
Other & 25 & 6.4 & 7.8 \\
\hline
\end{tabular}

\subsection{Conclusion}

This chapter has presented the findings regarding the DMZ visitors' decision-making and interest in battlefield tourism in Vietnam. It has discussed the role of the DMZ and other battlefields in tourists' decision to travel to Vietnam and provided an analysis of visitors' interest in visiting battlefield sites in Vietnam as well as their satisfaction with the DMZ trip.

To conclude, the DMZ and other battlefield sites in Vietnam played a small role in the respondents' decision to visit Vietnam. However, there are significant overall differences between the three visitor segments. The Enthusiasts tend to have the highest rates (measured by means) compared to the other two groups on all dimensions. In particular, this group of visitors put the highest level of importance on the DMZ and other Vietnamese battlefields in making their decision to travel to Vietnam. Enthusiast visitors also tend to have the highest level of knowledge of the DMZ and were the most interested in visiting battlefield sites. These visitors tend to plan their trip to the DMZ earlier than the other two groups. The Opportunists often fell between the Enthusiasts and the Passive Tourists. They have moderate interest in visiting the battlefield sites in Vietnam, which did not play a crucial role in their decision to visit the country initially, yet were interesting to learn about during the 
trip. The Passive Tourist, however, considered the DMZ and other Vietnamese battlefield sites as being of little importance to their decision-making.

Along with the previous two chapters, this chapter has presented the findings of this study. In particular, it addressed the third objective of this thesis: identifying the importance of battlefield sites in tourists' decision to travel to Vietnam. However, the significant and meaningful results described imply that further analysis and interpretation is needed to provide a clearer picture of the visitors to the Vietnamese DMZ. The next chapter will elaborate on the main findings discussed as well as putting these findings together in context with the research objectives. 


\section{Chapter 7: DISCUSSION, IMPLICATIONS AND CONCLUSION}

\subsection{Introduction}

Little research has been done on the Vietnamese tourism industry, and in particular, the importance of battlefield and war-related tourist sites. Accordingly, this thesis has sought to shed light on battlefield tourism in Vietnam, and whether this specifically motivates tourists to visit the country. By gaining an understanding of the type of tourists visiting battlefield sites in Vietnam and their motivations, the tourism industry can better target its marketing and manage the tourist activities to these important historical attractions.

Specifically, this thesis introduced the importance of battlefield and war-related sites to the Vietnamese tourism industry and suggested a need for visitor segmentation. The related literature was reviewed to establish a theoretical background, which highlighted a need for research on battlefield tourism, specifically the market segmentation of visitors by motivations. The importance of the DMZ and the Vịnh Mốc Tunnels to the Vietnamese war history, and the tunnels' status as one of the premier tourist attractions in the Quảng Trị province justified the selection of the tunnels as a study site. A quantitative questionnaire survey was used to collect primary data from international visitors at the Vịnh Mốc Tunnels. Statistical data analysis tools such as factor analysis, cluster analysis, multiple discriminant analysis, the Chi-square test and ANOVA were employed for this study's analytical purposes. Qualitative data from open-ended questions were used to complement and supplement results from the statistical analysis.

The analysis presented in the previous chapters revealed some complexities in the patterns of visitations to the DMZ. Despite some similarities, visitors to the DMZ show significant differences regarding their background and trip related characteristics, and demonstrate diversity in terms of travel motivations and decisionmaking. Therefore, it is important to bring these findings together to provide a clearer picture of visitors to the DMZ. It is also important to revisit the study objectives to assess how well these aims were achieved.

Table 7-1 provides a summary of this thesis, outlining the research objectives, the analytical techniques used to address each objective and the results achieved. In 
particular, the first objective was to identify the tourist motivations for visiting the Vietnamese DMZ. Using content analysis of self-expressed reasons, and means comparison and factor analysis of quantitative items, five major motivations were obtained: Personal involvement, Interest in war related sites and exhibitions, Education and exploration, Novelty seeking, and Location and convenience. The second objective was to define the DMZ visitor segments. Facilitated by cluster analysis, multiple discriminant analysis, ANOVA and the Chi-square test, this study identified three visitor segments: the Battlefield Tourism Enthusiast, the Opportunist, and the Passive Tourist. These segments were profiled and compared with each other to provide the Vietnamese tourism organisations with an overview of visitors to battlefield sites in Vietnam. Third, this study aimed to determine the attraction of battlefield sites in tourists' decision to travel to Vietnam. It found that the battlefield sites in Vietnam played a moderately small role in tourists' decision-making.

Table 7-1: Summary of the research's objectives, methodology and results

\begin{tabular}{|c|c|c|c|}
\hline & Objective 1 & Objective 2 & Objective 3 \\
\hline Objectives & $\begin{array}{l}\text { To identify the } \\
\text { motivations for } \\
\text { visiting the DMZ }\end{array}$ & $\begin{array}{l}\text { To segment the } \mathrm{DMZ} \\
\text { visitor based on } \\
\text { motivations }\end{array}$ & $\begin{array}{l}\text { To determine the } \\
\text { importance of } \\
\text { battlefield sites in } \\
\text { tourists' decision- } \\
\text { making }\end{array}$ \\
\hline $\begin{array}{l}\text { Methodology } \\
\text { Questionnaire } \\
\text { survey }\end{array}$ & $\begin{array}{l}\text { Content analysis } \\
\text { Means comparison } \\
\text { Factor analysis }\end{array}$ & $\begin{array}{l}\text { Cluster analysis, } \\
\text { Multiple discriminant } \\
\text { analysis } \\
\text { Cross-tabulation } \\
\text { analysis }\end{array}$ & $\begin{array}{l}\text { Analysis of } \\
\text { Variance }\end{array}$ \\
\hline Main results & $\begin{array}{l}\text { Identification of five } \\
\text { motivations: } \\
\text { - Personal } \\
\text { involvement } \\
\text { - Interest in war } \\
\text { related sites and } \\
\text { exhibitions } \\
\text { - Education and } \\
\text { exploration } \\
\text { - Novelty seeking } \\
\text { - Location and } \\
\text { convenience }\end{array}$ & $\begin{array}{l}\text { Identification of three } \\
\text { visitor segments: } \\
\text { (1) The Battlefield } \\
\text { Tourism Enthusiast: } \\
\text { (2) The Opportunist: } \\
\text { (3) The Passive } \\
\text { Tourist }\end{array}$ & $\begin{array}{l}\text { Identification of the } \\
\text { importance level of } \\
\text { the battlefield sites: } \\
\text { Moderately } \\
\text { important } \\
\text { Of little importance } \\
\text { Of little importance }\end{array}$ \\
\hline
\end{tabular}


This concluding chapter discusses the major issues emanating from these findings with more depth. It is structured into five sections: the first three sections (7.2, 7.3 and 7.4) discuss the findings in context with the three research objectives while the last two sections (7.5 and 7.6) examine some implications resulted from this study with further recommendations. Specifically, the next section (7.2) discusses the variety of tourists' motivations for visiting the DMZ (i.e. objective one), bringing together the results from factor analysis of quantitative motivational items as well as content analysis of open-ended questions. Section 7.3 summarises the profiles of the visitor segments and points out the main characteristics of the battlefield tourists (i.e. objective two). Section 7.4 draws conclusions about the role of battlefield sites in tourists' decision to travel to Vietnam based on the previous discussion and interpretations (i.e. objective three). The implications of the findings and follow-up research are presented next. In particular, section 7.5 gives recommendations for tourism practitioners, including the Vietnamese tourism organisations, DMZ tour operators and the managers of the Vịnh Mốc Tunnels and other historical sites. Implications for future research are presented in section 7.6. Some concluding remarks summarising the study's main findings, its significance and contribution are placed at the end of this chapter.

\subsection{Motivations for visiting battlefield sites}

As discussed in Chapter Two, tourists visit thanatouristic sites for several reasons. Some of the most common reasons were found to be an interest in history (Best, 2007; Gatewood \& Cameron, 2004), and education and exploration (Cooper, 2006; Strange \& Kempa, 2003; Yuill, 2003). Other motivations identified include: remembrance, location, recommended by someone, because of a vague sense of its historic importance, curiosity, identity, personal connection and so forth (e.g. Ashworth, 2004; Best, 2007; Cooper, 2006; Seaton, 1999; Strange \& Kempa, 2003).

In this study, five motivations were revealed from the factor analysis of 22 quantitative items namely "Personal involvement", "Interest in war related sites and exhibitions", "Education and Exploration", "Novelty seeking", and "Location and Convenience" (Table 5-3). Each of these factors was comprised of at least two interrelated motivational items. Collectively, the five factors explained $53.09 \%$ of the total variance. Despite not covering all possible tourist motivations, results from the factor analysis contribute to the exploratory initial understanding of motivations for visiting the $\mathrm{DMZ}$. 
Specifically, "Education and exploration" is a significant factor that draws tourists to the DMZ. This factor implies that visitors have an interest in history and a desire to improve their knowledge. In particular, by visiting the $\mathrm{DMZ}$, visitors sought to understand more about the Vietnam War. The DMZ was selected as it was believed to represent an important part of the War.

Likewise, "Interest in war related sites and exhibitions" is also an important reason for visiting the DMZ. This factor mostly implies an interest in physical war related remnants. Visitors might have seen some movies about the Vietnam War and wanted to see the places in real life. Undoubtedly, the DMZ was a famous historical site, which was often mentioned in the media about the Vietnam War, thus it is not surprising that the DMZ attracts much attention from tourists.

Conversely, there are cases where tourists visited the DMZ mainly because of the "Location and convenience" factor. Geographically, Vietnam occupies part of the Indochina peninsula, bordering the South China Sea. Most cities and tourist destinations in Vietnam generally can be included in one north-south route, which makes it easier for tourists to travel throughout the country. As discussed in the Introduction chapter, the $\mathrm{DMZ}$ is located in the Quảng Trị province, approximately at the $17^{0}$ latitude. Most tourists travelling in Vietnam would depart from Hanoi and end their trips in Ho Chi Minh City (or vice versa), therefore, except for those travelling by plane, the DMZ is on their way. Furthermore, the DMZ is very close to Huế - one of the main tourist cities in Vietnam. Hence, tourists stopping in Huế may conveniently visit the DMZ. These two advantages contribute to attracting tourists to the DMZ.

Moreover, a trip to the DMZ, for some tourists, was mainly "Novelty seeking". After a sequence of beaches and other natural landscapes, the $\mathrm{DMZ}$ gave them something new and different from their usual itineraries. Obviously, trying and exploring new experiences is among the most enjoyable activities for tourists. However, it may also be that tourists had no other activity to do or that they had to accompany someone else that they visited the DMZ. Therefore, their motivation is not related to a "serious interest" in the site.

Another motivation for visiting the DMZ is "Personal involvement". This motivation especially reflects in those who had a personal connection and/or were closely related to someone who had a connection with the DMZ. It describes the visitors' 
need to recall their memories, to confront a painful part of their past and to learn about their heritage. This not only applies to those who had a connection with the War, it is also relevant to those who had lived during the period of the War (mostly middle-aged visitors), who were directly or indirectly influenced by the War (e.g. war-time protests).

The quantitative findings above were supported and extended by content analysis of the open-ended questions. In particular, motivations for visiting the $\mathrm{DMZ}$ were described as interest in history and the Vietnam War, education (learning), interest in seeing the Vịnh Mốc Tunnels, to see the DMZ in real life, because the DMZ is an important site, to see the war artefacts, because it was recommended by others, curiosity and novelty seeking, to see how life was during the War, location and convenience, personal involvement and because it was a part of a package tour. While most self-expressed reasons were related to the delineated motivational factors, it is noteworthy that certain reasons were not included. Specifically, in some cases, tourists found only one specific aspect of the site played a role in their decision to visit. As shown in Table 5-1, more than one fifth of the respondents indicated that they came to the DMZ specifically to see the Vịnh Mốc Tunnels. This is in line with findings from Gatewood and Cameron's (2004) study, in which some visitors were found to be interested in only one typical physical aspect of a site.

While findings from the open-ended question contribute to supplement the unexplained variance in the factor analysis, it also confirms the importance of the "education" motivation for visiting the DMZ among visitors.

The discussion above shows that visitors to the DMZ may include those who are seriously interested in battlefield tourism and history as well as those who visit the site out of curiosity, novelty seeking and other similar reasons. It is thus essential to classify these tourists based on their motivations so as to better understand their behaviour and travel decision-making. Segmenting visitors on motivations will therefore be of great help.

\subsection{Battlefield visitors segmentation}

The special interest tourists profiled in the literature tend to be diverse in terms of socio-demographic characteristics (Hall \& Weiler, 1992). They are likely to be affluent adults, better educated, on higher incomes and also typically from Western 
and developed countries. Tourists to battlefield sites in particular were found to share similar profiles (Gatewood \& Cameron, 2004; Lee et al., 2007).

In line with findings from previous studies of visitations to battlefield sites, the DMZ visitors appeared to be well-educated with a majority having bachelor or post graduate degrees. Most visitors did not have any connection with the Vietnam War or membership of any military related associations. However, statistically significant differences occurred between groups of visitors based on motivations regarding several characteristics, especially decision-making.

Specifically, visitors to the DMZ can be categorised into three distinctive groups based on motivations, which are "The Battlefield Tourism Enthusiast", "The Opportunist" and "The Passive Tourist". In particular, the Enthusiasts are highly interested in visiting the DMZ for many reasons, mostly for "Education and Exploration", "Interest in war related sites and exhibitions", and "Personal involvement". The Opportunist visited the DMZ mainly for "Novelty seeking" purposes and because it was en-route on their trip. The Passive Tourist, however, indicated lowest ratings for all motivations compared to the other two groups. It is noted that these groups of visitors are not equal in size. Enthusiast is the smallest group, accounting for approximately $15 \%$ of the total visitor sample followed by the Opportunists (33\%). Conversely, the largest group, Passive Tourists, represents slightly more than half of the total visitors.

Enthusiast visitors are those who are highly interested in battlefield tourism in Vietnam. These tourists are more likely to have a connection with the Vietnam War (compared to their counterparts) and thus tend to be in older age groups (i.e. fifty plus). These visitors often place more emphasis on the education purpose in their trip to Vietnam than average. Enthusiast visitors are mainly attracted to Vietnam because of the country's history. This type of tourists is highly aware of the DMZ, information about which they obtained mostly from travel guidebooks, books and documentaries about the Vietnam War. Enthusiasts indicated a considerable interest in visiting the DMZ by making the decision to visit the site before their trip to Vietnam. Most of these visitors travelled on group tour bus to the DMZ although private tours were also popular. Compared to the other groups of visitors, Enthusiasts appear to be more interested in battlefield tourism as shown by a greater number of battlefield sites visited and a higher interest in visiting battlefield sites in Vietnam. 
For these tourists, the DMZ and other battlefield sites were more important in their decision to visit Vietnam than the other two segments.

Opportunist visitors, the second largest segment, include those who show a moderate interest in battlefield tourism. This group mostly consists of younger travellers in their twenties and thirties who have a little connection with the Vietnam War. These tourists often travel on holiday to Vietnam, which attracted them mainly because of the culture and landscape. Opportunists are less aware of the DMZ than the Enthusiasts and visiting the DMZ and other battlefield sites in Vietnam were not of high importance in their travel decision-making. Therefore, Opportunists tend to make their decision to visit the DMZ closer to the visiting day than the other groups, which is probably due to the influence from other travellers, one of their most common information sources. This group of tourists appears to have relatively low experience in battlefield tourism as shown by the small number of battlefield sites visited and future intended visits in Vietnam.

The third visitor segment, Passive Tourists, is considerably different with the Enthusiasts. However, these visitors share some similarities with the Opportunist regarding age structure, their purpose of visiting Vietnam, and which attributes of Vietnam they were attracted to. They appear to be least aware of the DMZ. Travel guidebooks and movies about the Vietnam War were their most important information sources. The decision to visit the $\mathrm{DMZ}$ was made more evenly between the four travel stages by the Passive Tourists than the other two visitor groups. These tourists tend to opt for the commercial group bus tour to visit the DMZ. As with the Opportunist, the Passive Tourists indicated a moderate interest in battlefield tourism and a low level of participation in battlefield tourism in Vietnam. However, the Vietnamese battlefield sites were not as important for them when compared to the Opportunist.

As discussed, there are three types of visitors to the DMZ, however, who among them are "battlefield tourists"? Defining a battlefield tourist, like defining a special interest tourist, is a difficult task.

In recent literature, special interest tourists have been studied in relation to cultural tourism (McKercher, 2002; McKercher \& Cros, 2003). McKercher (2002) argues that tourists visiting cultural or heritage attractions during their trip are not necessarily cultural tourists. His study reveals that one third of tourists experience 
cultural or heritage attractions at some stage of their visit, yet only a minority (4\%) were classified as purposeful cultural tourists, who travelled specifically to learn about cultural heritage and had a deep cultural learning experience. From the analysis of visitors to the DMZ in this study, it appears that tourists to Vietnamese battlefield sites demonstrate a similar pattern.

Bucking recent SIT research trends, McKercher and Chan (2005) call for the discontinuation of the method of using actions as a valid proxy for motives to travel or trip purpose to define SI tourism market segments. Their research proves that the use of activities as a valid proxy for a single, identifiable SI trip purpose is inappropriate. The prevalence of Passive Tourist motivations present in the study sample seems to suggest that as McKercher and Chan state, the method of using participation to demonstrate motives fails to delve deep enough into the true motivations behind battlefield tourism. The authors argue that the practice of comparing participants with non-participants was flawed because it tests effect-effect relationships and not cause-effect relationship. More accurately, the term "special interest tourists" describes those who "visit attractions or activities that are evocative of a specialist interest" (p.30). Hence, calling someone a special interest tourist means that specialist interest is the primary reasons in his or her travel decision and destination choice, whilst "the more benign term 'a tourist who visited an activity that is suggestive of a specialist interest at some time during their trip' (i.e. someone who visited a museum at some time during his or her trip) describes behaviour making without any inferences about its underlying cause" (p. 30). As the constructs of special interest tourists seem to explain relatively little of the behaviours and motivations of tourists in this study, it leaves the question of more explanatory constructs open to further research.

In addition, Slade (2003) argues that the presence of people at places associated with death and disaster does not necessarily mean that their motivations are thanatouristic or that they are thanatourists. Rather, in the case of Australians and New Zealanders visiting Gallipoli for example, it was concerned with nationhood (e.g. to discover who they are, where they came from, and what the meanings of their nations might be in the modern world) (Slade, 2003).

Similarly, in this study, not all DMZ visitors are battlefield tourists or should be considered as "battlefield tourists". Taking in Trauer's (2006), Charters and Knight's 
(2002), and McKercher's (2002) recommendations for defining a special interest tourist to apply to this study, presumably, battlefield tourists are those who have a high interest in visiting battlefield sites, high awareness and knowledge of the sites, high level of participation in battlefield tourism and place high importance in visiting the battlefields in their trip. In addition, the battlefield related motives need to be highly important for those classified as battlefield tourists. Among the three groups of visitors identified in this study, only the Enthusiasts tended to meet these requirements. These are the tourists that have a passion for battlefield tourism in Vietnam and have considerably high importance level of battlefield related motivations. However, the number of visitors in this category is smallest compared to other groups ( $15 \%$ of the total sample). Conversely, the Opportunists and Passive Tourists account for a significant proportion of the total visitors (85\%).

In short, it can be seen that most tourists to the DMZ are general tourists. The number of tourists who may be classified as "battlefield tourists" is small. This is in line with other SIT studies (Charters \& Ali-Knight, 2002; McKercher, 2002; McKercher \& Cros, 2003; Mehmetoglu, 2005). Compared to the cultural tourists as found by McKercher (2002) for example, the Enthusiast in this study shares some similarities with the "Purposeful cultural tourist": they were looking for an intellectual learning experience and placed high importance on special interest motivation in the decision to visit a destination. Likewise, the Passive Tourist was similar to the "Casual cultural tourist", who was only slightly motivated to travel for special interest reasons. In addition, the "Opportunist" is comparable to the "Incidental cultural tourist", who often visited attractions based on convenience.

The visitor segmentation suggests that not all tourists were highly interested in visiting battlefield sites in Vietnam. Therefore, assessment of the attraction of battlefield sites in Vietnam for international tourists is needed in order to justify the national tourism marketing strategies.

\subsection{The attractions of Vietnam: the role of battlefield sites in tourists' decision to travel to Vietnam}

It is believed that Vietnam was made famous by war (Alneng, 2002). The Vietnam National Administration of Tourism therefore started to include the Vietnam War in marketing the country to international visitors, especially Americans (Schwenkel, 2006). However, the attraction of Vietnamese battlefield sites for international 
tourists is questionable. Research shows that attributes of Vietnam that were highly appreciated by tourists include world heritage sites, the excitement of the experience and positive emotion, accessible and authentic attractions, friendly people, and service quality (Tran, Schneider, \& Gartner, 2006), and culture and history (Truong \& Foster, 2006). Battlefields were not among the most appealing factors. Furthermore, the war tourism products were targeted at Americans, yet according to Agrusa, Tanner, and Dupuis (2006), the Vietnam War American veterans had a low interest in returning to Vietnam as tourists.

Similarly, this study found that battlefields sites per se were not the most important attractions of Vietnam for tourists. Instead, the culture, landscape and history of the country are most attractive (Table 5-17). Visitors demonstrated only a moderate interest (means of 3.12) in visiting battlefield sites in Vietnam. Earlier discussion indicates that battlefield sites in general and the DMZ in particular played a little role in tourists' decision to visit Vietnam (means of 2.22 and 2.09 respectively). This is reinforced by tourists' relatively low participation in battlefield tourism in Vietnam (Table 6-15 and 6-18).

Clearly, Vietnam has much more to offer tourists other than just battlefield sites. Therefore, knowledge of highly rated attributes is critical for tourism planners to develop appropriate marketing strategies. In addition, understanding the role of the battlefield sites is vital to build better suited strategies aimed at the right customers.

Undoubtedly, operating and managing sites associated with death and disaster as tourist attractions represent many challenges. As demonstrated by the predominance of Opportunist and Passive Tourists in the sample, while tourists are interested in visiting thanatouristic sites, the psyche of the tourists is more targeted towards enjoyment of a holiday and relaxation, with historical "dark" tourist sites secondary. The primary question in managing these sites is the morality and sensitivity of the commodification of suffering and its evident entertainment value resulting from the refashioning of historical agonies as a tourism product (Strange \& Kempa, 2003). According to Miles (2002), the challenge for all dark tourism is to convert the memorial "thing" into a live "memory". The author suggests that in order to be successful, a dark tourist attraction must create a level of empathy between the sightseer and the past victim. Positioning battlefields and war related sites as attractive tourist destinations is therefore a difficult task. As Henderson (2007) 
asserts, wartime heritage attractions are facing typical challenges. They have to hold on to the historical facts while at the same time articulate the ambiguities of historical truths. As a part of the leisure and tourism industry, these sites must have both entertaining and education functions. The author states that these dilemmas must be handled with care so as to ensure appropriate treatment and avoid excessive commercialisation. With regards to the development of wartime attractions in Vietnam, Henderson (2000) suggests that although the position of wartime heritage attractions in Vietnam's overall tourism product should not be overemphasised, this has been a growth area. The author questions the effectiveness of the interpretation and presentation of the $\mathrm{Cu}$ Chi Tunnels, which are believed to be more entertainment focused, and thus undermine the educative function of such a site. Henderson states that establishing a suitable and acceptable form of communication remains problematic in the Vietnam War attractions. These implications are useful to supplement the particular case of this study considering that the Vịnh Mốc Tunnels share some similarities, although less commercialised, with the $\mathrm{Cu}$ Chi Tunnels.

Regarding the DMZ as a battlefield attraction, in spite of a reasonably high level of tourist satisfaction, there is still room for improvement. Findings from this thesis have brought out several implications for tourism practitioners in Vietnam.

\subsection{Implications and recommendations for tourism practitioners}

This section summarises the implications for tourism practitioners from macro to micro level, including the Vietnam national tourism organisations, the DMZ tour

operators and the management of the Vịnh Mốc Tunnels and other historical sites. It also provides some recommendations for each practitioner in order to develop better marketing strategies and improve product and service quality.

\subsubsection{Implications and recommendations for Vietnam's national tourism organisations}

The first implication for the national tourism organisations in Vietnam is that battlefield sites are not the main attraction for international tourists. Thus these sites should not be overemphasised in tourism marketing strategies. In other words, although the Vietnam War may play a significant role in attracting tourists' attention to Vietnam, battlefield sites per se cannot be the sole leading tourism product. Rather, marketing strategies should centre on the most appealing factors of Vietnam. 
The low emphasis on battlefield sites to the tourists of this study demonstrates that while tourists acknowledge the Vietnam War, they wish to visit Vietnam to learn about other areas of the country instead. Based on the tourists' assessment, it is necessary to focus on and take advantage of the strengths while improving the weaknesses. Specifically, history, culture and landscape are considered the most important attractions of Vietnam as shown by their high level of importance for tourists. Therefore, these factors should be emphasised in marketing strategies and in promoting the country internationally. In fact, Vietnam is endowed with a diversity of landscapes and sceneries, a unique culture, a long rich history and so on. These national assets offer numerous tourism opportunities. However, on the other hand, attention should be also given to service quality and tourism infrastructure. Improvements in service quality and investment in tourism infrastructure are recommended in order to provide a better experience for tourists and to improve the tourists' image of Vietnam accordingly.

The second implication for tourism organisations is that visitors to battlefield sites are diverse. In particular, there are three groups of visitors to battlefield sites: the Enthusiast, the Opportunist, and the Passive Tourist. These three visitor segments differ in terms of socio-demographic characteristics, trip characteristics, motivations and travel decision-making. Therefore specific marketing strategies are needed to better meet their needs.

The Enthusiasts are highly interested in visiting the battlefield sites in Vietnam, which makes this group the target for war tourism products. As Enthusiasts often make their decision well in advance, it is important to provide them with sufficient information before their trip. The internet thus could be an effective information channel. However, it is noted that the number of tourists falling in this group is small. Therefore, investment in this segment should be carefully considered. Conversely, the Opportunist and the Passive Tourist have a relatively low interest in visiting battlefield sites in Vietnam. Since these tourists tend to make their decision closer to their visiting day, on site marketing is important. Specifically, brochures, leaflets and guidebooks about battlefield sites and tours should be made available at every city's tourist information centres, accommodation and transportation providers.

The third implication is regarding visitor motivations for visiting battlefield sites. As discussed, most visitors were seeking "education" while visiting the DMZ. 
Therefore, it is important to offer tourists rich information about the sites and the related historical events. Visitors to Vietnamese battlefield sites are provided with the Vietnamese view of the history and the war. However, it would be useful to include a wide range of accounts to avoid making tourists feel overwhelmed with one-sided stories, which is often interpreted as "propaganda". Besides education, it is also important to recall that "novelty seeking" is a common need for tourists. Therefore, it is critical to bring some entertainment elements (educational activities and interaction for example) to the site while remaining loyal to its important historical position. Specific recommendations for the DMZ tour operators and the management of the Vịnh Mốc Tunnels follow.

\subsubsection{Implications and recommendations for DMZ tour operators}

Although visitors were generally satisfied with their trip experience, some aspects could be improved. Based on the tourists' comments, some major improvements are recommended.

First, the discussion about tourists' most important information sources shows that the travel organisations (e.g. visitor information centres, travel agents, accommodation providers, and transportation providers) in Vietnam in general and Huế and Quảng Trị in particular were considered least important by tourists. In other words, these organisations have not been effective in providing necessary information for tourists. Given the majority of tourists are general tourists, who are likely to require on-site information, it is critical to provide sufficient information by means of brochures, posters, booklets, and so on at major tourist sites in the area.

Second, the DMZ tour exhibits some similarities with the commercial tours to the Great War battlefield sites on the Western Front as documented in Iles (2006). Like tourists on the Western Front, DMZ visitors tend to encounter a landscape which now visually portrays comparatively little of the historical war events. Most of the pulverised and battle-scarred terrain has long since vanished under crop cultivation and urban development. In fact, there are very few war relics left to see. Visitors in this study indicated their disappointment at the lack of visual reminders of the war, which is in line with Schwenkel's study (2006). Consequently, as Iles (2006) pointed out, the guides play a central role in the success of any battlefield tours, which is also the case in the DMZ tour. The guides have considerable influence on the tourists' perception of the places visited. Therefore, it is important to have experienced guides 
who are proficient in English and other popular languages to articulate the information efficiently and to provide tourists with positive emotions.

Third, as a matter of fact, during the DMZ tour, visitors were given a great amount of information within a short period of time by the guides. The intensive information deluge together with the difficult Vietnamese names of sites and people confuse tourists and reduce their ability to remember things accurately. Therefore, it is better for tourists to get as much information as they can get in their hands before and during the tour, instead of hearing the information solely from the guides. In particular, tourists should be provided with a reading list, detailed itineraries of the tour, descriptions of the sites, brief related facts and figures and so on. Moreover, as tourists spend a lot of time on the bus travelling from place to place on their tour, it would be useful to show some documentaries and films about the Vietnam history as well as the Vietnam War. This will not only provide tourists with some interesting and necessary information, but also keep them entertained during the long rides.

Fourth, in order to minimise the time spent on travelling from site to site, the tour should be organised effectively. Obviously, the distances between sites in the DMZ cannot be changed. However, what can be improved are the transportation and the selection of sites. Specifically, tour buses should be upgraded. In addition, the tour should include fewer sites, which can give tourists more time to explore the sites in depth rather than going around many places without really getting to know them.

Last but not least, it is suggested that tourists be provided with stories from both sides of the War. However, as Henderson (2000) acknowledges, it is difficult and perhaps impossible for the interpreter working within the confines of a particular political system to satisfy the demands of a variety of visitors while maintaining authenticity and integrity. On the other hand, some personal stories, meeting with the people who lived around the DMZ during the War, and more contact with local people would personalise the experience on an individual level and allow tourists to feel a personal connection with a historical event that is fast fading from global memory.

\subsubsection{Implications and recommendations for the management of the Vịnh Mốc Tunnels and other Vietnamese historical sites}

Comments from the visitors about their experience in the DMZ provided several implications and recommendations for the management of the Vịnh Mốc Tunnels. 
To begin with, the fact that tourists visited the DMZ and the Vịnh Mốc Tunnels mainly for learning emphasises the importance of information. Therefore, it is important that visitors are provided with the information they need (e.g. history of the Tunnels, description of the systems, related war events and so on) from the tour guides or from information handouts such as brochures and maps. The information should be available in different languages, especially English. Therefore, it is critical to have well-trained guides with proficiency in foreign languages.

As part of the information service, a good museum is important to satisfy the tourists' need for information about the site. At present, the museum at the Vịnh Mốc Tunnels is very simple and does not contain enough information. There are merely some black and white photos, a map of the area, a plan of the tunnels structure and a few tools used to dig the tunnels displayed. To compensate for the lack of the reminders of the War, it is useful to include some visual aids, for example, video showing documentaries of the Vietnam War in the museum. It would also be interesting for tourists to have a guide that was personally connected with the Tunnels (e.g. one of the children who were born in the Tunnels) to make the stories more lively and effective.

Furthermore, it is important to improve the site facilities to provide tourists with better experiences. In particular, apart from a museum, a common room for tourists to rest after the long walk around the Tunnels is needed. It would also be useful to improve the sanitary facilities (i.e. rest rooms) for the comfort of tourists at the site.

These recommendations were made for the Vịnh Mốc Tunnels particularly. However, they can be applied to other historical sites that share similar characteristics and functions. One typical example is the $\mathrm{Cu}$ Chi Tunnels, which was criticised for being overly commercialised and entertainment focused as discussed earlier (Henderson, 2000). Taking in the implications from this study, the management should give more attention to the educative capability of the site.

\subsection{Implications for future research}

This study has employed a robust methodology which has brought about meaningful results. However, several issues have arisen, which call for further investigation.

Firstly, the study site may have influenced the research findings. If this study had been conducted in another battlefield site in Vietnam or in another country, the 
results would have been different. Hence, it would be interesting to compare findings of this study with other battlefield sites in the world such as those in France, Belgium, Korea, Japan, Cambodia and so on.

Secondly, this study only focused on international visitors to a particular battlefield site in Vietnam. Therefore, it would be useful to examine a wider tourist group, including both international and domestic tourists. Specifically, a study on Vietnamese visitors to battlefield sites would extend the understanding of tourist motivations, providing more insight into the literature on battlefield tourism motivation and Vietnam tourism. Given the difficulties of employing self-completed survey encountered in this study, focus group or interview methods may be more appropriate for Vietnamese respondents.

Continuing research on motivations for visiting battlefield sites is another possible direction. For instance, it would be interesting to study how these motivations will change when the last of the veterans, widows and children of the war die as it is anticipated that the motivation of "personal involvement" will vanish.

Finally, as Seaton and Lennon (2004) once wondered, it is left open to see if research will position thanatourism as normal behaviour or a darker kind of practice. The findings of this study show that tourists visiting battlefields do not necessarily manifest thanatouristic motivations. Rather, they were more likely to look for educational information. Therefore, another question that remains is whether battlefield tourism is a part of dark tourism or merely an overlap with this field. This would, again, require agreement between researchers regarding the terms "special interest tourism" and "dark tourism".

\subsection{Conclusion}

This study has made both a theoretical contribution to tourism research and a practical contribution to the tourism industry in Vietnam. Three major conclusions were drawn from this study. The first is that tourists visit the DMZ for a variety of reasons. This emphasises the dynamics of tourist motivations and the importance of motivation research. Second, most DMZ visitors are not (specialist) battlefield tourists but instead are general tourists with casual reasons to visit battlefield sites. Accordingly, appropriate marketing strategies are needed to target the right customers. Last but not least, battlefield sites are not the main attraction of Vietnam for tourists and do not play a significant role in tourists' decision to travel to Vietnam 
in general. However, the Vietnam War has left a mark on world history, and still attracts much attention from all over the world. Therefore, even though battlefields and war tourism products should not be the main construct in the national tourism marketing, there should be proper care and investment in the development of battlefield and historical sites. If managed properly, these sites could contribute to improving understanding and raising awareness of the human cruelty and suffering of war, and assist us in avoiding the same mistakes in the future. 


\section{Appendices}




\section{Appendix 1: Information handout for survey participants}

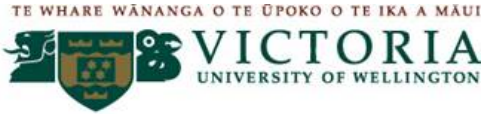

MTM Research Thesis

DMZ VISITOR SURVEY

INFORMATION HANDOUT FOR SURVEY PARTICIPANTS

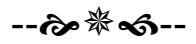

Hello/Xin chào!

My name is Diem-Trinh Thi Le (Vi). I am a student at Victoria University of Wellington. I am conducting this survey for my Master of Tourism Management thesis.

\section{Project Overview}

This research project examines the characteristics of visitors to the De-militarised Zone in Vietnam. It seeks to identify and investigate the different groups of visitors so that recommendations can be made to better respond to visitors, and to improve the tourism products in Huế and Quảng Trị Province, Vietnam.

- The completion of the questionnaire takes approximately 10-15 minutes.

- Your participation in this survey is voluntary and you are free to withdraw at any stage, in this case, your incomplete questionnaire will be destroyed.

- Your answers will be treated as anonymous and destroyed at the completion of the project.

- The results may be used for a future conference report or a publication and shared with the local tourism industry.

- Your participation in this survey will be considered as your agreement with the conditions outlined above.

\section{CONTACT INFORMATION}

Principal investigator:

Diem-Trinh Thi Le

Masters of Tourism Management Student

Victoria Management School

Victoria University of Wellington, New

Zealand

Email: diemtrinh.le@vuw.ac.nz

Phone: +84-935.229.085 (Vietnam)

+64-212.922.757 (New Zealand)
Supervisors:

Prof. Douglas Pearce

Email: Douglas.Pearce@vuw.ac.nz

Dr. Christian Schott

Email: Christian.Schott@vuw.ac.nz

Victoria Management School

Victoria University of Wellington, New

Zealand

P.O. Box 600, Wellington

Phone: +64-4-463 5715

Fax: +64-4-463-5180 


\section{Appendix 2: Self-completed questionnaire for survey participants}

\section{QUESTIONNAIRE}

Please tick in the box $\square$ and circle the number that most applies to you and fill in the lines.

\section{A. Your trip to Vietnam}

1. Is this your first trip to Vietnam?

Yes

$\square_{1} \quad$ No

$\square_{2}$

If not, how many times have you previously visited Vietnam?

$1 b$

2. Did you travel on a package tour to Vietnam?

Yes

$\square_{1} \quad$ No

3. What is your main purpose for visiting Vietnam?

Visiting friends and relatives

Business

Vacation

$\begin{array}{lll}\square_{1} & \text { Education } & \square_{4} \\ \square_{2} & \text { Other (please specify) } & \square_{5} \\ \square_{3} & \end{array}$

4. Please indicate from the following list the three most important attributes of Vietnam that attracted you to visit the country?

Price (e.g. cost, good value for money)

Culture

Opportunities for outdoor activities

Safety

Local people's attitude towards tourists

Infrastructure and tourism facilities

History

$\begin{array}{lll}\square_{1} & \text { Landscape (beautiful scenery) } & \square_{8} \\ \square_{2} & \text { Climate (pleasant weather) } & \square_{9} \\ \square_{3} & \text { Accessibility } & \square_{10} \\ \square_{4} & \text { Service quality } & \square_{11} \\ \square_{5} & \text { Battlefield sites } & \square_{12} \\ \square_{6} & \text { Other (please specify) } & \square_{13} \\ \square_{7} & \end{array}$

5. How many days are you planning to stay in Vietnam?

B. Your visit to the De-militarised Zone (DMZ)

6. Is this your first trip to the DMZ?

Yes

$\square_{1} \quad$ No

$\square_{2}$

If not, how many times have you previously visited the DMZ?

$6 b$

7. How did you make your travel arrangement to the DMZ?

$\begin{array}{llll}\text { It is a part of your package tour to } & \square_{1} & \text { Taken by friends/relatives } & \square_{4} \\ \text { Vietnam } & \square_{2} & \text { Bought a private tour to the DMZ } & \square_{5} \\ \text { Organised by yourself } & \square_{3} & \text { Other (please specify) } & \square_{6}\end{array}$

8. Who are you travelling with to the DMZ?

By yourself

Friends

Partner

$\begin{array}{lll}\square_{1} & \text { Family and/or relatives } & \square_{4} \\ \square_{2} & \text { Colleagues } & \square_{5} \\ \square_{3} & \text { Other (please specify) } & \square_{6}\end{array}$

9. How long are you going to spend in the DMZ on this trip?
$1 / 2$ day

1 day $\square_{1} \quad 2$ days

$\square_{2} \quad$ Other (please specify) $\square$

$\square_{6}$ 
10. When did you decide to visit the DMZ?

$\begin{array}{lll}\text { Before your trip to Vietnam } & \square_{1} & \begin{array}{l}\text { During your stay in Hue/Quang Tri/Quang } \\ \text { Binh }\end{array} \square_{3} \\ \text { Before your trip to Hue/Quang Tri/Quang } & \square_{2} & \text { On the way to somewhere else today }\end{array} \square_{4}$

Binh

11. Were you aware of the DMZ before your visit to Vietnam?

$\rightarrow$ If not, please go to question 13

Yes

$\square_{1} \quad$ No

12. How would you evaluate your knowledge of the $\mathbf{D M Z}$ before your visit to Vietnam?

$\begin{array}{lllllll}\text { Minimal knowledge } & 1 & 2 & 3 & 4 & 5 & \text { Very good }\end{array}$

13. What was the main aspect of the DMZ that you were aware of before your visit to the DMZ?

14. What were your three most important sources of information about the DMZ?

$\begin{array}{llll}\text { Family and relatives } & \square_{1} & \text { Visitor centre/Information centre } & \square_{9} \\ \text { Other travellers } & \square_{2} & \text { Documentaries about the Vietnam War } & \square_{10} \\ \text { Movies about the Vietnam War } & \square_{3} & \text { Newspapers and magazines } & \square_{11} \\ \text { Vietnamese travel agents } & \square_{4} & \text { Travel guidebooks } & \square_{12} \\ \text { Internet } & \square_{5} & \text { School education } & \square_{13} \\ \text { Books about the Vietnam War } & \square_{6} & \text { Travel agents in your home countries } & \square_{14} \\ \text { Accommodation providers } & \square_{7} & \text { Friends } & \square_{15} \\ \text { Transportation providers } & \square_{8} & \text { Other (please specify) } & \square_{16}\end{array}$

15. Why did you visit the DMZ?

16. Please rate the following reasons for your visiting the DMZ

$\begin{array}{lllllll} & \begin{array}{l}\text { Un- } \\ \text { importa } \\ \text { nt }\end{array} & \begin{array}{l}\text { Of little } \\ \text { importa } \\ \text { nce }\end{array} & \begin{array}{l}\text { Modera } \\ \text { tely } \\ \text { importa } \\ \text { nt }\end{array} & \begin{array}{l}\text { Import } \\ \text { ant }\end{array} & \begin{array}{l}\text { Very } \\ \text { impo } \\ \text { rtant }\end{array} & \begin{array}{l}\text { N/ } \\ \text { A }\end{array} \\ \text { a Because I am interested in history } & 1 & 2 & 3 & 4 & 5 & - \\ \text { b To see real places from the movies I } & 1 & 2 & 3 & 4 & 5 & - \\ \quad \text { watched } & & & & & & \\ \text { C Because it is a part of a package tour } & 1 & 2 & 3 & 4 & 5 & - \\ \text { d Because I am curious } & 1 & 2 & 3 & 4 & 5 & - \\ \text { e Because it is on my way } & 1 & 2 & 3 & 4 & 5 & - \\ \text { f Because I have no other activity to do } & 1 & 2 & 3 & 4 & 5 & - \\ \text { g To accompany someone else } & 1 & 2 & 3 & 4 & 5 & -\end{array}$




\begin{tabular}{|c|c|c|c|c|c|c|c|}
\hline $\mathrm{h}$ & To try something new and different & 1 & 2 & 3 & 4 & 5 & - \\
\hline i & $\begin{array}{l}\text { To understand more about the Vietnam- } \\
\text { America War }\end{array}$ & 1 & 2 & 3 & 4 & 5 & - \\
\hline j & To get away from my daily routine & 1 & 2 & 3 & 4 & 5 & - \\
\hline k & Because I am interested in the military & 1 & 2 & 3 & 4 & 5 & - \\
\hline l & Because the DMZ is a famous attraction & 1 & 2 & 3 & 4 & 5 & - \\
\hline m & $\begin{array}{l}\text { To visit the places where someone I am } \\
\text { closely related to had connection with }\end{array}$ & 1 & 2 & 3 & 4 & 5 & - \\
\hline$n$ & $\begin{array}{l}\text { Because I am interested in battlefield } \\
\text { tourism }\end{array}$ & 1 & 2 & 3 & 4 & 5 & - \\
\hline 0 & Because it is near other attractions & 1 & 2 & 3 & 4 & 5 & - \\
\hline$p$ & $\begin{array}{l}\text { Because it represents an important part in } \\
\text { the Vietnam-America War }\end{array}$ & 1 & 2 & 3 & 4 & 5 & - \\
\hline$q$ & To confront a painful part of my past & 1 & 2 & 3 & 4 & 5 & - \\
\hline$r$ & $\begin{array}{l}\text { To honour and pay tribute to the people } \\
\text { whose lives were lost in the war }\end{array}$ & 1 & 2 & 3 & 4 & 5 & - \\
\hline S & To remember the days of my youth & 1 & 2 & 3 & 4 & 5 & - \\
\hline $\mathrm{t}$ & To see the war artefacts & 1 & 2 & 3 & 4 & 5 & - \\
\hline u & To learn about my heritage & 1 & 2 & 3 & 4 & 5 & - \\
\hline $\mathrm{v}$ & $\begin{array}{l}\text { Because I had personal connection with the } \\
\text { DMZ }\end{array}$ & 1 & 2 & 3 & 4 & 5 & - \\
\hline w & Other (please specify) & 1 & 2 & 3 & 4 & 5 & - \\
\hline
\end{tabular}

17. How important was the DMZ in your decision to travel to Vietnam?

$\begin{array}{lllllll}\text { Unimportant } & 1 & 2 & 3 & 4 & 5 & \text { Very important }\end{array}$

Please add some comments about the importance of the DMZ in your travel decision:

18. Which of the following sites have you visited or are you going to visit on this tour to the DMZ?

$\begin{array}{llll} & & \text { Have visited } & \begin{array}{l}\text { Are going to } \\ \text { visit }\end{array} \\ 1 & \text { The Rockpile } & \square_{1} & \square_{2} \\ 2 & \text { The Ho Chi Minh Trail and the Dakrong Bridge } & \square_{1} & \square_{2} \\ 3 & \text { Khe Sanh Marine Base } & \square_{1} & \square_{2} \\ 4 & \text { Truong Son National Cemetery } & \square_{1} & \square_{2} \\ 5 & \text { Doc Mieu } & \square_{1} & \square_{2} \\ 6 & \text { Ben Hai river and Hien Luong Bridge } & \square_{1} & \square_{2} \\ 7 & \text { The Vinh Moc Tunnels } & \square_{1} & \square_{2} \\ 8 & \text { A Sau Valley and Hamburger Hill } & \square_{1} & \square_{2} \\ 9 & \text { The Quang Tri Citadel } & \square_{1} & \square_{2} \\ 10 & \text { Ai Tu Base and Airfield } & \square_{1} & \square_{2} \\ 11 & \text { Lang Vay Special Forces Camp } & \square_{1} & \square_{2} \\ 12 & \text { Thach Han river } & \square_{1} & \square_{2} \\ 13 & \text { Other (please specify) } & \square_{1} & \square_{2} \\ & & \square_{1} & \square_{2}\end{array}$

19. How would you rate your trip experience in the DMZ?

$\begin{array}{lllllll}\text { Not good at all } & 1 & 2 & 3 & 4 & 5 & \text { Very good }\end{array}$


20. What did you find the most interesting about your experience in the DMZ?

21. What would have improved your experience in the DMZ?

\section{Your interest in battlefield tourism}

22. How interested are you in visiting the battlefield sites in Vietnam?

$\begin{array}{lllllll}\text { Not interested at all } & 1 & 2 & 3 & 4 & 5 & \text { Very interested }\end{array}$

23. Please indicate how important the battlefield sites were in your decision to travel to Vietnam?

$\begin{array}{lllllll}\text { Unimportant } & 1 & 2 & 3 & 4 & 5 & \text { Very important }\end{array}$

Please add some comments about the importance of the battlefield sites in your travel decision:

24. What other battlefield sites in Vietnam have you visited or are you going to visit on this trip apart from the DMZ?

$\begin{array}{llll} & & \text { Have visited } & \text { Are going to visit } \\ 1 & \text { Dien Bien Phu } & \square_{1} & \square_{2} \\ 2 & \text { Hoa Lo Prison } & \square_{1} & \square_{2} \\ 3 & \text { The War Remnants Museum in Ho Chi Minh city } & \square_{1} & \square_{2} \\ 4 & \text { The Cu Chi Tunnels } & \square_{1} & \square_{2} \\ 5 & \text { My Lai/Son My village } & \square_{1} & \square_{2} \\ 6 & \text { Ve River (Quang Ngai Province) } & \square_{1} & \square_{2} \\ 7 & \text { Vietnam Gulf of Tonkin } & \square_{1} & \square_{2} \\ 8 & \text { Ia Drang Valley (Pleiku Province) } & \square_{1} & \square_{2} \\ 9 & \text { Pleime, Dak To (KonTum Province) } & \square_{1} & \square_{2} \\ 10 & \text { Other (please specify) } & \square_{1} & \square_{2} \\ & & \square_{1} & \square_{2}\end{array}$

25. Do you have any personal connection with the Vietnam War?

26. Does anyone you are closely related to have any personal connection with the Vietnam War?

$\begin{array}{llll}\text { Yes } & \square_{1} & \text { No } & \square_{2} \\ \text { Yes } & \square_{1} & \text { No } & \square_{2}\end{array}$

Please give some comments: 
27. What other battlefield sites in the world have you visited over the last two years?

\section{Your information}

Could you please tell me a bit about yourself?

28. Which age group are you in?

$\begin{array}{rrrrrrrr}<18 & \square_{1} & 30-39 & \square_{3} & 50-59 & \square_{5} & 70+\square_{7} \\ 19-29 & \square_{2} & 40-49 & \square_{4} & 60-69 & \square_{6} & \end{array}$

29. Which is the highest level of formal education you have completed?

$\begin{array}{llll}\text { Primary school } & \square_{1} & \text { Vocational school } & \square \\ \text { Secondary school } & \square_{2} & \text { College/University Graduate } & \square \\ \text { High school } & \square_{3} & \text { Post graduate } & \square \\ & & \text { Other (please specify) }\end{array}$

30. What is your nationality?

$\begin{array}{llll}\text { Vietnamese } & \square_{1} & \text { French } & \square_{6} \\ \text { American } & \square_{2} & \text { German } & \square_{7} \\ \text { Australian } & \square_{3} & \text { Japanese } & \square_{8} \\ \text { New Zealander } & \square_{4} & \text { Korean } & \square_{9} \\ \text { British } & \square_{5} & \text { Other } & \square_{10}\end{array}$

31. Are you currently a member of any groups listed below?

Veterans Association

Military Association

None of these

$\begin{array}{lll}\square_{1} & \text { Armed Forces Association } & \square \\ \square_{2} & \text { Other related Association } & \square\end{array}$

$\square_{5} \quad$ (please specify)

32. What is your gender?

Male

$\square_{1} \quad$ Female

33. Are there any other comments or suggestions you would like to make?

THANK YOU VERY MUCH FOR YOUR TI ME AND COOPERATI ON!

*** Please return your completed questionnaire to me at the ticket booth or to the tour guide and bus driver if you are on the bus. Thank you very much. Have a great time in Vietnam! 
Appendix 3: Information about questionnaire data collection

(22 June - 22 July, 2008)

\begin{tabular}{|c|c|c|c|}
\hline Date & $\begin{array}{c}\text { No. } \\
\text { questionnaires } \\
\text { distributed }\end{array}$ & $\begin{array}{c}\text { No. of usable } \\
\text { questionnaires } \\
\text { collected }\end{array}$ & Responses rate \\
\hline 22-Jun & 20 & 15 & 75.00 \\
\hline 23-Jun & 53 & 19 & 35.85 \\
\hline 24-Jun & 22 & 16 & 72.73 \\
\hline \multicolumn{4}{|l|}{ 25-Jun* } \\
\hline 26-Jun & 30 & 21 & 70.00 \\
\hline 27-Jun & 9 & 4 & 44.44 \\
\hline 28-Jun & 37 & 29 & 78.38 \\
\hline 29-Jun & 28 & 24 & 85.71 \\
\hline 30-Jun & 5 & 3 & 60.00 \\
\hline \multicolumn{4}{|l|}{ 1-Jul* } \\
\hline 2-Jul & 31 & 21 & 67.74 \\
\hline \multicolumn{4}{|l|}{ 3-Jul* } \\
\hline 4-Jul & 11 & 9 & 81.82 \\
\hline 5-Jul & 24 & 10 & 41.67 \\
\hline 6-Jul & 37 & 31 & 83.78 \\
\hline 7-Jul & 27 & 22 & 81.48 \\
\hline 8-Jul & 42 & 34 & 80.95 \\
\hline 9-Jul & 47 & 36 & 76.60 \\
\hline 10-Jul & 30 & 22 & 73.33 \\
\hline 11-Jul & 29 & 24 & 82.76 \\
\hline 12-Jul & 11 & 9 & 81.82 \\
\hline \multicolumn{4}{|l|}{ 13-Jul* } \\
\hline 14-Jul & 13 & 11 & 84.62 \\
\hline 15-Jul & 40 & 14 & 35.00 \\
\hline 16-Jul & 22 & 6 & 27.27 \\
\hline 17-Jul & 30 & 17 & 56.67 \\
\hline 18-Jul & 24 & 16 & 66.67 \\
\hline 19-Jul & 46 & 15 & 32.61 \\
\hline 20-Jul & 25 & 18 & 72.00 \\
\hline 21-Jul & 21 & 7 & 33.33 \\
\hline 22-Jul & 30 & 28 & 93.33 \\
\hline Total & 744 & 481 & 64.65 \\
\hline
\end{tabular}

*: day off 
Appendix 4: International visitors to Vietnam in 2007 by country

\begin{tabular}{|c|c|c|}
\hline Country & No. of tourists & $\%$ of total \\
\hline China & 558,719 & 13.39 \\
\hline South Korea & 475,535 & 11.4 \\
\hline USA & 412,301 & 9.88 \\
\hline Japan & 411,557 & 9.87 \\
\hline Taiwan (China) & 314,026 & 7.53 \\
\hline Australia & 227,300 & 5.45 \\
\hline France & 182,501 & 4.37 \\
\hline Thailand & 160,747 & 3.85 \\
\hline Cambodia & 150,655 & 3.61 \\
\hline Malaysia & 145,535 & 3.49 \\
\hline Singapore & 127,040 & 3.05 \\
\hline United Kingdom & 105,918 & 2.54 \\
\hline Germany & 95,740 & 2.3 \\
\hline Canada & 89,084 & 2.14 \\
\hline Russia Federal & 44,554 & 1.07 \\
\hline Netherlands & 36,622 & 0.88 \\
\hline Philippines & 31,820 & 0.76 \\
\hline Laos & 31,374 & 0.75 \\
\hline Spain & 27,224 & 0.65 \\
\hline Indonesia & 22,941 & 0.55 \\
\hline Sweden & 22,409 & 0.54 \\
\hline Italy & 21,933 & 0.53 \\
\hline Denmark & 21,130 & 0.51 \\
\hline Switzerland & 20,683 & 0.5 \\
\hline New Zealand & 20,173 & 0.48 \\
\hline Belgium & 18,706 & 0.45 \\
\hline Norway & 11,573 & 0.28 \\
\hline Finland & 6,262 & 0.15 \\
\hline Hong Kong (China) & 5,864 & 0.14 \\
\hline Others & 371,638 & 8.91 \\
\hline Total & $4,171,564$ & 100.00 \\
\hline
\end{tabular}

Source: Vietnam National Administration of Tourism (2008) 
Appendix 5: International visitors to Vietnam in July 2008 by country

\begin{tabular}{|l|c|c|}
\hline Country & No. of tourists & \% of total \\
\hline China & 44,194 & 13.39 \\
\hline USA & 39,812 & 12.06 \\
\hline South Korea & 32,443 & 9.83 \\
\hline Taiwan (China) & 29,867 & 9.05 \\
\hline Japan & 27,165 & 8.23 \\
\hline Australia & 22,538 & 6.83 \\
\hline France & 13,611 & 4.12 \\
\hline Malaysia & 13,587 & 4.12 \\
\hline Cambodia & 11,777 & 3.57 \\
\hline Singapore & 11,673 & 3.54 \\
\hline Thailand & 10,498 & 3.18 \\
\hline Canada & 8,857 & 2.68 \\
\hline United Kingdom & 8,066 & 2.44 \\
\hline Germany & 6,789 & 2.06 \\
\hline Netherlands & 4,555 & 1.38 \\
\hline Philippines & 3,776 & 1.14 \\
\hline Norway & 2,735 & 0.83 \\
\hline Russia Federal & 2,368 & 0.72 \\
\hline Denmark & 2,279 & 0.69 \\
\hline Laos & 2,156 & 0.65 \\
\hline Spain & 2,092 & 0.63 \\
\hline Belgium & 2,091 & 0.63 \\
\hline Switzerland & 2,046 & 0.62 \\
\hline New Zealand & 2,028 & 0.61 \\
\hline Indonesia & 1,731 & 0.52 \\
\hline Sweden & 1,679 & 0.51 \\
\hline Italy & 1,284 & 0.39 \\
\hline Finland & 404 & 0.12 \\
\hline Hong Kong (China) & $\mathbf{3 3 0 0 0 0}$ & 0.11 \\
\hline Others & & \\
\hline Total & 375 & \\
\hline
\end{tabular}

Source: Vietnam National Administration of Tourism (2008) 
Appendix 6: Distances between final clusters in six cluster solutions

\begin{tabular}{|c|c|c|c|c|c|c|c|}
\hline Formation & Cluster & 1 & 2 & 3 & 4 & 5 & 6 \\
\hline \multirow[t]{2}{*}{ 2-cluster } & 1 & & 2.114 & & & & \\
\hline & 2 & 2.114 & & & & & \\
\hline \multirow{3}{*}{ 3-cluster } & 1 & & 2.436 & 2.722 & & & \\
\hline & 2 & 2.436 & & 1.839 & & & \\
\hline & 3 & 2.722 & 1.839 & & & & \\
\hline \multirow{4}{*}{ 4-cluster } & 1 & & 3.574 & 2.967 & 2.633 & & \\
\hline & 2 & 3.574 & & 1.44 & 1.915 & & \\
\hline & 3 & 2.967 & 1.44 & & 1.896 & & \\
\hline & 4 & 2.633 & 1.915 & 1.896 & & & \\
\hline \multirow{5}{*}{ 5-cluster } & 1 & & 3.039 & 2.584 & 3.573 & 2.499 & \\
\hline & 2 & 3.039 & & 2.811 & 1.618 & 1.841 & \\
\hline & 3 & 2.584 & 2.811 & & 2.26 & 2.487 & \\
\hline & 4 & 3.573 & 1.618 & 2.26 & & 1.731 & \\
\hline & 5 & 2.499 & 1.841 & 2.487 & 1.731 & & \\
\hline \multirow{6}{*}{ 6-cluster } & 1 & & 1.682 & 2.12 & 2.182 & 2.44 & 2.257 \\
\hline & 2 & 1.682 & & 1.969 & 3.006 & 2.679 & 1.812 \\
\hline & 3 & 2.12 & 1.969 & & 2.806 & 3.088 & 1.667 \\
\hline & 4 & 2.182 & 3.006 & 2.806 & & 2.542 & 2.231 \\
\hline & 5 & 2.44 & 2.679 & 3.088 & 2.542 & & 3.226 \\
\hline & 6 & 2.257 & 1.812 & 1.667 & 2.231 & 3.226 & \\
\hline
\end{tabular}




\section{References}

Agrusa, J., Tanner, J., \& Dupuis, J. (2006). Determining the potential of American Vietnam veterans returning to Vietnam as tourists. International Journal of Tourism Research, 8(3), 223-234.

Alneng, V. (2002). 'What the Fuck is a Vietnam?': Touristic Phantasms and the Popcolonization of (the) Vietnam (War). Critique of Anthropology, 22(4), 461-489.

Andreu, L., Kozak, M., Avci, N., \& Cifter, N. (2005). Market segmentation by motivations to travel: British tourists visiting Turkey. Journal of Travel \& Tourism Marketing, 19(1), 1-14.

Ashworth, G. J. (2004). Tourism and the heritage of atrocity: Managing the heritage of South African Apartheid of entertainment. In T. V. Singh (Ed.), New horizons in tourism: Strange experiences and stranger practices (pp. 95-108). London: CABI Publishing.

Bansal, H., \& Eiselt, H. A. (2004). Exploratory research of tourist motivations and planning. Tourism Management, 25(3), 387-396.

Bartholomew, D. J., Steele, F., Moustaki, I., \& Galbraith, J. I. (2002). The analysis and interpretation of multivariate data for social scientists. Boca Raton: Chapman \& Hall/CRC.

Ben Hai River and Hien Luong Bridge: Visitor Statistics. (2008). Quang Tri: Ben Hai River and Hien Luong Bridge's Management Board.

Best, M. (2007). Norfolk Island: Thanatourism, history and visitor emotions. The International Journal of Research into Island Cultures, 1(2), 30-49.

Bieger, T., \& Laesser, C. (2002). Market segmentation by motivation: The case of Switzerland. Journal of Travel Research, 41(1), 68-76.

Blaine, T. W., Mohammed, G., Ruppel, F., \& Var, T. (1995). US demand for Vietnam tourism. Annals of Tourism Research, 22(4), 934-936.

Braithwaite, D., \& Lee, L. L. (2006). Dark tourism, hate and reconciliation: The Sandakan Experience. Paper presented at the "Peace through tourism: A range of perspectives" Conference. Global Educators' Network of the International Institute for Peace through Tourism. 
Burstein, P., \& Freudenburg, W. (1978). Changing public policy: The impact of public opinion, antiwar demonstrations, and war costs on senate voting on Vietnam War motions. The American Journal of Sociology, 84(1), 99-122.

Butler, R., \& Hajar, R. (2005). After the war: Ethnic tourism to Lebanon. In G. Ashworth \& R. Hartmann (Eds.), Horror and human tragedy revisited: The management of sites of atrocities for tourism (pp. 211-223). New York: Cognizant Communication Corporation.

Cavana, R. Y., Delahaye, B. L., \& Sekaran, U. (2001). Applied business research: Qualitative and Quantitative methods. Milton, Qld: John Wiley \& Sons Australia Ltd.

Cha, S., McCleary, K. W., \& Uysal, M. (1995). Travel motivations of Japanese overseas travelers: A factor-cluster segmentation approach. Journal of Travel Research, 34(1), 33-39.

Chan, Y. W. (2006). Coming of age of the Chinese tourists: The emergence of nonWestern tourism and host--guest interactions in Vietnam's border tourism. Tourist Studies, 6(3), 187-213.

Chandler, J. A., \& Costello, C. A. (2002). A profile of visitors at heritage tourism destinations in East Tennessee according to Plog's lifestyle and activity level preferences model. Journal of Travel Research, 41(2), 161-166.

Chang, J. (2006). Segmenting tourists to aboriginal cultural festivals: An example in the Rukai tribal area, Taiwan. Tourism Management, 27(6), 1224-1234.

Charters, S., \& Ali-Knight, J. (2002). Who is the wine tourist? Tourism Management, 23(3), 311-319.

CIA. (2008). The world factbook: Vietnam. Retrieved 1 November, 2008, from https://www.cia.gov/library/publications/the-world-factbook/print/vm.html

Cooper, M. (2006). The Pacific War battlefields: Tourist attractions or war memorials? International Journal of Tourism Research, 8(3), 213-222.

Correia, A., Oom do Valle, P., \& Moco, C. (2007). Modeling motivations and perceptions of Portuguese tourists. Journal of Business Research, 60(1), 7680 .

Creswell, J. W. (1994). Research design: Qualitative and quantitative approaches. Thousand Oaks: Sage Publications.

Crompton, J. L. (1979). Motivations for pleasure vacation. Annals of Tourism Research, 6(4), 408-424. 
Dann, G. M. S. (1977). Anomie, ego-enhancement and tourism. Annals of Tourism Research, 4(4), 184-194.

Dann, G. M. S. (2005). Children of the dark. In G. Ashworth \& R. Hartmann (Eds.), Horror and human tragedy revisited: The management of sites of atrocities for tourism (pp. 253-262). New York: Cognizant Communication Corporation.

DCST. (2008). Tourists arrivals in Hue from 2001-2007. Hue: Thua Thien Hue's Department of Culture, Sports and Tourism.

Derrett, R. (2001). Special Interest Tourism: Starting with the individual. In N. Douglas, N. Douglas \& R. Derrett (Eds.), Special Interest Tourism (pp. 1-28). Sydney: John Wiley \& Sons Australia, Ltd.

Do, N.-T., \& Kumar, S. (2005). Resource use and waste management in Vietnam hotel industry. Journal of Cleaner Production, 13(2), 109-116.

EIU. (2005). Vietnam: Market profile. Economist Intelligence Unit.

EIU. (2008). Country Profile 2008: Vietnam. Economist Intelligence Unit.

Eskew, G. T. (2001). From Civil War to Civil Rights: Selling Alabama as heritage tourism. International Journal of Hospitality \& Tourism Administration, 2(3/4), 201-214.

Fesenmaier, D. R., \& Jeng, J.-m. (2000). Assessing structure in the pleasure trip planning process. Tourism Analysis, 5(1), 13-27.

Field, A. (2005). Discovering statistics using SPSS. (2nd ed.). London: Sage Publications.

Fodness, D. (1994). Measuring tourist motivation. Annals of Tourism Research, 21(3), 555-581.

Frost, W. (2006). Braveheart-ed Ned Kelly: Historic films, heritage tourism and destination image. Tourism Management, 27(2), 247-254.

Gatewood, J. B., \& Cameron, C. M. (2004). Battlefield pilgrims at Gettysburg National Military Park. Ethnology, 43(3), 193-216.

Goossens, C. (2000). Tourism information and pleasure motivation. Annals of Tourism Research, 27(2), 301-321.

Gordon, B. M. (1998). Warfare and tourism: Paris in World War II. Annals of Tourism Research, 25(3), 616-638.

Gursoy, D., \& McCleary, K. W. (2004). An intergrative model of tourists' information search behaviour. Annals of Tourism Research, 31(2), 353-373. 
Hair, J. F., Anderson, R. E., Tatham, R. L., \& Black, W. C. (1998). Multivariate data analysis. (5th ed.). Upper Saddle River: Prentice Hall.

Hair, J. F., Bush, R. P., \& Ortinau, D. J. (2003). Marketing Research within a changing information environment. (2nd ed.). Boston: McGraw-Hill/Irwin

Haley, U. C. V., \& Haley, G. T. (1997). When the tourists flew in: Strategic implications of foreign direct investment in Vietnam. Management Decision, 35(7/8), 595-605.

Hall, C. M., \& Weiler, B. (1992). Introduction: What's special about Special Interest Tourism? In C. M. Hall \& B. Weiler (Eds.), Special Interest Tourism (pp. 114). London: Belhaven Press.

Hanink, D. M., \& Stutts, M. (2002). Spatial demand for national battlefield parks. Annals of Tourism Research, 29(3), 707-719.

Henderson, J. C. (2000). War as a tourist attraction: The case of Vietnam. The International Journal of Tourism Research, 2(4), 269-280.

Henderson, J. C. (2007). Remembering the Second World War in Singapore: Wartime heritage as a visitor attraction. Journal of Heritage Tourism, 2(1), $36-52$.

Hobson, J. S. P., Heung, V. C. S., \& Chon, K.-S. (1994). Vietnam's tourism industry: Can it be kept afloat? The Cornell Hotel and Restaurant Administration Quarterly, 35(5), 42-49.

Hodgson, A. (2007). Vietnam to be among the world's top ten tourist destinations by 2016. Retrieved 3 Feb, 2007, from http://www.euromonitor.com/Vietnam_to_be_among_the_worlds_top_ten_to urist_destinations_by_2016.

Holden, A. (1999). Understanding skiers motivation using Pearce's "Travel Career" construct. Annals of Tourism Research, 26(2), 435-438.

HRTSMO. (2006). System of underground shelters for villages in Vinh Linh. Quang Tri: Quang Tri's Historical Relics and Tourism Spots Management Office HRTSMO. (2007). Quang Tri Citadel. Hue: Thuan Hoa.

Iles, J. (2006). Recalling the ghosts of war: Performing tourism on the battlefields of the Western Front. Text and Performance Quarterly, 26(2), 162 - 180.

Iso-Ahola, S. E. (1982). Toward a social psychological theory of tourism motivation: A rejoinder. Annals of Tourism Research, 9(2), 256-262.

Jeng, J., \& Fesenmaier, D. R. (2002). Conceptualising the travel decision-making hierarchy: A review of recent developments. Tourism Analysis, 7(1), 15-32. 
Kau, A. K., \& Lim, P. S. (2005). Clustering of Chinese tourists to Singapore: An analysis of their motivations, values and satisfaction. International Journal of Tourism Research, 7(4-5), 231-248.

Khe Sanh Museum: Visitor Statistics (2008). Quang Tri: Khe Sanh Museum's Management Board.

Kozak, M. (2002). Comparative analysis of tourist motivations by nationality and destinations. Tourism Management, 23(3), 221-232.

Le, Y. H. (2005). Perceptions of Vietnamese tourism businesses toward the adoption of sustainable tourism practices. Unpublished Ph.D., University of Idaho, United States -- Idaho.

Lee, C.-K., Lee, Y.-K., Bernhard, B. J., \& Yoon, Y.-S. (2006). Segmenting casino gamblers by motivation: A cluster analysis of Korean gamblers. Tourism Management, 27(5), 856-866.

Lee, C.-K., Lee, Y.-K., \& Wicks, B. E. (2004). Segmentation of festival motivation by nationality and satisfaction. Tourism Management, 25(1), 61-70.

Lee, C.-K., Yoon, Y.-S., \& Lee, S.-K. (2007). Investigating the relationships among perceived value, satisfaction, and recommendations: The case of the Korean DMZ. Tourism Management, 28(1), 204-214.

Lee, Y.-S. (2006). The Korean War and tourism: Legacy of the war on the development of the tourism industry in South Korea. International Journal of Tourism Research, 8(3), 157-170.

Lennon, J., \& Foley, M. (2000). Dark tourism: The attraction of death and disaster. London: Continuum.

Lloyd, D. W. (1998). Battlefield tourism: Pilgrimage and the commemoration of the Great War in Britain, Australia and Canada 1919-1939. Oxford: Berg.

Lunn, K. (2007). War memorialisation and public heritage in Southeast Asia: Some case studies and comparative reflections. International Journal of Heritage Studies, 13(1), 81-95.

Malhotra, N. K. (2007). Marketing Research - An applied orientation. (5th ed.). New Jersey: Pearson Prentice Hall.

Mansfeld, Y. (1992). From motivation to actual travel. Annals of Tourism Research, 19(3), 399-419.

Mayan, M. J. (2001). An introduction to qualitative methods: A training module for students and professionals. Edmonton, Alta.: International Institute for Qualitative Methodology. 
Mazanec, J. (1992). Classifying tourists into segments: A neutral network approach. Journal of Travel and Tourism Marketing, 1(1), 2-6.

McKercher, B. (2002). Towards a classification of cultural tourists. International Journal of Tourism Research, 4(1), 29-38.

McKercher, B., \& Chan, A. (2005). How special is Special Interest Tourism? Journal of Travel Research, 44(1), 21-31.

McKercher, B., \& Cros, H. D. (2003). Testing a cultural tourism typology. International Journal of Tourism Research, 5(1), 45-58.

Mehmetoglu, M. (2005). A case study of nature-based tourists: Specialists versus generalists. Journal of Vacation Marketing, 11(4), 357.

Miles, W. F. S. (2002). Auschwitz: Museum interpretation and darker tourism. Annals of Tourism Research, 29(4), 1175-1178.

Milstein, J. S. (1974). Dynamics of the Vietnam War: A quantitative analysis and predictive computer simulation. Columbus: The Ohio State University Press.

Mok, C., \& Lam, T. (2000). Vietnam's tourism industry: Its potential and challenges. In K. S. Chon (Ed.), Tourism in Southeast Asia: A new direction (pp. 157164). New York: The Haworth Hospitality Press.

Molera, L., \& Pilar Albaladejo, I. (2007). Profiling segments of tourists in rural areas of South-Eastern Spain. Tourism Management, 28(3), 757-767.

Moscardo, G., Morrison, A. M., Pearce, P. L., Lang, C.-T., \& O'Leary, J. T. (1996). Understanding vacation destination choice through travel motivation and activities. Journal of Vacation Marketing, 2(2), 109-122.

Moutinho, L. (1987). Consumer behaviour in tourism. European Journal of Marketing, 21(10), 5.

Nguyen, T. C. (2007). Vietnam welcomes 4 millionth tourist. Retrieved 5 Feb 2008, from http://www.saigontourist.net/english/news_details.php?id=452.

Park, D.-B., \& Yoon, Y.-S. (2009). Segmentation by motivation in rural tourism: A Korean case study. Tourism Management, 30(1), 99-108.

Pearce, P. L. (1993). Fundamentals of tourist motivation. In D. G. Pearce \& R. Butler (Eds.), Tourism Research: Critiques and Challenges. London: Routledge.

Pearce, P. L., \& Lee, U.-I. (2005). Developing the Travel Career approach to tourist motivation. Journal of Travel Research, 43(3), 226-237.

Pham, A. (2006). 85\% international visitors do not return to Vietnam. Retrieved 13 November, 2008, from http://vietbao.vn/Kinh-te/85-khach-du-lich-quoc-tekhong-quay-tro-lai-Viet-Nam/65059404/87/ 
Plog, S. C. (1974). Why destination areas rise and fall in popularity. Cornell Hotel and Restaurant Administration Quarterly, 14(4), 55-58.

Punch, K. F. (2005). Introduction to social research: Quantitative and Qualitative approaches. (2nd ed.). London: Sage Publications.

Robson, C. (1993). Real world research: A resource for social scientists and practitioner-researchers. Oxford: Blackwell.

Rugendyke, B., \& Nguyen, T. S. (2005). Conservation costs: Nature-based tourism as development at Cuc Phuong National Park, Vietnam. Asia Pacific Viewpoint, 46(2), 185-200.

Rummel, R. J. (2008). Statistics of Vietnamese democide estimates, calculations, and sources. Statistics of Democide Retrieved 6 Oct, 2008, from http://www.hawaii.edu/powerkills/SOD.CHAP6.HTM

Ryan, C. (1998). The Travel Career Ladder: An appraisal. Annals of Tourism Research, 25(4), 936-957.

Saunders, J. A. (1980). Cluster analysis for market segmentation. European Journal of Marketing, 14(7), 422.

Schwenkel, C. (2006). Recombinant history: Transnational practices of memory and knowledge production in contemporary Vietnam. Cultural Anthropology, 21(1), 3-31.

Seaton, A. V. (1996). Guided by the dark: From thanatopsis to thanatourism. International Journal of Heritage Studies, 2(4), 234 - 244.

Seaton, A. V. (1999). War and thanatourism: Waterloo 1815-1914. Annals of Tourism Research, 26(1), 130-158.

Seaton, A. V., \& Lennon, J. J. (2004). Thanatourism in the early 21 st century: Moral panics, ulterior motives and alterior desires. In T. V. Singh (Ed.), New Horizons in Tourism: Strange experiences and Stranger practices (pp. 6382). London: CABI Publishing.

Seddighi, H. R., \& Theocharous, A. L. (2002). A model of tourism destination choice: a theoretical and empirical analysis. Tourism Management, 23(5), 475-487.

Sekhar, N. U. (2005). Integrated coastal zone management in Vietnam: Present potentials and future challenges. Ocean \& Coastal Management, 48(9-10), 813-827.

Sharma, S. (1996). Applied multivariate techniques. New York: John Wiley \& Sons. 
Sirakaya, E., Uysal, M., \& Yoshioka, C. F. (2003). Segmenting the Japanese tour market to Turkey. Journal of Travel Research, 41(3), 293.

Slade, P. (2003). Gallipoli thanatourism: The Meaning of ANZAC. Annals of Tourism Research, 30(4), 779-794.

Smith, V. L. (1998). War and tourism: An American ethnography. Annals of Tourism Research, 25(1), 202-227.

Sorensen, L. (1993). The special-interest travel market. Cornell Hotel and Restaurant Administration Quarterly, 34(3), 24.

Stone, P. R. (2006). A dark tourism spectrum: Towards a typology of death and macabre related tourist sites, attractions and exhibitions. Tourism, 54(2), 145160.

Strange, C., \& Kempa, M. (2003). Shades of dark tourism: Alcatraz and Robben Island. Annals of Tourism Research, 30(2), 386-405.

Sung, H. H. (2004). Classification of adventure travelers: Behavior, decision-making, and target markets. Journal of Travel Research, 42(4), 343-356.

Tarlow, P. E. (2005). Dark tourism: The appealing "dark" side of tourism and more. In N. Marina (Ed.), Niche tourism: Contemporary issues, trends and cases. Oxford: Elsevier.

Timothy, D. J., Prideaux, B., \& Seongseop-Kim, S. (2004). Tourism at the borders of conflict and (De)militarized Zones. In T. V. Singh (Ed.), New horizons in tourism: Strange experiences and stranger practices (pp. 83-94). London: CABI Publishing.

Tran, T. H., Schneider, I. E., \& Gartner, W. C. (2006). Image of Vietnam held by US tourists: Initial inquiry. Asia Pacific Journal of Tourism Research, 11(2), 147 $-159$.

Trauer, B. (2006). Conceptualising special interest tourism--frameworks for analysis. Tourism Management, 27(2), 183-200.

Truong, T.-H., \& Foster, D. (2006). Using HOLSAT to evaluate tourist satisfaction at destinations: The case of Australian holidaymakers in Vietnam. Tourism Management, 27(5), 842-855.

Um, S., \& Crompton, J. L. (1990). Attitude determinants in tourism destination choice. Annals of Tourism Research, 17(3), 432-448.

van Raaij, W. F., \& Francken, D. A. (1984). Vacation decisions, activities, and satisfactions. Annals of Tourism Research, 11(1), 101-112. 
Vietnam Trade Information Centre. (2005). Vietnam tourism posting 7th in growth rate in the world. Vietnam Trade Information Centre. Trade News (Online).

Vinh Moc Tunnels: Visitor Statistics (2008). Quang Tri: Vinh Moc Tunnels' Management Board.

VNAT. (1995). Summary Report of the Tourism Development Master Plan to the year 2010. Hanoi: Vietnam National Administration of Tourism.

VNAT. (2008). Tourist Statistics. Retrieved 5 Feb 2008, from http://www.vietnamtourism.com/e_pages/news/index.asp?loai=1\&chucnang= 07

Weaver, D., \& Lawton, L. (2005). Using cluster analysis to segment a sample of Australian ecotourists. In B. W. Ritchie, P. Burns \& C. Palmer (Eds.), Tourism research methods (pp. 211-220): CABI Publishing.

Wedel, M., \& Kamakura, W. A. (1999). Market segmentation: Conceptual and methodological foundation. (2nd ed.). Boston: Kluwer Academic Publishers.

Weiler, B., \& Hall, C. M. (1992). Special Interest Tourism: In search of an alternative. In B. Weiler \& C. M. Hall (Eds.), Special Interest Tourism (pp. 199-204). London: Belhaven Press.

Withiam, G. (1994). Which glass is this? Cornell Hotel and Restaurant Administration Quarterly, 35(3), 96.

Woodside, A. G., \& Lysonski, S. (1989). A general model of traveler destination choice. Journal of Travel Research, 27(4), 8-14.

Yen, H. (2006). More tourists return to Vietnam. Vietnamnet. Retrieved 13 November, 2008, from http://vietnamnet.vn/kinhte/thitruong/2006/02/542230/

Yuan, J. J., Cai, L. A., Morrison, A. M., \& Linton, S. (2005). An analysis of wine festival attendees' motivations: A synergy of wine, travel and special events? Journal of Vacation Marketing, 11(1), 41-58.

Yuill, S. M. (2003). Dark tourism: Understanding visitor motivation at sites of death and disaster. Texas A\&M University, Texas. 